\title{
Avaliação da radioatividade natural em algumas rochas graníticas do estado do Paraná e sua utilização na construção civil
}

\section{Ademar de Oliveira Ferreira}

Tese apresentada como parte dos requisitos para a obtenção do Grau de Doutor em Ciências na Área de Tecnologia Nuclear-Aplicações.

Orientadora:

Profa. Dra. Brigitte Roxana Soreanu Pecequilo.

São Paulo 


\section{INSTITUTO DE PESQUISAS ENERGÉTICAS E NUCLEARES Autarquia associada à Universidade de São Paulo}

Avaliação da radioatividade natural em algumas rochas graníticas do estado do Paraná e sua utilização na construção civil

Ademar de Oliveira Ferreira

Tese apresentada como parte dos requisitos para a obtenção do Grau de Doutor em Ciências na Área de Tecnologia Nuclear-Aplicações.

\section{Orientadora:}

Profa. Dra. Brigitte Roxana Soreanu Pecequilo.

\section{Versão Corrigida}

Versão original encontra-se disponível no IPEN

São Paulo

2013 
Dedico a meus pais Antônio e Vergília, meus sobrinhos Isabelli e Matheus, todos os meus familiares e amigos. 


\section{AGRADECIMENTOS}

Ao Instituto de Pesquisas Energéticas e Nucleares pela oportunidade de realizar este trabalho.

À Comissão Nacional de Energia Nuclear pela Bolsa de estudo.

À $\operatorname{Dr}^{\mathrm{a}}$ Linda V. E. Caldas pela infraestrutura da Gêrencia de Metrologia das Radiações .

À Dr ${ }^{\mathrm{a}}$ Bárbara Paci Mazzilli pela infraestrutura do Laboratório de Radiometria Ambiental (LRA).

À Prof ${ }^{a}$ Brigitte por indicar a direção nos momentos de incertezas, pelo exemplo de profissionalismo e disciplina, pela orientação, amizade, sinceridade e presença.

Ao M. Sc. Marcelo Bessa Nisti pela participação em todas as etapas deste trabalho, por estar sempre acessível, contribuindo com sugestões valiosas.

Ao Dr. Marcelo Francis Máduar, pelos livros emprestados, por ter desenvolvido o modelo matemático utilizado e principalmente pelas conversas descontraídas na copa e no Greic.

À Dr ${ }^{\mathrm{a}}$ Márcia Pires de Campos pelas discussões sobre o radônio que esclareceram muitos aspectos da técnica de medida.

À $\operatorname{Dr}^{\mathrm{a}}$ Sandra Regina Damatto pela disponibilidade em ajudar sempre que precisei, pelas referências bibliográficas sugeridas e por todas as contribuições dadas ao trabalho.

Ao M. Sc. Paulo Rene Nogueira, pela ajuda em uma das etapas da preparação das amostras e por tornar discussões técnicas em conversas agradáveis.

Ao Dr. Marcos Antonio Scapin e à Dr ${ }^{\mathrm{a}}$ Vera Lucia Ribeiro Salvador, do Centro de Química e Meio Ambiente, por terem cedido o laboratório para preparação das amostras, pelas análises de fluorescência de raios X e pelas conversas e sugestões a respeito do trabalho.

Ao Dr. Luis Antonio Genova, do Centro de Ciência e Tecnologia dos Materiais, pela fundamental contribuição em relação à pesagem hidrostática. 
A todos os funcionários do LRA que participaram direta ou indiretamente deste trabalho.

À dupla de inseparáveis Lucia Helena e Sueli de Jesus, pelos hot-dogs, pizzas e conversas de bandejão.

A Alice Costa, Bruna Sobral, Fábio Sussa, Fernanda Cavalcante, Flávia Valverde, Guilherme Groppo, Lívia Barros, Luiz Flávio, Marcos Medrado, Paulo Sérgio, Raquel Bovolini, pela amizade, e pelos finais de tarde e churrascos no Greic.

A todos os bolsistas, estagiários, amigos e colegas do LRA, pela convivência e pelos cafés na copa.

Aos amigos do Conjunto Residencial da USP (CRUSP), por todas as reuniões sempre muito bem pautadas e divertidas, agendadas pelo interfone a qualquer hora e sem protocolos.

Aos irmãos do CRUSP Gleidson Gomes e Ivan Rocha, pelos coffee break, pela amizade e cumplicidade e por ensinarem que a melhor forma de somar é dividir.

Ao Reginaldo Aquino, pelas pizzas, pelas pimentas, feijoadas, pelas aventuras nos congressos, por todos esses anos de participação no laboratório e fora dele, e pela amizade.

A família Giuli da Silva, por terem me recebido em São Paulo, pelo suporte, apoio e por todos os finais de semana juntos.

À Juliana Isabel, por participar de todos os momentos alegres e também dos menos alegres, pela cumplicidade, amor e pela paciência.

A meus familiares, pelo amor e carinho, apesar da minha ausência.

Obrigado. 
"Quando nada parece ajudar, eu vou e olho o cortador de pedras martelando sua rocha, talvez cem vezes sem que nem uma só rachadura apareça.

No entanto, na centésima primeira martelada, a pedra se abre em duas e eu sei que não foi aquela a que conseguiu, mas todas as que vieram antes" 


\title{
RESUMO
}

\author{
AVALIAÇÃO DA RADIOATIVIDADE NATURAL EM ALGUMAS ROCHAS \\ GRANíTICAS DO ESTADO DO PARANÁ E SUA UTILIZAÇÃO NA \\ CONSTRUÇÃO CIVIL
}

\author{
Ademar de Oliveira Ferreira
}

Os radionuclídeos naturais de origem primordial, ou terrestres, são encontrados em quantidades variadas em todo meio ambiente. Nas residências, um importante incremento de dose (INDOOR), é devido aos materiais de construção, que contribuem tanto com a dose externa gama, proveniente das séries do ${ }^{238} \mathrm{U},{ }^{235} \mathrm{U}$ e ${ }^{232} \mathrm{Th}$ e do radionuclídeo isolado ${ }^{40} \mathrm{~K}$, quanto com a dose interna que é devida principalmente à inalação do ${ }^{222} \mathrm{Rn}$. Uma vez que rochas graníticas são amplamente utilizadas como materiais de construção, tanto estruturais como de revestimento, estas podem tornar-se uma importante fonte de dose, dependendo das concentrações de radioatividade que apresentem, e da forma e quantidade que são aplicadas nas construções. Neste trabalho foi gerado um banco de dados para rochas graníticas do escudo cristalino paranaense (principalmente da Região Metropolitana de Curitiba, RMC), que são utilizadas na construção civil avaliando em termos de proteção radiológica o incremento da dose, externa e interna, causada pela utilização destes materiais. Também foram estudadas as possíveis correlações entre a concentração de atividade de ${ }^{226} \mathrm{Ra}$, taxa de exalação de ${ }^{222} \mathrm{Rn}$, densidade, porosidade e composição química (teor de óxidos constituintes) nestas amostras. A dose externa foi avaliada por meio da técnica de espectrometria gama com detector de germânio hiperpuro, onde as concentrações de atividade dos radionuclídeos ${ }^{226} \mathrm{Ra},{ }^{232} \mathrm{Th}$ e ${ }^{40} \mathrm{~K}$ são os parâmetros utilizados em modelos dosimétricos (Índices Dosimétricos), os quais estabelecem limites máximos permitidos de acordo com forma, quantidade e aplicação do material de construção. Para o cálculo da dose efetiva anual externa foi adotado o modelo de sala com dimensões $4 \mathrm{~m} \mathrm{x} 5 \mathrm{~m} \mathrm{x} \mathrm{2,8} \mathrm{m}$ e todas as paredes são revestidas internamente com granitos de espessura de $2 \mathrm{~cm} \mathrm{e}$ considerando o tempo de exposição anual de 7000 h, conforme sugerido pela Comissão Européia de Proteção Radiológica para materiais de revestimento interno superficial. A exposição interna foi avaliada a partir da concentração de radônio no ar da sala modelo, simulada a partir do valor da taxa de exalação superficial de ${ }^{222} \mathrm{Rn}$. A taxa de exalação foi determinada pela técnica de detecção passiva utilizando detectores sólidos de traços nucleares (CR-39) por meio da técnica do recipiente selado, considerando taxa de ventilação de $0,5 \mathrm{~h}^{-1}$ e tempo de exposição anual de $7000 \mathrm{~h}$. Os resultados 
destes estudos mostram que o incremento da dose efetiva anual externa variou de $(62 \pm 3) \mu \mathrm{Sv} \cdot \mathrm{a}^{-1}$ a $(138 \pm 1) \mu \mathrm{Sv} \cdot \mathrm{a}^{-1}$ e o incremento da dose efetiva anual interna variou de $(0,39 \pm 0,04) \mu \mathrm{Sv} \cdot \mathrm{a}^{-1}$ a $(70 \pm 4) \mu \mathrm{Sv} \cdot \mathrm{a}^{-1}$. Estes valores estão abaixo do limite máximo de $1 \mathrm{mSv}^{-1} \mathrm{a}^{-1}$ sugerido pela Comissão Européia de Proteção Radiológica, portanto os granitos avaliados neste trabalho podem ser utilizados sem implicações radiológicas desde que obedecido o cenário descrito. Os valores obtidos para a contribuição devida à dose interna variaram de $1 \%$ a $78 \%$ dos valores obtidos para a respectiva dose externa, mostrando que a contribuição do radônio varia fortemente com o tipo da rocha. Os resultados das correlações entre taxa de exalação superficial de ${ }^{222} \mathrm{Rn}$, concentração de atividade de ${ }^{226} \mathrm{Ra}$, densidade, porosidade e principais óxidos componentes das amostras, mostraram que, em termos de influência na fração de emanação do radônio, o parâmetro mais importante é a densidade, devido a baixa porosidade e a semelhança em termos de composição química entre as amostras. 


\title{
ABSTRACT \\ EVALUATION OF NATURAL RADIOACTIVITY IN SOME GRANITIC ROCKS IN THE STATE OF PARANÁ AND ITS USE IN CIVIL CONSTRUCTION
}

\author{
Ademar de Oliveira Ferreira
}

Primordial, or terrestrial natural radionuclides, are found in different amounts in the environment. In dwellings, an important dose increment is due to building materials, which contribute for both the external gamma dose from the radionuclides of the ${ }^{238} \mathrm{U}$, ${ }^{235} \mathrm{U}$ and ${ }^{232} \mathrm{Th}$ series and the natural ${ }^{40} \mathrm{~K}$ and the internal dose, due mainly to ${ }^{222} \mathrm{Rn}$ inhalation. Once granitic rocks are widely used both as construction materials or structural flooring, those rocks can become an important dose source, depending on the content of concentrations of radioactivity, and the construction application. In this work, a database for granitic rocks of the crystalline shield of Paraná (mainly in the Metropolitan Region of Curitiba, RMC), used in civil construction, was generated, evaluating in terms of radiological protection the external and internal dose increments, caused by the use of these materials. Also, possible correlations between the ${ }^{226} \mathrm{Ra}$ activity concentration, the ${ }^{222} \mathrm{Rn}$ exhalation rate, density, porosity and chemical composition (oxide content) in these samples had been studied. The external dose was assessed by gamma-ray spectrometry with High-Purity Germanium detectors, where the activity concentration of the radionuclides ${ }^{232} \mathrm{Th},{ }^{226} \mathrm{Ra}$ and ${ }^{40} \mathrm{~K}$ are the parameters used in dosimetric models (Dosimetric Indexes), which established limits in accordance with the form, amount and application of material of construction. For the calculation of the annual effective external dose it was assumed a room model with dimensions of $4 \mathrm{~m} \times 5 \mathrm{~m} \times 2.8 \mathrm{~m}$ and all walls internally covered with $2 \mathrm{~cm}$ thickness of granite and an annual exposure time of $7000 \mathrm{~h}$ as suggested by the European Commission of Radiological Protection for internal superficial coating materials. The internal exposure was assessed from the radon concentration in the air of the room model, simulated from the superficial exhalation rate of ${ }^{222} \mathrm{Rn}$. The exhalation rate was determined by the passive detection technique with the Solid State Nuclear Track Detectors (CR-39) and the sealed can technique, assuming a ventilation rate of $0.5 \mathrm{~h}^{-1}$ and an annual exposure time of $7000 \mathrm{~h}$. The results for this studies show that the annual effective dose ranged from $(62 \pm 3) \mu \mathrm{Sv} \cdot \mathrm{y}^{1}$ to $(138 \pm 1) \mu \mathrm{Sv} \cdot \mathrm{y}^{-1}$ and the internal annual effective dose ranged from $(0,39 \pm 0,04) \mu \mathrm{Sv} \cdot \mathrm{y}^{-1}$ to $(70 \pm 4) \mu \mathrm{Sv} \cdot \mathrm{y}^{-1}$. These values are below the maximum limit of $1 \mathrm{mSv}^{-1} \mathrm{y}^{-1}$ suggested by the European Commission 
of Radiological Protection, meaning that the granitic rocks evaluated can be used without radiological implications since the considered scenario is obeyed. The values obtained for the contribution due to the internal dose ranged from $1 \%$ to $78 \%$ of the values obtained for the respective external dose showing the radon contribution varies strongly with the rock type. The results of the correlations between ${ }^{222} \mathrm{Rn}$ superficial exhalation rate, ${ }^{226} \mathrm{Ra}$ activity concentration, density, porosity and major oxides of the samples, showed that, in terms of influence in the emanation fraction of radon, the most important parameter is the density, due to low porosity and similarity in terms of chemical composition amid the studied samples. 


\title{
SUMÁRIO
}

\author{
Lista de Tabelas
}

Lista de Figuras

1 Introdução $\quad \mathbf{1 7}$

1.1 Radionuclídeos naturais . . . . . . . . . . . . . 18

1.2 Rochas ígneas e a radioatividade natural . . . . . . . . . . . . 24

1.3 Interação da radiação ionizante com a matéria . . . . . . . . . . . . 28

1.3.1 Interação da radiação ionizante com a matéria . . . . . . . . 28

1.3.2 Interação de partículas carregadas pesadas com a matéria . . . . 29

1.4 Aspectos geológicos da área de estudo . . . . . . . . . . . . . 31

1.5 Recursos minerais no estado do Paraná . . . . . . . . . . . . . . 32

1.6 Justificativa . . . . . . . . . . . . . . . . . . 33

2 Objetivos $\quad \mathbf{3 4}$

2.1 Objetivo geral . . . . . . . . . . . . . . . . . 34

2.2 Objetivos específicos . . . . . . . . . . . . . 34

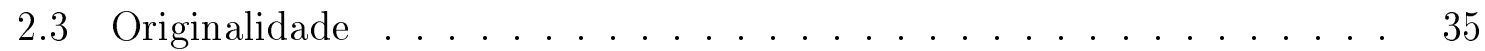

3 Revisão de Literatura $\quad 36$

3.1 Espectrometria Gama de Radionuclídeos Naturais . . . . . . . . . . . 36

3.2 Aplicação de detectores (SSNTD) para medidas de ${ }^{222} \mathrm{Rn} \quad \ldots . . . . .38$

3.3 Estudo da correlação entre concentração de Urânio e emanação de Radônio 38

4 Materiais e métodos $\quad 41$

4.1 Amostragem . . . . . . . . . . . . . . . . 41

4.1.1 Estudo da variabilidade da amostragem . . . . . . . . . . 43

4.2 Espectrometria gama . . . . . . . . . . . . . . . . . 44

4.2.1 Pré-tratamento e preparo das amostras . . . . . . . . . . 44

4.2.2 Estudo da autoatenuação da radiação gama nas amostras estudadas 47

4.2.3 Cálculo da concentração de atividade . . . . . . . . . 50

4.3 Índices dosimétricos . . . . . . . . . . . . . . . . . . 53

4.3.1 Atividade equivalente em rádio $\left(\mathrm{Ra}_{e q}\right) \ldots \ldots \ldots 53$

4.3 .2 Índice $\left(\mathrm{H}_{E X}\right) \ldots \ldots \ldots \ldots \ldots . \ldots \ldots 53$

4.3 .3 Índice gama $\left(\mathrm{I}_{\gamma}\right) \ldots \ldots \ldots \ldots \ldots \ldots$

4.4 Taxa de dose e Dose efetiva anual . . . . . . . . . . . . 55

4.4.1 Cálculo da taxa de dose . . . . . . . . . . . . . 55

4.4 .2 Cálculo da dose efetiva anual . . . . . . . . . . 59

4.5 Radônio . . . . . . . . . . . . . . . . . 59 
4.5.1 Técnica de deteç̧ão $\ldots \ldots \ldots$. . . . . . . . . . . . 59

4.5 .2 Taxa de exalação . . . . . . . . . . . . . . . . . . 64

4.5.3 Estimativa do incremento da concentração de ${ }^{222} \mathrm{Rn}$ devido ao ${ }^{226} \mathrm{Ra}$ nos materiais de construção e estimativa da fração de emanação . . . . . . . . . . . . . . . 65

4.6 Cálculo da dose efetiva anual devida ao radônio . . . . . . . . . 67

4.7 Análise dos principais óxidos componentes por fluorescência de raios X 67

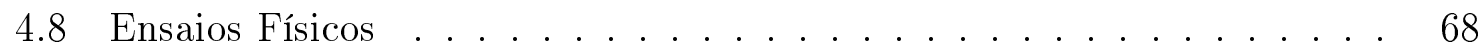

5 Resultados 70

5.1 Concentração de atividade por Espectrometria Gama de alta resolução $\quad 70$

5.1 .1 Medida da autoatenuação . . . . . . . . . . . . . . 71

5.1 .2 Qui-quadrados $\left(\chi^{2}\right) \ldots \ldots \ldots \ldots \ldots \ldots \ldots$

5.1.3 Concentrações de atividades do ${ }^{40} \mathrm{~K},{ }^{232} \mathrm{Th}$ e ${ }^{226} \mathrm{Ra} \ldots \ldots . . .75$

5.1 .4 Variabilidade . . . . . . . . . . . . . . . . . 77

5.1.5 Índices Dosimétricos . . . . . . . . . . . . . . . . . . 81

5.1 .6 Taxa de Dose absorvida no ar . . . . . . . . . . . 82

5.2 Radônio . . . . . . . . . . . . . . . . . . . . 86

5.2.1 Fração de Emanação e concentração de radônio na sala padrão . 89

5.2.2 Dose efetiva anual na sala padrão devido à radiação gama e ao radônio . . . . . . . . . . . . . . . . . . 9 92

5.3 Análise dos principais elementos componentes por fluorescência de raios X 93

5.4 Propriedades físicas . . . . . . . . . . . . . . . . . 96

5.5 Correlações entre ${ }^{226} \mathrm{Ra},{ }^{222} \mathrm{Rn}$, principais óxidos componentes e propriedades físicas . . . . . . . . . . . . . . . 97

5.5.1 Radônio vs (Rádio, Tório e Potássio) _ . . . . . . . . . . 97

5.5.2 Correlações entre Rádio e Radônio normalizadas pelas propriedades

físicas . . . . . . . . . . . . . . . . 100

6 Conclusões 103

6.1 Sugestões para trabalhos futuros . . . . . . . . . . . . . . . . . 104

$\begin{array}{ll}\text { Referências Bibliográficas } & 105\end{array}$

7 Apêndices 112

7.1 Apêndice A . . . . . . . . . . . . . . . . . . . . . . . 113

7.2 Apêndice B . . . . . . . . . . . . . . . . . . 114 


\section{LISTA DE TABELAS}

1.1 Isótopos do ${ }^{222} \mathrm{Rn} . \quad \ldots \ldots \ldots \ldots \ldots . \ldots \ldots 23$

1.2 Decaimento radioativo do ${ }^{222} \mathrm{Rn} . \ldots \ldots \ldots . \ldots . \ldots . \ldots 24$

1.3 Classificação química das rochas, a série é denominada de acordo com a porcentagem de $\mathrm{SiO}_{2}$ obtida quando a igualdade $\left(\mathrm{Na}_{2} \mathrm{O}+\mathrm{K}_{2} \mathrm{O}\right)=\mathrm{CaO}$ é atingida (Williams et al., 1970). . . . . . . . . . 26

4.1 Amostras de rochas da RMC, obtidas na forma comercial em fábricas da região. . . . . . . . . . . . . . . . . . 42

4.2 Amostras obtidas em revendedoras locais da RMC para estudo da variabilidade. . . . . . . . . . . . . . . . 43

4.4 Transições gama selecionadas para o estudo de autoatenuação. . . . . . 48

4.6 Transições gama utilizadas para determinação das concentrações de atividade dos radionuclídeos ${ }^{40} \mathrm{~K},{ }^{232} \mathrm{Th}$ e do ${ }^{226} \mathrm{Ra}$. . . . . . . . . . 51

4.8 Fatores de conversão de concentração de atividade em taxa de dose (EC,

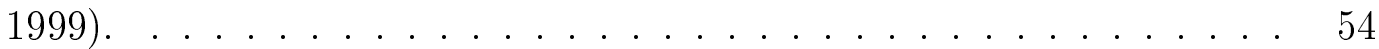

4.9 Critérios de dose para materiais de construção (EC, 1999). . . . . . 55

5.1 Resultados reportados na literatura e neste trabalho para concentrações de atividade em rochas. . . . . . . . . . . . . . . 77 


\section{LISTA DE FIGURAS}

1.1 Série radioativa do ${ }^{238} \mathrm{U}$, modificado de IAEA-TECDOC-1363 (2003). . 19

1.2 Série radioativa do ${ }^{235} \mathrm{U}$, modificado de IAEA-TECDOC-1363 (2003). . $\quad 20$

1.3 Série radioativa do ${ }^{232} \mathrm{Th}$, modificado de IAEA-TECDOC-1363 (2003). 21

1.4 Diagrama simplificado do decaimento do ${ }^{40} \mathrm{~K}$ modificado de (Kathren, 1998; LNHB, 2013). . . . . . . . . . . . . . . . 22

1.5 Possíveis modos de emanação do radônio. . . . . . . . . . . . . . . 27

1.6 Importância relativa das seções de choque com a energia e com o número atômico Z do meio absorvedor modificado de (IAEA-TECDOC-1363,

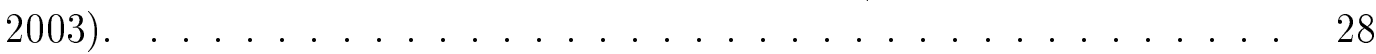

1.7 Geologia do Paraná, modificado de (MINEROPAR, 2010). . . . . . . . 32

4.1 Ilustração da área de estudo. . . . . . . . . . . . . . . . . . . . 41

4.2 Pré-tratamento das amostras (a) Diferentes etapas de preparação, (b) Pilão de aço e peneira de $2 \mathrm{~mm}$, utilizados na pré-britagem (c) e (d) Moinho vibratório e respectiva "panela" utilizados na pulverização, (e) e (f) Selagem das amostras. . . . . . . . . . . . . . . .

4.3 (a) Sistema de medida (b) Detector HPGe série GEM Ortec com respectiva blindagem e amostra na geometria de medida. . . . . . . .

4.4 Diagrama do arranjo experimental do método de transmissão gama para a correção da autoatenuação nas amostras. . . . . . . . . . . . .

4.5 Modelo de sala padrão para estimativa da taxa de dose gama externa

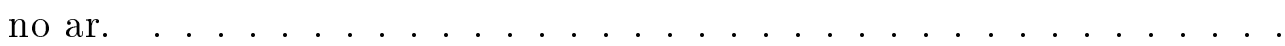

4.6 (a) Diagrama ilustrativo da Técnica do recipiente selado (b) Câmara de difusão NRPB e detector CR-39 (c) Amostra no fundo do recipiente de

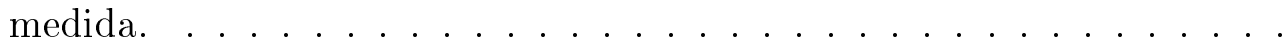

4.7 (a) Banho-maria utilizado para revelação, (b) Microscópio ótico Zeiss Axiolab 100, utilizado para contagem dos traços e microcomputador, (c) Detalhe dos traços em um detector CR-39 após revelação, foto de (Alberigi, 2011). . . . . . . . . . . . . . . .

4.8 (a) Câmara utilizada para calibração dos detectores CR-39 (b) Fonte de fluxo contínuo Pylon, Rn-1025. . . . . . . . . . . . . .

4.9 (a) Detalhe da balança adaptada para pesagem hidrostática (b) Corpos de prova de uma das amostras. . . . . . . . . . . . . 6 69

5.1 Espectro de raios gama da amostra 34 em contagem de 86 ks. . . . . . 71

5.2 Fatores de autoatenuação e ajuste da curva para a amostra $1 . \quad$. . . . 72

5.3 Fatores de autoatenuação e ajuste da curva para a amostra 24 . . . . . 72

5.4 Fatores de autoatenuação medidos em função da energia para todas as amostras de rochas da RMC . . . . . . . . . . . . . . . 73 
5.5 Ajustes dos fatores de autoatenuação em função da energia para todas as amostras de rochas da RMC . . . . . . . . . . . . . . . . .

5.6 Valores de Qui-quadrado determinados para as estimativas do ${ }^{226} \mathrm{Ra}$ e do ${ }^{232}$ Th, considerando $n=2$, (estas estimativas foram realizadas considerando dois radionuclídeos TAB. 4.6). . . . . . . . . . . .

5.7 Concentração de atividades de ${ }^{40} \mathrm{~K}$ nas amostras de rochas obtidas na

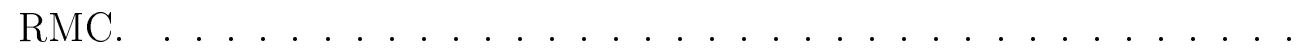

5.8 Concentração de atividades de ${ }^{232}$ Th nas amostras de rochas obtidas na

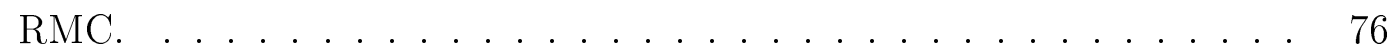

5.9 Concentração de atividades de ${ }^{226} \mathrm{Ra}$ nas amostras de rochas obtidas na

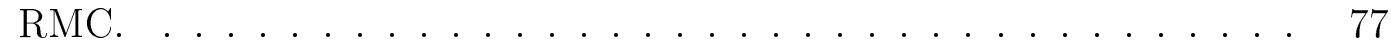

5.10 Resultados do estudo da variabilidade para as 5 amostras extraídas pelas duas fábricas utilizando os radioisótopos (a) ${ }^{40} \mathrm{~K}$ (b) ${ }^{232} \mathrm{Th}$ e (c) ${ }^{226} \mathrm{Ra}$.

5.11 Resultados do estudo da variabilidade para as 8 amostras utilizando os radioisótopos (a) ${ }^{40} \mathrm{~K}$ (b) ${ }^{232} \mathrm{Th}$ e (c) ${ }^{226} \mathrm{Ra}$. . . . . . . . . . . . . .

5.12 Valores calculados para o indice Atividade Equivalente em Rádio para as rochas estudadas. . . . . . . . . . . . . . . 81

5.13 Valores calculados para o Índice externo para as rochas estudadas. . . . 81

5.14 Valores calculados para o Índice gama. . . . . . . . . . . . . . . 82

5.15 Taxa de dose Absorvida no ar dentro da sala padrão (4 m x 5 m x 2,8 m), decorrente da utilização da rochas estudadas com resvestimento interno.

5.16 Resultados para Taxa de dose Absorvida no ar dentro da sala padrão (4 m x $5 \mathrm{~m}$ x 2,8 m), obtidos pelos modelos descritos em (EC, 1999; Máduar, 2000) decorrente da utilização das rochas estudadas como revestimento interno. . . . . . . . . . . . . .

5.17 Comparação dos valores de taxa de dose calculados em três situações diferentes. . . . . . . . . . . . . . . 81

5.18 Fatores de conversão de dose em função da espessura da parede, calculados pelo programa EDVOS, para as rochas estudadas. . . . . . 86

5.19 Fator de calibração (eficiência de detecção) dos detectores CR-39, determinados experimentalmente para a geometria de medida. . . . . 86

5.20 Concentração de radônio na câmara selada. . . . . . . . . . . . . 87

5.21 Taxa de exalação superficial de radônio das amostras de rochas estudadas. 88

5.22 Taxa de exalação de radônio por massa das amostras de rochas estudadas. 88

5.23 Valores teóricos e valores experimentais de taxa de exalação superficial de radônio das rochas estudadas. . . . . . . . . . . . . . 89

5.24 Fração de emanação valores teóricos e valores medidos para a rochas

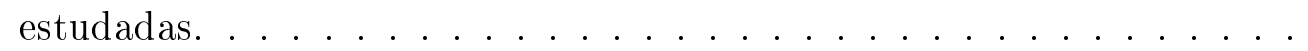

5.25 Incremento de concentração de radônio na sala padrão (valor teórico e valor medido) devido ao revestimento interno com as rochas estudadas.

5.26 Incremento da dose efetiva anual causado pelo revestimento interno de uma sala padrão devido a radiação gama externa e a inalação do radônio. 92

5.27 Análise por agrupamento dos óxidos principais constituintes das amostras de rochas estudadas. . . . . . . . . . . . . . . . 
5.28 Teor em (\%) de óxidos nas amostras 1, 4, 20 e 35 extremos do dendograma. 95

5.29 Densidade aparente das amostras medidas conforme norma ABNT (2010). 96

5.30 Porosidade aparente das amostras medidas conforme norma ABNT (2010). 96

5.31 Concentração de ${ }^{222} \mathrm{Rn}$ na câmara em função da concentração de atividade do ${ }^{226} \mathrm{Ra}$ nas amostras de rocha estudadas. . . . . . . . . . 97

5.32 Taxa de exalação superficial de ${ }^{222} \mathrm{Rn}$ em função da concentração de atividade do ${ }^{226} \mathrm{Ra}$ nas amostras de rochas estudadas. . . . . . . . . . 98

5.33 Taxa de exalação por massa de ${ }^{222} \mathrm{Rn}$ em função da concentração de atividade do ${ }^{226} \mathrm{Ra}$ nas amostras de rochas estudadas. . . . . . . . . . 98

5.34 Taxa de exalação superficial de ${ }^{222} \mathrm{Rn}$ em função da concentração de atividade de ${ }^{232}$ Th nas amostras de rochas estudadas. . . . . . . . . . 99

5.35 Taxa de exalação superficial de ${ }^{222} \mathrm{Rn}$ em função da concentração de atividade de ${ }^{40} \mathrm{~K}$ nas amostras de rochas estudadas. . . . . . . . . . . 99

5.36 Concentração de atividade de ${ }^{232}$ Th em função da concentração de atividade do ${ }^{226} \mathrm{Ra}$ nas amostras de rochas estudadas. . . . . . . . . . 100

5.37 Taxa de exalação superficial de ${ }^{222} \mathrm{Rn}$ em função da razão (concentração

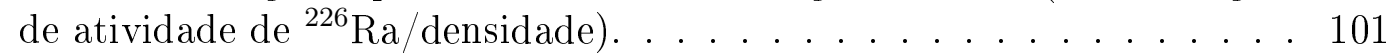

5.38 Taxa de exalação superficial de ${ }^{222} \mathrm{Rn}$ em função da razão (concentração de atividade de ${ }^{226} \mathrm{Ra}$ /porosidade). . . . . . . . . . . . . . 101

5.39 Razão (Taxa de exalação superficial de ${ }^{222} \mathrm{Rn} /$ Densidade) em função da concentração de atividade de ${ }^{226}$ Ra. . . . . . . . . . . . . . . 102

5.40 Razão (Taxa de exalação superficial de ${ }^{222} \mathrm{Rn} /$ Porosidade) em função da concentração de atividade de ${ }^{226}$ Ra . . . . . . . . . . . . . . 102 


\section{CAPÍTUlo}

\section{INTRODUÇÃO}

Os radionuclídeos naturais de origem primordial, ou terrestres, são encontrados em quantidades variadas em todo meio ambiente: organismos vivos, rochas, solos, água, atmosfera. Assim, eles contribuem na dose a seres humanos tanto externamente (materiais de construção e solo p.ex.), como internamente (sendo incorporados por meio da ingestão de alimentos e inalação do ar contaminado)(UNSCEAR, 2000).

Em residências, o principal incremento da dose causado por radionuclídeos naturais é originado dos materiais de construção. A dose externa gama tem origem na exposição devida a radionuclídeos naturais que podem ocorrer de forma isolada ou em séries radioativas (as séries do ${ }^{238} \mathrm{U},{ }^{235} \mathrm{U}$ e ${ }^{232} \mathrm{Th}$ e o radionuclídeo isolado ${ }^{40} \mathrm{~K}$ representam 16,97\% da dose efetiva média anual mundial). A dose interna é decorrente principalmente da inalação do isótopo do radônio, ${ }^{222} \mathrm{Rn}$, que é um gás nobre originado por meio de emissão de partículas alfa durante a desintegração radioativa do ${ }^{226} \mathrm{Ra}$, que por sua vez, é produto de decaimento da série do ${ }^{238} \mathrm{U}$. A inalação do radônio representa $47,6 \%$ da dose efetiva média anual mundial devido a radionuclídeos naturais (UNSCEAR, 2000).

Uma vez que rochas são amplamente utilizadas como materiais de construção, tanto estruturais como de revestimento, elas podem tornar-se uma importante fonte de dose se as concentrações de radioatividade forem altas, e dependendo da forma e quantidade com que são aplicadas. A radioatividade natural das rochas, por sua vez, varia de acordo com sua natureza, em geral concentrações mais altas são comuns em rochas ígneas (graníticas) em relação às sedimentares e metamórficas. Assim, torna-se importante, em termos radiológicos, fazerem-se estudos da aplicação de rochas graníticas como materiais de construção, com o objetivo de avaliar o aumento da dose que esta aplicação pode causar às pessoas.

Estudos de radiotividade natural em rochas, para este fim, têm sido feitos, em vários países (Turhan, 2008; Faheem et al., 2008; Marocchi et al., 2011), em sua maioria, no que diz respeito a granitos (utilizados como materiais de construção), determinando a concentração de atividade de ${ }^{226} \mathrm{Ra},{ }^{232} \mathrm{Th}$ e ${ }^{40} \mathrm{~K}$, por meio da técnica de espectrometria gama, e estes valores servem então de parâmetros em modelos dosimétricos, buscando limitar a dose a um certo nível abaixo do qual não se espera danos para o indivíduo do público. Neste trabalho foram calculados os três índices dosimétricos, que são amplamente utilizados na literatura, atividade equivalente em rádio $\mathrm{Ra}_{e q}$, e os índices de dose gama externa, $\mathrm{H}_{E X}$ e $\mathrm{I}_{\gamma}$ (item 4.3). Alguns destes 
modelos supõem que uma dada concentração de ${ }^{226} \mathrm{Ra}$ (limite máximo permitido) não gere concentrações de radônio superiores a 200 Bq.m ${ }^{-3}$ (EC, 1999).

\subsection{Radionuclídeos naturais}

A dose externa gama devida a radionuclídeos naturais pode ser causada por radionuclídeos das séries radioativas ou por radionuclídeos que ocorrem de forma isolada.

Três séries radioativas são encontradas na natureza, são elas: ${ }^{238} \mathrm{U}$ (abundância isotópica de 99,27\%, e $\mathrm{t}_{1 / 2}=4,46 \times 10^{9}$ anos), ${ }^{235} \mathrm{U}$ (abundância isotópica de $0,7 \%$, e $\mathrm{t}_{1 / 2}=7,13 \times 10^{8}$ anos) e ${ }^{232} \mathrm{Th}$ (abundância isotópica $100 \%$, e $\mathrm{t}_{1 / 2}=1,39 \times 10^{10}$ anos) (IAEA-TECDOC-1363, 2003), as FIG. 1.1, 1.2 e 1.3 apresentam estas três séries respectivamente. 


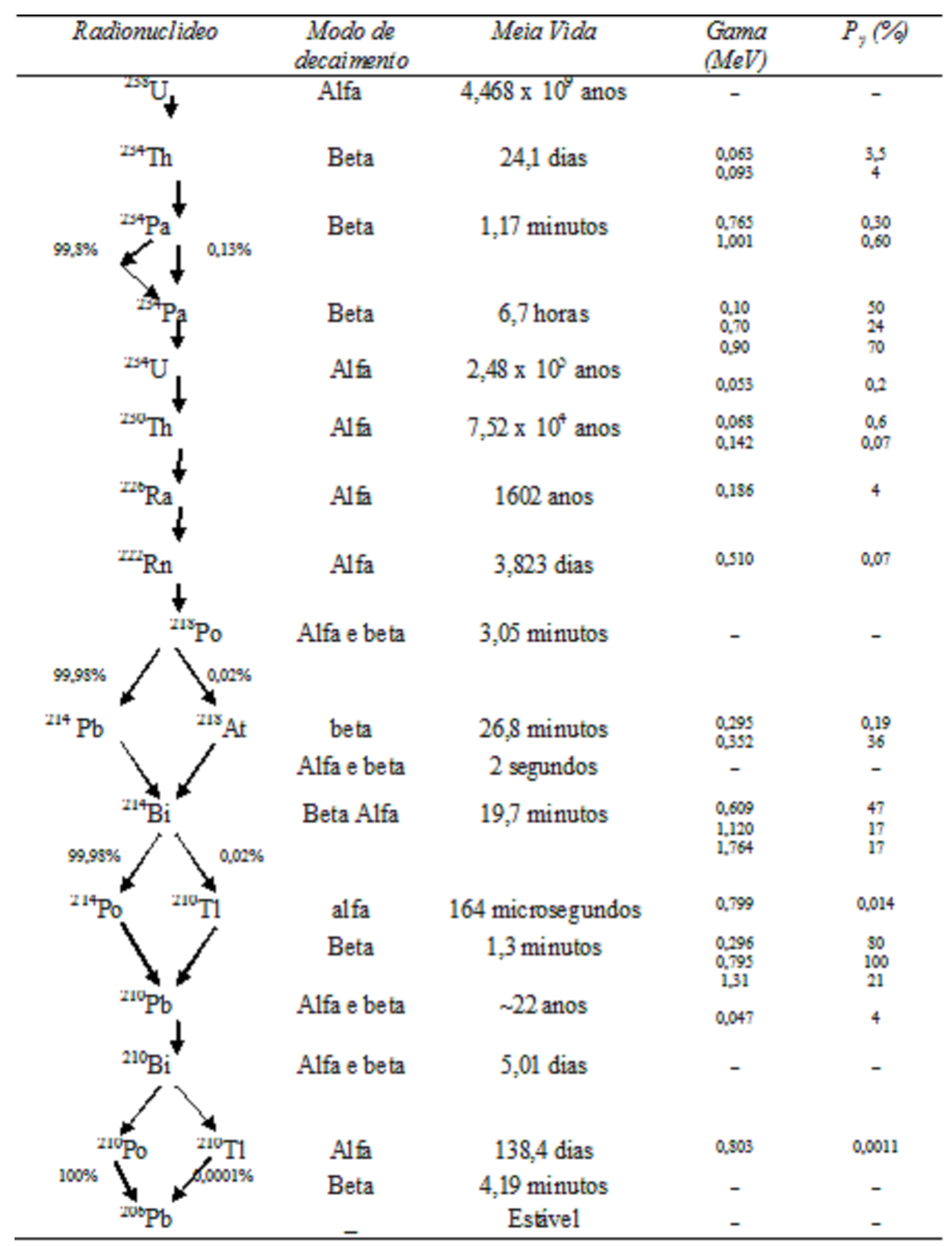

Figura 1.1: Série radioativa do ${ }^{238} \mathrm{U}$, modificado de IAEA-TECDOC-1363 (2003). 


\begin{tabular}{|c|c|c|c|c|}
\hline Radioisótopo & $\begin{array}{c}\text { Modo de } \\
\text { decaimento }\end{array}$ & Meia Vida & $\begin{array}{l}\text { Gama } \\
(\mathrm{MeV})\end{array}$ & $\mathrm{P}_{\mathrm{Y}}(\%)$ \\
\hline $235 \mathrm{U}$ & Alfa & $7,038 \times 10^{8}$ anos & $\begin{array}{l}0,143 \\
0,185 \\
0,204\end{array}$ & $\begin{array}{c}11 \\
54 \\
5\end{array}$ \\
\hline${ }^{231} \mathrm{Th}$ & Beta & 25,6 horas & $\begin{array}{l}0,026 \\
0,084\end{array}$ & $\begin{array}{c}2 \\
10\end{array}$ \\
\hline & Alfa & $3,43 \times 10^{4}$ anos & $\begin{array}{c}0,027 \\
0,29\end{array}$ & $\begin{array}{l}6 \\
6\end{array}$ \\
\hline $60 \%$ & Alfa e beta & 21,6 anos & 0,070 & 0,08 \\
\hline${ }^{227} \mathrm{Th}$ & Alfa & 18,2 dias & $\begin{array}{c}0,050 \\
0,237 \\
0,31\end{array}$ & $\begin{array}{c}8 \\
15 \\
8\end{array}$ \\
\hline & Alfa e beta & 22 minutos & $\begin{array}{l}0,050 \\
0,080 \\
0,234\end{array}$ & $\begin{array}{c}40 \\
13 \\
4\end{array}$ \\
\hline & Alfa & 11,68 dias & $\begin{array}{c}0,149 \\
0,270 \\
0,33\end{array}$ & $\begin{array}{c}10 \\
10 \\
6\end{array}$ \\
\hline & Alfa & 3,92 segundos & $\begin{array}{l}0,272 \\
0,401\end{array}$ & $\begin{array}{l}9 \\
5\end{array}$ \\
\hline & Alfa & 1,83 milisegundos & - & - \\
\hline & Beta & 36,1 minutos & $\begin{array}{l}0,405 \\
0,427 \\
0,832\end{array}$ & $\begin{array}{l}3,4 \\
1,8 \\
3,4\end{array}$ \\
\hline $99,7 \%$ & Alfa e beta & 2,15 minutos & 0,351 & 14 \\
\hline${ }^{211} \mathrm{Po}$ & Alfa & 0,52 segundos & $\begin{array}{c}0,570 \\
0,90\end{array}$ & $\begin{array}{l}0,5 \\
0,5\end{array}$ \\
\hline & Beta & 4,79 minutos & 0,897 & 0,16 \\
\hline${ }^{207} \mathrm{~Pb}$ & - & Estável & - & - \\
\hline
\end{tabular}

Figura 1.2: Série radioativa do ${ }^{235} \mathrm{U}$, modificado de IAEA-TECDOC-1363 (2003). 


\begin{tabular}{|c|c|c|c|}
\hline Radioisótopo & $\begin{array}{l}\text { Modo de } \\
\text { decaimento }\end{array}$ & Meia Vida & $\begin{array}{l}\text { Gama } \\
(\mathrm{MeV})\end{array}$ \\
\hline Th & Alfa & $1,39 \times 10^{10}$ anos & - \\
\hline & Beta & 5,75 anos & - \\
\hline & Beta & 6,13 horas & $\begin{array}{l}034 \\
0905 \\
096\end{array}$ \\
\hline & Alfa & 1,91 anos & $\begin{array}{r}0054 \\
0214\end{array}$ \\
\hline & Alfa & 3,64 dias & 0241 \\
\hline & Alfa & 55,6 segundos & 0.55 \\
\hline & Alfa & 0,15 segundos & - \\
\hline & Beta & 10,64 horas & $\begin{array}{l}0,939 \\
0300\end{array}$ \\
\hline & Alfa e beta & 60,5 minutos & $\begin{array}{l}0,040 \\
0,777 \\
1,60\end{array}$ \\
\hline${ }^{\mathrm{H}} \mathrm{Po}$ & $\begin{array}{l}\text { Alfa } \\
\text { Beta }\end{array}$ & $\begin{array}{c}304 \\
\text { namosegundos } \\
3,1 \text { minutos }\end{array}$ & $\begin{array}{l}0,311 \\
0583 \\
0,560 \\
2,614\end{array}$ \\
\hline${ }^{205} \mathrm{~Pb}$ & 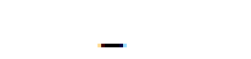 & Estável & - \\
\hline
\end{tabular}

Figura 1.3: Série radioativa do ${ }^{232} \mathrm{Th}$, modificado de IAEA-TECDOC-1363 (2003). 
Do ponto de vista biológico-ambiental, somente dois radionuclídeos isolados que ocorrem naturalmente são relevantes: ${ }^{40} \mathrm{~K}$ e o ${ }^{87} \mathrm{Rb}$, sendo o ${ }^{40} \mathrm{~K}$ o mais importante, do ponto de vista biológico (Kathren, 1998). Dos três isótopos naturais do potássio, o ${ }^{40} \mathrm{~K}$ é o único radioativo, com meia-vida de $1,28 \times 10^{9}$ anos e uma abundância isotópica de $0,0118 \%$. Na FIG. 1.4 é apresentado o diagrama simplificado do decaimento do ${ }^{40} \mathrm{~K}$.

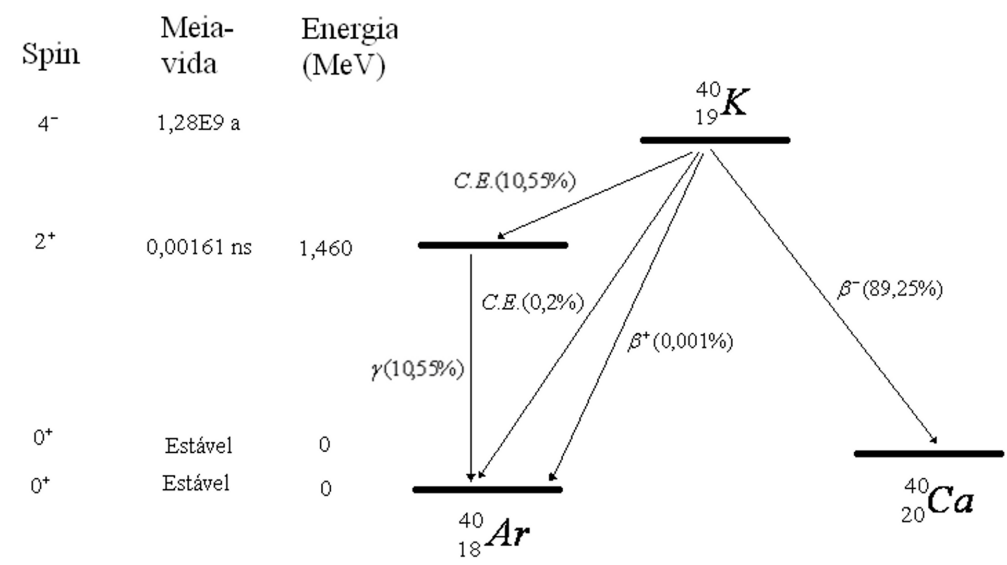

Figura 1.4: Diagrama simplificado do decaimento do ${ }^{40} \mathrm{~K}$ modificado de (Kathren, 1998; LNHB, 2013).

O ${ }^{40} \mathrm{~K}$ decai para o ${ }^{40} \mathrm{Ca}$, por emissão $\beta^{-}$com $89,25 \%$ de probabilidade, uma pequena fração $\left(1 \times 10^{-3} \%\right)$ que decai por $\beta^{+}$para o ${ }^{40} \mathrm{Ar}$ no estado fundamental, $0,2 \%$ decaem por captura eletrônica para o ${ }^{40} \mathrm{Ar}$ no estado fundamental e os $10,55 \%$ restantes do ${ }^{40} \mathrm{~K}$ decaem por captura eletrônica para o ${ }^{40} \mathrm{Ar}$ em um estado excitado, que emite um fóton característico de $1460 \mathrm{keV}$, que é utilizado para a identificação e quantificação do ${ }^{40} \mathrm{~K}$ por espectrometria gama, além de fornecer um excelente ponto de calibração, uma vez que o potássio está presente em quase todas as amostras ambientais.

A dose interna deve-se principalmente à inalação do isótopo do radônio, ${ }^{222} \mathrm{Rn}$ proveniente da série do ${ }^{238} \mathrm{U}$, porém, além deste, existem outros dois isótopos naturais do radônio, provenientes das séries do ${ }^{235} \mathrm{U}$ e do ${ }^{232} \mathrm{Th}$, todos emissores de partículas alfa (NCRP, 1998), TAB. 1.1. 
Tabela 1.1: Isótopos do ${ }^{222} \mathrm{Rn}$.

\begin{tabular}{ccc}
\hline \hline Série & Isótopo & Meia vida \\
\hline${ }^{238} \mathrm{U}$ & ${ }^{222} \mathrm{Rn}$ & $3,8 \mathrm{~d}$ \\
${ }^{235} \mathrm{U}$ & ${ }^{219} \mathrm{Rn}$ & $3,96 \mathrm{~s}$ \\
${ }^{232} \mathrm{Th}$ & ${ }^{220} \mathrm{Rn}$ & $55,6 \mathrm{~s}$ \\
\hline
\end{tabular}

Devido às meias-vidas curtas dos isótopos ${ }^{220} \mathrm{Rn}$ e ${ }^{219} \mathrm{Rn}$ e à baixa abundância isotópica do ${ }^{235} \mathrm{U}$ (apenas $0,71 \%$ do urânio natural), em situações normais onde a concentração de tório não é muito alta, a maior preocupação radiológica concentra-se na determinação do ${ }^{222} \mathrm{Rn}$, que apresenta a maior meia-vida (3,8 dias).

A exposição ao ${ }^{222} \mathrm{Rn}$ é reconhecida como um importante risco ao sistema respiratório, principalmente pela incorporação dos seus descendentes de meia-vida curta (TAB. 1.2), sendo que o ${ }^{218} \mathrm{Po}$ e ${ }^{214} \mathrm{Po}$ são emissores alfa, radiação com maior transferência linear de energia e responsável pelo aumento na incidência de câncer no pulmão (UNSCEAR, 2000). Os filhos, diferentemente do pai, podem se associar facilmente a partículas de aerossóis, ou qualquer outro tipo de superfície, fenômeno conhecido como plate-out. Associados ou não a aerossóis os filhos podem ser inalados, depositando-se nos pulmões (SRS33, 2003). Segundo a Organização Mundial de Saúde (WHO, 2007), o ${ }^{222} \mathrm{Rn}$ e sua progênie são os maiores contribuintes para a dose de radiação recebida pela população mundial, sendo também reconhecido como a segunda maior causa de câncer de pulmão depois do tabaco. 
Tabela 1.2: Decaimento radioativo do ${ }^{222} \mathrm{Rn}$.

\begin{tabular}{cccc}
\hline \hline Isótopo & Meia-vida & $E_{\alpha}(\mathrm{MeV})$ & $E_{\beta} \max (\mathrm{MeV})$ \\
\hline \hline${ }^{222} \mathrm{Rn}$ & $3,823 \mathrm{~d}$ & 5,49 & - \\
${ }^{218} \mathrm{Po}$ & $3,05 \mathrm{~min}$ & 6,00 & - \\
${ }^{214} \mathrm{~Pb}$ & $26,8 \mathrm{~min}$ & - & 0,72 \\
${ }^{214} \mathrm{Bi}$ & $19,7 \mathrm{~min}$ & - & 1,78 \\
${ }^{214} \mathrm{Po}$ & $164 \mathrm{~ms}$ & 7,69 & - \\
${ }^{210} \mathrm{~Pb}$ & $21 \mathrm{a}$ & - & 0,02 \\
${ }^{210} \mathrm{Bi}$ & $5,01 \mathrm{~d}$ & - & 1,16 \\
${ }^{210} \mathrm{Po}$ & $138,4 \mathrm{~d}$ & 5,31 & - \\
\hline${ }^{206} \mathrm{~Pb}$ & estável & - & - \\
\hline \hline
\end{tabular}

O ${ }^{222} \mathrm{Rn}$ é um gás nobre que se origina por meio de emissão de partículas alfa durante a desintegração radioativa do ${ }^{226} \mathrm{Ra}$, que, por sua vez, é produto de decaimento da série do ${ }^{238} \mathrm{U}$. Por ser elemento da família dos gases nobres, não interage com outros elementos e, por sua natureza gasosa, possui capacidade de exalar do solo ou rocha com extrema facilidade e de se concentrar em ambientes fechados (Eisenbud, 1987).

Como urânio e rádio estão presentes no solo, rochas, água, materiais de construção, é natural a existência de radônio no ar, sendo sua concentração determinada principalmente pelos seguintes fatores: revestimento do solo (por exemplo, pavimentação, construções e vegetação), porosidade e granulometria do solo, temperatura, pressão atmosférica, altitude, teor de umidade do solo, condições atmosféricas e estações do ano. Do total de ${ }^{222} \mathrm{Rn}$ liberado no ar, estimado em aproximadamente $9 \times 10^{19} \mathrm{~Bq}$ por ano, dois terços são provenientes do solo e a maioria do restante da água doce, a contribuição dos oceanos é de cerca de $1 \%$ do total, com ainda menor contribuição de fontes, tais como depósitos de fosfato e pilhas de rejeitos de urânio (Kathren, 1998). A inalação do radônio representa 47,6 \% da dose efetiva média anual mundial devido à radionuclídeos naturais (UNSCEAR, 2000).

\subsection{Rochas ígneas e a radioatividade natural}

As rochas ígneas são formadas pelo resfriamento e solidificação do magma primário, isto pode acontecer, por um processo específico ou combinações destes, gerando uma grande variedade de rochas ígneas (Williams et al., 1970). 
A diferenciação é o processo no qual o magma inicialmente homogêneo desdobra-se em frações de composição diferente, o processo de diferenciação mais importante é o fracionamento resultante da cristalização, assim certos minerais estão sempre associados porque cristalizam aproximadamente na mesma temperatura.

Quando a cristalização progride, existe uma tendência para a manutenção do equilíbrio entre a fase sólida e a líquida. Para manter este equilíbrio, quando a temperatura diminui, os cristais precoces reagem com o líquido mudando de composição. Esta reação pode ser progressiva de modo que se produz uma série contínua de soluções sólidas homogêneas (série de reação contínua). Certos minerais por outro lado, transformam-se a temperaturas definidas, em outros minerais de estrutura cristalina diferente (série de reação descontínua). Quando a reação termina, os minerais da rocha final são os últimos formados. Porém, se a reação não for completa, devido a resfriamento muito rápido ou a outras razões, os membros precoces de ambas as séries podem persistir como resíduos na rocha final (Williams et al., 1970). A evolução do magma pode ser influenciada também pela reação com as rochas das paredes, se a temperatura do magma for maior que a temperatura de fusão das paredes do reservatório.

Uma região é chamada uma província petrográfica se ela contém rochas ígneas aproximadamente da mesma idade, que derivam da mesma matriz magmática. Nesta região, todas as rochas intrusivas ou extrusivas têm peculiaridades tanto mineralógicas como químicas que as tornam diferentes das rochas de outra província. Quimicamente, a série de rochas ígneas pode ser dividida em quatro grupos, (TAB. 1.3), baseados na relação da cal para os álcalis (Williams et al., 1970). 
Tabela 1.3: Classificação química das rochas, a série é denominada de acordo com a porcentagem de $\mathrm{SiO}_{2}$ obtida quando a igualdade $\left(\mathrm{Na}_{2} \mathrm{O}+\mathrm{K}_{2} \mathrm{O}\right)=\mathrm{CaO}$ é atingida (Williams et al., 1970).

\begin{tabular}{ccc}
\hline \hline $\begin{array}{c}\left(\mathrm{Na}_{2} \mathrm{O}+\mathrm{K}_{2} \mathrm{O}\right)=\mathrm{CaO} \\
(\% \text { em massa })\end{array}$ & $\mathrm{SiO}_{2}$ & Série \\
\hline \hline & & \\
& 561 & Cálcica \\
& $51-51$ & Calco-alcalina \\
& $<51$ & Alcalino - cálcica \\
& & \\
\hline \hline
\end{tabular}

Desta forma, as rochas ígneas apresentam uma considerável variação em função das características químicas, mineralógicas, petrográficas e estruturais. Assim, a abundância de urânio e tório nestas rochas, além da concentração inicial, depende também da história pós-cristalização das rochas.

Nas rochas ígneas, a radioatividade provém principalmente de minerais acessórios levemente radioativos como zircão esfeno e apatita, pois, minerais acessórios altamente radioativos, como por ex. a monazita, alanita, pirocloro, uraninita e torita são mais escassos que estes (Larsen e George, 1957). Estudos têm mostrado que em geral concentrações maiores de radionuclídeos são mais comuns em rochas ígneas em relação às sedimentares (UNSCEAR, 2000; El-Arabi, 2007; Bastos, 2008; Marocchi et al., 2011) sendo que os principais radionuclídeos contribuintes são o ${ }^{238} \mathrm{U},{ }^{232} \mathrm{Th}$ e ${ }^{40} \mathrm{~K}$, todos litófilos e concentrados preferencialmente nas rochas ígneas ácidas, em relação às intermediárias, básicas e ultrabásicas (Adams, 1957; Larsen e George, 1957; Santos, 2001).

O urânio ocorre numa grande variedade de minerais; em maior concentração em minerais como uraninita e uranita e como traço em minerais principais como quartzo e feldspatos. O tório é o maior dos cátions tetravalentes com raio iônico de 1,47 $\AA$, ocorre em minerais puros com a torianita $\left(\mathrm{ThO}_{2}\right)$ ou torita $\left(\mathrm{ThSiO}_{2}\right)$ que são raros, mas ocorre também em menor quantidade em grande número de minerais que contêm urânio e terras raras como, por exemplo a monazita. O potássio, junto com o $\mathrm{Na}$ e o Ca, é um importante elemento constituinte de minerais formadores de rochas como álcali feldspatos, biotita, glauconita, leucita, microcrínio, ortoclásio, muscovita, nefelina, silvita. $\mathrm{O}$ volume de potássio na crosta terrestre está principalmente nos álcali feldspatos (Moura, 2005).

Dentro de residências, a exposição externa devido a raios gama e a exposição interna, causada pela inalação do radônio $\left({ }^{222} \mathrm{Rn}\right)$, pode ser aumentada se materiais 
terrestres (rochas, solos e derivados) forem utilizados na construção (UNSCEAR, 2000). Dessa forma, em uma construção, todos os materiais contêm quantidades variadas de radionuclídeos naturais, sendo que as séries radioativas do ${ }^{238} \mathrm{U},{ }^{232} \mathrm{Th}$ e ${ }^{235} \mathrm{U}$ e radionuclídeo isolado ${ }^{40} \mathrm{~K}$ são os principais contribuintes em rochas, solos e materiais derivados destes (EC, 1999).

Nas rochas, os átomos de radônio são gerados do decaimento alfa do ${ }^{226} \mathrm{Ra}$ com energia inicial de $86,0 \mathrm{keV}$, com alcance em materiais sólidos da ordem de dezenas de nm. Dependendo do local original do átomo de ${ }^{226} \mathrm{Ra}$ na estrutura e da direção do recuo, os átomos de radônio podem escapar para os poros (microporos, fissuras), (FIG. 1.5 a), permanecer nos grãos minerais, (FIG. 1.5 b), ou parar em um grão mineral vizinho, (FIG. 1.5 c), como ilustra de maneira simplificada a FIG. 1.5, (Sakoda et al., 2010).
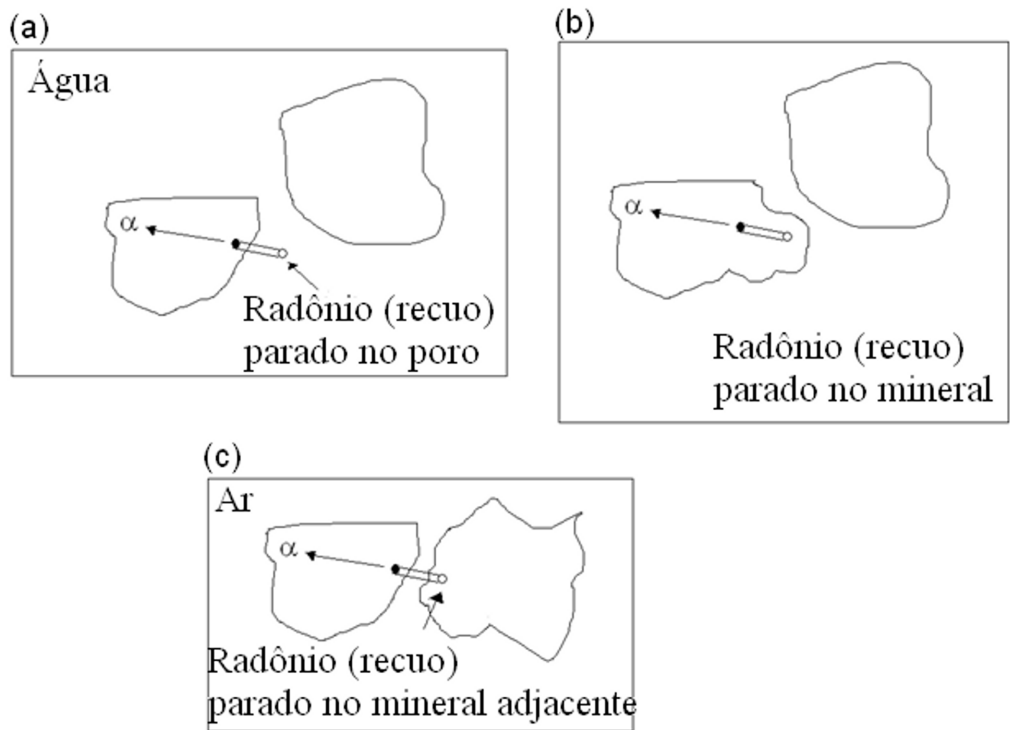

Figura 1.5: Possíveis modos de emanação do radônio.

Quando os poros são preenchidos com água, o átomo de recuo é freado nesta com maior eficiência que no ar e fica livre para difusão, (FIG. 1.5 a). Geralmente, o teor de umidade nos poros aumenta o coeficiente de emanação em relação aos poros preenchidos com ar. Contudo, os átomos irão se difundir mais no material se os poros forem preenchidos com ar do que com água (Morawska e Phillips, 1993). Se as amostras constituem-se de grãos pequenos, os espaços porosos podem não ser suficientes para parar o átomo de recuo, consequentemente alguns átomos de radônio podem ser implantados em grãos vizinhos, (FIG. 1.5 c), estes quando são liberados mais tarde são denominados átomos de recuo indireto (Semkow, 1990). Assim, a difusão e o transporte do radônio são bastante complexos e dependem de muitos fatores como, por exemplo, concentração e distribuição de ${ }^{226} \operatorname{Ra}$ (Morawska e Phillips, 1993), tamanho 
dos grãos (Semkow, 1990), teor de umidade (Fleischer, 1987) e composição mineralógica (Sakoda et al., 2010).

\subsection{Interação da radiação ionizante com a matéria}

A operação dos detectores de radiação depende da maneira como esta interage com a matéria. Assim, para entender a resposta de um determinado detector a um tipo específico de radiação numa certa faixa de energia é importante conhecer os mecanismos fundamentais de interação e transferência de energia da radiação na matéria (no detector) (Knoll, 1999). Neste trabalho, foram feitas medidas de radiação gama e radiação alfa, por conseguinte apenas estas são discutidas neste texto.

\subsubsection{Interação da radiação ionizante com a matéria}

Embora existam vários mecanismos de interação de raios gama com a matéria, três têm probabilidade maior de ocorrência, que são: efeito fotoelétrico, espalhamento compton e produção de pares (Evans, 1979). A ocorrência de um mecanismo em particular depende da energia do gama incidente e do número atômico $(Z)$ do material, como exposto na FIG. 1.6.

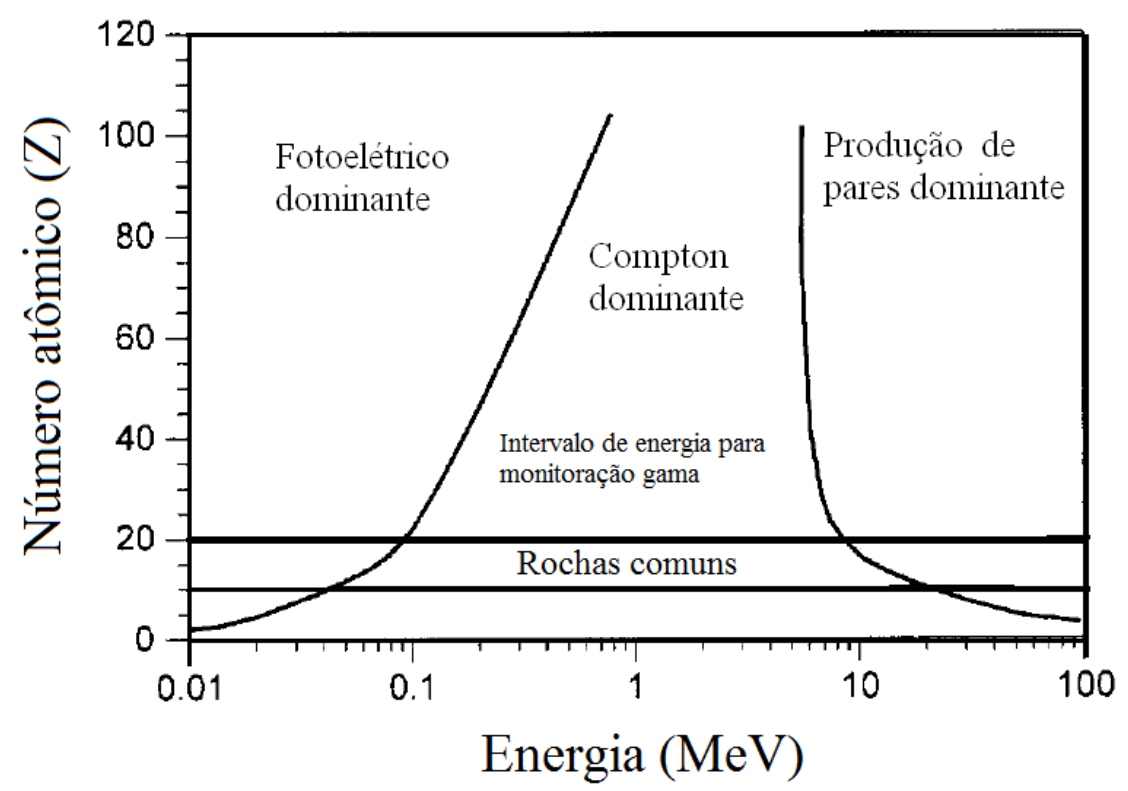

Figura 1.6: Importância relativa das seções de choque com a energia e com o número atômico Z do meio absorvedor modificado de (IAEA-TECDOC-1363, 2003). 
A passagem da radiação eletromagnética pela matéria é caracterizada por uma atenuação exponencial:

$$
I=I_{0} e^{-\mu x}
$$

Onde:

$I=$ intensidade do feixe de fótons transmitidos

$I_{0}=$ intensidade do feixe de fótons incidentes

$\mu=$ o coeficiente de atenuação linear $\mathrm{m}^{-1}$

$x=$ espessura do material $(\mathrm{m})$

Neste trabalho, a espectrometria gama, para avaliar a radioatividade natural em rochas foi realizada utilizando-se detectores de Germânio Hiperpuro (HPGe) (número atômico 32), onde, na faixa de interesse entre 0 e $3 \mathrm{MeV}$, uma maior fração de fótons interage com o detector e com a própria amostra (autoatenuação) por meio dos três processos mostrados na FIG. 1.6.

\subsubsection{Interação de partículas carregadas pesadas com a matéria}

A interação de partículas carregadas pesadas $\left(M \gg m_{0}\right)$ com a matéria é mais simples que a interação de partículas carregadas leves (elétrons). Prótons, partículas $\alpha,{ }^{2} \mathrm{H},{ }^{3} \mathrm{H},{ }^{3} \mathrm{He}$, transferem a maior parte da energia por meio de excitação e ionização nos átomos do meio absorvedor, sendo a transferência devido ao espalhamento elástico pelo núcleo e à radiação de freamento insignificantes em comparação com a ionização. Assim, o caminho percorrido por estas partícula no meio (path) tende a ser linear e equivalente ao alcance $\mathrm{R}$, devido ao menor número de interações e a maior transferência linear de energia (Evans, 1979).

Neste trabalho, para a determinação da exalação do radônio, foi usada a técnica dos detectores sólidos de traços nucleares (SSNTD) (Fleischer et al., 1975). Em termos de detecção de partículas carregadas pesadas utilizando-se detectores (SSNTD), os primeiros experimentos sugeriam que a formação dos traços era governada pela taxa de transferência total de energia $(\mathrm{dE} / \mathrm{dx})$, mas experimentos mais detalhados sugerem que uma descrição mais satisfatória é fornecida pela ionização primária e excitação dos átomos do meio (Fleischer et al., 1975). A expressão clássica que descreve a transferência de energia, E, de uma dada partícula em um meio absorvedor é conhecida como fórmula de Bethe (Evans, 1979; Knoll, 1999) e expressa como:

$$
-\frac{d E}{d x}=\frac{4 \pi e^{4} Z^{2}}{m_{0} \nu^{2}} N B
$$


Onde o termo B é e expresso por:

$$
B=Z\left[\ln \frac{2 m_{0} \nu^{2}}{I}-\ln \left(1-\frac{\nu^{2}}{c^{2}}\right)-\frac{\nu^{2}}{c^{2}}\right]
$$

Onde:

$$
\begin{aligned}
& \nu=\text { velocidade da partícula primária } \\
& Z e=\text { carga da partícula primária } \\
& N=\text { número de átomos por } \mathrm{cm}^{3} \text { do meio } \\
& Z=\text { número atômico do meio absorvedor } \\
& m_{0}=\text { massa de repouso do elétron } \\
& e=\text { carga eletrônica. }
\end{aligned}
$$

O parâmetro I representa o potencial médio de excitação e ionização do absorvedor e é um parâmetro determinado experimentalmente para cada elemento (Knoll, 1999). Para partículas não relativísticas, onde $\nu \ll c$, somente o primeiro termo da equação 1.3 é significativo. Assim, pode-se tirar três conclusões da equação 1.2: primeiro, para estas partículas, $\mathrm{dE} / \mathrm{dx}$ varia com $1 / \nu^{2}$ ou inversamente com a energia da partícula; segundo, para partículas de mesma velocidade e com cargas diferentes $\mathrm{dE} / \mathrm{dx}$ varia linearmente com $Z^{2}$; terceiro, em termos da comparação de diferentes materiais absorvedores, $\mathrm{dE} / \mathrm{dx}$ varia primariamente com o produto NZ. A equação 1.2, falha para energias baixas onde a captura e perda de elétrons da particula torna-se importante (Knoll, 1999).

Outros dois modelos de transferência de energia também são importantes e mais reais nos extremos onde a equação 1.2 falha, a transferência de energia restrita, equação 1.4, e a transferência de energia por ionização primária, equação 1.5 .

$$
\left(\frac{d E}{d x}\right)_{E<E_{0}}=\frac{C_{1} Z^{* 2}}{\beta^{2}}\left[\ln \left(\frac{W_{\max } E_{0}}{I^{2}}\right)-\beta^{2}-\delta-U\right]
$$

Onde:

$\left(\frac{d E}{d x}\right)_{E<E_{0}}=$ transferência de energia restrita.

$C_{1} \quad=2 \pi n_{e} e^{4} / m c^{2}$

$n_{e}=$ número de elétrons $/ \mathrm{cm}^{3}$ no detector 


$$
\begin{array}{lll}
\mathrm{n} & = & \text { massa do elétron } \\
Z^{*} & = & Z\left[1-\exp \left(-130 \beta / Z^{2 / 3}\right)\right] \\
\beta & = & \text { velocidade } \nu \text { do íon relativo à velocidade da luz c } \\
W_{\max } & = & 2 m c^{2} \beta^{2} \gamma^{2}, \gamma=\left(1-\beta^{2}\right)^{-1 / 2} \\
E_{0} & = & \text { limite máximo de energia dos raios delta } \\
I & = & \text { potencial de ionização médio do detector } \\
\delta & = & \text { correção para o efeito de polarização do meio à velocidades relativísticas } \\
U & = & \text { correção para baixas velocidades da não participação da camada interna } \\
& \text { de elétrons }
\end{array}
$$$$
U=\text { correção para baixas velocidades da não participação da camada interna }
$$

Onde:

$\mathrm{J}=$ transferência de energia por ionização primária.

$C_{2}=$ fração efetiva destes elétrons fracamente ligados

$I_{0}=$ potencial de ionização dos elétrons mais fracamente ligados no detector

$K=$ constante que depende da composição do meio

A transferência de energia restrita, equação 1.4, representa a fração da energia total transferida que produz raios delta $(\delta)$ com energias menores que um certo valor específico (neste caso $350 \mathrm{eV}$ ), neste modelo a transferência de energia se torna a menor fração da energia total transferida para altas energias e tem seu valor máximo para energias baixas. O segundo modelo, equação 1.5, devido ao fato de não "considerar" os raios delta, tem seu máximo a energias ainda mais baixas (que o modelo anterior), mais "decai" mais rapidamente para energias maiores. Destes três modelos o que melhor representa a formação dos traços em detectores SSNTD é o da transferência de energia restrita, equação 1.4 (Fleischer et al., 1975).

\subsection{Aspectos geológicos da área de estudo}

No estado do Paraná a geologia, FIG. 1.7, é representada por um intervalo de idades desde mais antigas de 2.800 milhões de anos até o presente, onde o embasamento ou escudo cristalino, formado por rochas magmáticas e metamórficas mais antigas que 570 milhões de anos, foi recoberto pelas rochas vulcânicas e sedimentares paleozoicas e mesozoicas da Bacia Sedimentar do Paraná. Esta cobertura foi posteriormente 
erodida, devido ao soerguimento da crosta continental a leste, expondo o embasamento. Sedimentos recentes com idades inferiores a 1,8 milhões de anos recobrem parcialmente as rochas da Bacia e do Escudo (MINEROPAR, 2010).
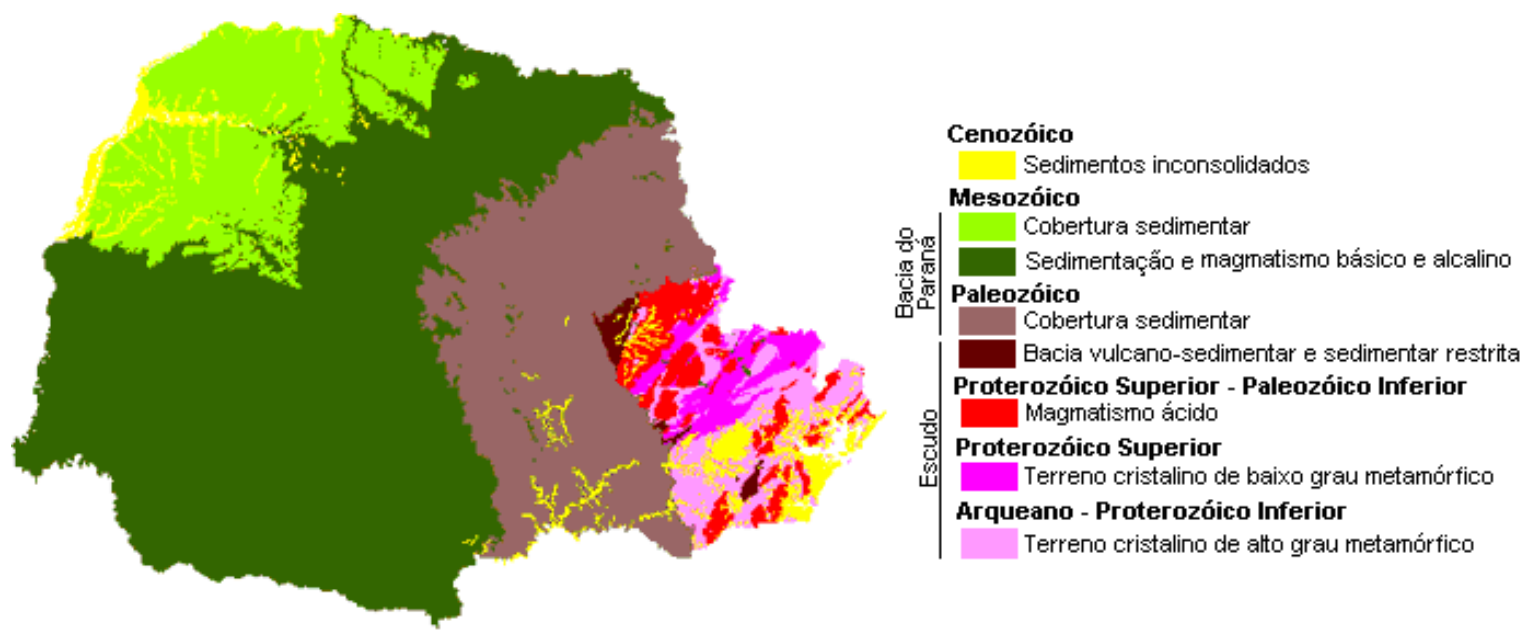

Figura 1.7: Geologia do Paraná, modificado de (MINEROPAR, 2010).

O escudo cristalino é formado por rochas ígneas e metamórficas com idades variando do Arqueano ao Proterozoico e é localmente recoberto por sequências vulcano-sedimentares, sedimentares e sedimentos inconsolidados. As rochas mais antigas, de alto grau metamórfico, afloram na porção sudeste, e as de baixo grau na porção norte-noroeste. No Proterozoico e Cambriano, início do Paleozoico, manifestações magmáticas originaram as rochas granitoides. No Mesozoico ocorreram intrusões de rochas carbonáticas, alcalinas e básicas MINEROPAR (2010). Este escudo é a mais importante fonte de rochas para a construção civil no estado, tanto como agregados, matéria prima para indústria do cimento e como rochas ornamentais.

\subsection{Recursos minerais no estado do Paraná}

O embasamento cristalino constitui o embasamento da Bacia do Paraná e geograficamente corresponde ao Litoral e Primeiro Planalto. É representado por uma ampla diversidade de ambientes e tipos litológicos que ocupam cerca de $10 \%$ do território paranaense $\left(21.000 \mathrm{~km}^{2}\right)$. Esta porção geográfica é responsável por cerca de $65 \%$ do valor da produção mineral paranaense, com a Região Metropolitana de Curitiba (RMC), respondendo por cerca de $70 \%$ deste valor ou seja, $45 \%$ do total do Estado (MINEROPAR, 2010).

Devido à grande variedade de minerais extraídos na RMC, eles foram agrupados de acordo com substância/usos, onde a denominação comercial Granitos refere-se aos minerais agrupados (granitos, gnaisses, migmatitos, sienitos e basalto), cujos principais 
usos são britas, rochas ornamentais e pedras de cantaria. A RMC participa em termos quantitativos com $87 \%$ do granito produzido no Paraná, sendo uma importante produtora de insumos minerais para a construção civil, setor que consome $80 \%$ da quantidade e $50 \%$ do valor mineral.

Na RMC existem: 40 frentes de lavra de granitos ativas cujos principais usos são calçamento, brita, pavimentação, agregados para concreto, ornamental, pedra para guia, construção civil; 25 frentes de lavra de Migmatito-gnaisse ativas cujos principais usos são pavimentação, brita, agregados para concreto; 9 frentes de lavra de Sianitos ativas cujo principal uso é para rochas ornamentais e 2 frentes de lavra de Granito ornamental ativas cujo principal uso é para rochas ornamentais (DNPM/MINEROPAR, 2010).

\subsection{Justificativa}

Conforme discutido no item 1.2, estas formações rochosas apresentam teores mensuráveis de radioatividade natural. Assim, como estas rochas têm muitas aplicações comerciais e são a principal fonte de abastecimento para construção civil local, torna-se importante fazer um estudo da sua radioatividade natural e avaliar o incremento da dose efetiva anual decorrente da utilização destas rochas em moradias e consequente exposição externa à radiação gama e exposição interna devida à inalação do radônio. 


\section{CAPÍtulo}

\section{OBJETIVOS}

\section{$2.1 \quad$ Objetivo geral}

O objetivo geral deste trabalho é gerar um banco de dados de concentrações de atividade de ${ }^{226} \mathrm{Ra},{ }^{232} \mathrm{Th}$ e ${ }^{40} \mathrm{~K}$, para diversas rochas graníticas do escudo cristalino paranaense, principalmente da RMC, utilizadas na construção civil e avaliar em termos de proteção radiológica a dose externa devido à radiação gama e a dose interna devido à inalação de radônio.

\subsection{Objetivos específicos}

Os principais objetivos específicos deste trabalho são:

- Medir a concentração de atividade de ${ }^{226} \mathrm{Ra},{ }^{232} \mathrm{Th}$ e ${ }^{40} \mathrm{~K}$ em diversas rochas do escudo cristalino do estado do Paraná, determinando assim a sua contribuição a dose total devido à radiação gama;

- Calcular, a partir das concentrações de ${ }^{226} \mathrm{Ra},{ }^{232} \mathrm{Th}$ e ${ }^{40} \mathrm{~K}$, os índices: $R a_{e q}, I_{\gamma}$ e $H_{e x}$ e avaliar se estes materiais podem ser utilizados no interior e na estrutura das residências ou somente como revestimento externo e pavimentação;

- Determinar a taxa de exalação de radônio para estas amostras, e a partir desta estimar a dose interna decorrente da inalação do radônio;

- Fazer um estudo das possíveis correlações entre alguns fatores físicos (densidade, porosidade e composição), taxa de exalação de radônio e concentração de atividade de ${ }^{226} \mathrm{Ra}$ nas amostras. 


\subsection{Originalidade}

Quanto à originalidade deste trabalho é importante ressaltar alguns pontos:

- Gerar banco de dados para rochas graníticas paranaenses utilizadas na construção civil (inexistente até o presente 2013); Avaliar a partir das concentrações de atividade de ${ }^{226} \mathrm{Ra},{ }^{232} \mathrm{Th}$ e ${ }^{40} \mathrm{~K}$, o incremento da dose efetiva anual, devido à radiação externa gama, causado pela utilização destas rochas como revestimento interno;

- Determinar a taxa de exalação superficial de radônio destas amostras na forma comercial, para a partir desta calcular a concentração de radônio causada devido à aplicação destas rochas como revestimento, e a dose efetiva anual devido à inalação do radônio;

- Estudar as correlações entre concentração de ${ }^{226}$ Ra, taxa de exalação de radônio, densidade, porosidade e composição química (teor de óxidos constituintes) para estas rochas. 


\section{Capítulo}

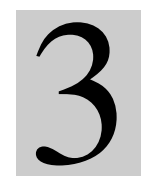

\section{REVISÃO DE LITERATURA}

\subsection{Espectrometria Gama de Radionuclídeos Naturais}

Estudos realizados em várias partes do mundo têm medido concentrações de atividade de ${ }^{238} \mathrm{U},{ }^{232} \mathrm{Th}$ e ${ }^{40} \mathrm{~K}$ em granitos com aplicação na construção civil como revestimentos internos ou rochas ornamentais e também em rochas utilizadas como materiais de construção; agregados, cimentos, areia e cal (El-Arabi, 2007; Krsti'c et al., 2007; Ngachin et al., 2007; El-Dine, 2008; Turhan, 2008; Lu e Zhang, 2008).

Turhan (2008) estimou níveis de radioatividade natural em 42 diferentes tipos de granitos, utilizados como ornamentais, dos maiores revendedores locais na Turquia, por meio do cálculo dos índices de dose interna e externa, da taxa de dose absorvida gama e da dose efetiva anual correspondente. As concentrações de atividade variaram de 9,2 Bq. $\mathrm{kg}^{-1}$ até $192,5 \mathrm{~Bq} \cdot \mathrm{kg}^{-1}$ para o ${ }^{226} \mathrm{Ra}$, de $7,5 \mathrm{~Bq} \cdot \mathrm{kg}^{-1}$ até $344,6 \mathrm{~Bq} \cdot \mathrm{kg}^{-1}$ para o ${ }^{232} \mathrm{Th}$ e de $92,1 \mathrm{~Bq} \cdot \mathrm{kg}^{-1}$ até $4155,9 \mathrm{~Bq} \cdot \mathrm{kg}^{-1}$ para o ${ }^{40} \mathrm{~K}$. Os valores da taxa de dose gama absorvida (INDOOR) variaram de $5 \mathrm{nGy} \cdot \mathrm{h}^{-1}$ a $85 \mathrm{nGy} \cdot \mathrm{h}^{-1}$. Os autores concluíram que os granitos estudados estão todos dentro dos níveis recomendados e não representam qualquer fonte significativa de perigo de radiação.

No Paquistão Faheem et al. (2008) encontraram variações de concentrações de ${ }^{226} \mathrm{Ra},{ }^{232} \mathrm{Th}$ e ${ }^{40} \mathrm{~K}$, em solos e materiais de construção, de $(20 \pm 9) \mathrm{Bq} \cdot \mathrm{kg}^{-1} \mathrm{a}$ $(43 \pm 17) \mathrm{Bq} \cdot \mathrm{kg}^{-1},(29 \pm 8) \mathrm{Bq} \cdot \mathrm{kg}^{-1}$ a $(53 \pm 9) \mathrm{Bq} \cdot \mathrm{kg}^{-1}$ e $(98 \pm 38) \mathrm{Bq} \cdot \mathrm{kg}^{-1} \mathrm{a}$ $(621 \pm 189) \mathrm{Bq} \cdot \mathrm{kg}^{-1}$, respectivamente, valores de $\mathrm{Ra}_{e q}$ variando de $(69 \pm 25) \mathrm{Bq} \cdot \mathrm{kg}^{-1}$ a $(165 \pm 32) \mathrm{Bq} \cdot \mathrm{kg}^{-1}$, índice externo de 0,18 $\pm 0,09$ a 0,45 \pm 0,09, índice interno de $0,25 \pm 0,14$ a $0,56 \pm 0,10$ e dose efetiva anual de $(0,10 \pm 0,08) \mathrm{mSv}$ a $(0,39 \pm 0,07) \mathrm{mSv}$.

Joshua e colaboradores (Joshua et al., 2009) mediram as concentrações de ${ }^{226}$ Ra, ${ }^{232} \mathrm{Th}$ e ${ }^{40} \mathrm{~K}$ em 38 rochas de ocorrências geológicas distintas do sudeste da Nigéria. Os valores médios mais altos de concentração de atividade encontrados pelos autores foram devido aos granitos, sendo $(129 \pm 38) \mathrm{Bq} \cdot \mathrm{kg}^{-1}$ para o ${ }^{226} \mathrm{Ra},(131 \pm 43) \mathrm{Bq} \cdot \mathrm{kg}^{-1}$ para o ${ }^{232}$ Th e $(882 \pm 298) \mathrm{Bq} \cdot \mathrm{kg}^{-1}$ para o ${ }^{40} \mathrm{~K}$. Os autores determinaram ainda os índices $\mathrm{Ra}_{e q}, \mathrm{H}_{e x}, \mathrm{I}_{\gamma}$ e $\mathrm{D}$ obtendo para os granitos os valores respectivamente $384 \mathrm{~Bq} \cdot \mathrm{kg}^{-1}$, $1,04,1,38$ e 0,042 mGy.h ${ }^{-1}$.

No Brasil, estudos apresentaram a concentração de atividades de ${ }^{238} \mathrm{U},{ }^{232} \mathrm{Th}$ e ${ }^{40} \mathrm{~K}$ em areias (Veiga et al., 2006). Em 2005, Anjos e colaboradores (Anjos et al., 
2005) mediram, por espectrometria gama com detector $\mathrm{NaI}(\mathrm{Tl})$, as concentrações de ${ }^{238} \mathrm{U},{ }^{226} \mathrm{Th}$ e ${ }^{40} \mathrm{~K}$ em 110 diferentes tipos de granitos comerciais, coletados em 10 estados brasileiros, utilizados como rocha ornamental e de revestimento. A taxa de dose absorvida medida variou de $0,1 \mathrm{mSv} \cdot \mathrm{a}^{-1}$ até $2,2 \mathrm{mSv} \cdot \mathrm{a}^{-1}$ e o índice de dose externa devido à radiação gama, com variação de 0,1 até 2, 9. Moura (2005) estudou 14 rochas pertencentes a diferentes séries magmáticas (de unidades geológicas ocorrentes no estado de São Paulo e sul de Minas Gerais) obtendo concentrações de $12,18 \mathrm{~Bq} \cdot \mathrm{kg}^{-1}$ a $251,90 \mathrm{~Bq} \cdot \mathrm{kg}^{-1}$ para o ${ }^{238} \mathrm{U}$, de $9,55 \mathrm{~Bq} \cdot \mathrm{kg}^{-1}$ a $347,47 \mathrm{~Bq} \cdot \mathrm{kg}^{-1}$ para o ${ }^{232} \mathrm{Th}$ e de 407, $50 \mathrm{~Bq} \cdot \mathrm{kg}^{-1}$ a $1615 \mathrm{~Bq} \cdot \mathrm{kg}^{-1}$ para o ${ }^{40} \mathrm{~K}$. Também calculou o $\mathrm{Ra}_{e q}$ com variação de $57,21 \mathrm{~Bq} \cdot \mathrm{kg}^{-1}$ a $752,81 \mathrm{~Bq} \cdot \mathrm{kg}^{-1}, \mathrm{I}_{\gamma}$ (índice de concentração de atividade gama) variando de 0,23 a 2,61 e $\mathrm{H}_{e x}$ (índice de risco de radiação externa) com variação de 0,15 a 2,03 .

Anjos e colaboradores (Anjos et al., 2011) calcularam a taxa de dose externa devido à radiação gama e a concentração de radônio, por um método indireto a partir das concentrações de atividades de ${ }^{226} \mathrm{Ra},{ }^{232} \mathrm{Th}$ e ${ }^{40} \mathrm{~K}$ e simulação no Monte Carlo. Cerca de 300 amostras de 100 tipos diferentes de granitos comerciais brasileiros de 10 estados foram medidas. O modelo de sala utilizado para medida da taxa de dose tem dimensões de 4, $0 \mathrm{~m}$ x 5, $0 \mathrm{~m}$ x 2,8 m, largura, comprimento e altura, respectivamente. As paredes foram revestidas com placas de $3 \mathrm{~cm}$ de granito e o chão com blocos de $20 \mathrm{~cm}$ de espessura. As concentrações de atividade variaram de $190 \mathrm{~Bq} \cdot \mathrm{kg}^{-1}$ a $2029 \mathrm{~Bq} \cdot \mathrm{kg}^{-1}$ para o ${ }^{40} \mathrm{~K}$, de $5 \mathrm{~Bq} \cdot \mathrm{kg}^{-1}$ a $160 \mathrm{~Bq} \cdot \mathrm{kg}^{-1}$ para o ${ }^{226} \mathrm{Ra}$ e de $4,5 \mathrm{~Bq} \cdot \mathrm{kg}^{-1}$ a $450 \mathrm{~Bq} \cdot \mathrm{kg}^{-1}$ para o ${ }^{232} \mathrm{Th}$. A variação da taxa de dose calculada para o modelo de sala descrita foi de $4,4 \mathrm{nGy} \cdot \mathrm{h}^{-1}$ a $120 \mathrm{nGy} \cdot \mathrm{h}^{-1}$. A variação para a taxa de exalação de radônio foi de 0,6 Bq.m $\mathrm{m}^{-2} \cdot \mathrm{h}^{-1}$ a $21 \mathrm{~Bq} \cdot \mathrm{m}^{-2} \cdot \mathrm{h}^{-1}$ (onde a taxa de ventilação adotada no modelo foi de $\left.0,5 \mathrm{~h}^{-1}\right)$.

No Paraná, há poucos estudos da radioatividade natural em rochas e solos, Ferreira et al. (2010) mediram concentrações de ${ }^{238} \mathrm{U},{ }^{226} \mathrm{Ra},{ }^{232} \mathrm{Th}$ e ${ }^{40} \mathrm{~K}$ em um perfil de rochas sedimentares carbonáticas, utilizadas como corretivo agrícola.

Bastos e Appoloni (2009) mediram concentrações de atividade de ${ }^{238} \mathrm{U},{ }^{226} \mathrm{Ra}$, ${ }^{232}$ Th e ${ }^{40} \mathrm{~K}$ em 87 amostras de rochas de 14 formações geológicas distintas pertencentes à bacia hidrográfica do rio Tibagi, das quais três são formações de rochas ígneas, duas ácidas e uma básica. Os valores mais altos de dose foram obtidos para as rochas ígneas ácidas: Riolito Castro, $(129,8 \pm 3,7)$ nGy.h ${ }^{-1}$ e granito Cunhaporanga, $(167 \pm 37)$ nGy.h ${ }^{-1}$. Valores menores foram obtidos para as demais formações, entre elas o basalto, rocha ígnea básica (Formação Serra Geral). 


\subsection{Aplicação de detectores (SSNTD) para medidas de ${ }^{222} \mathbf{R n}$}

Muitos trabalhos têm avaliado taxas de emanação de radônio em materiais de construção (Khan et al., 1992; Pakou et al., 1994; Baykara et al., 2005; Righi e Bruzzi, 2006; Faheem et al., 2008).

Estudos de exalação de radônio têm sido feitos em amostras de concretos, (Burke, 2002), no interior de residências (Vilalobos, 1991; Burke, 2002). Estes estudos têm mostrado que a principal fonte de radônio no interior de casas é devido à concentração de urânio e tório no solo, e em apartamentos, sua ocorrência é decorrente principalmente dos materiais de construção, rochas de revestimento interno e ornamentais (Moura, 2005).

No Brasil, vários estudos foram desenvolvidos avaliando exposição e dose devido ao radônio em casas, em Campinas (Neman, 2000), em São Paulo (Silva, 2005), em Poços de Caldas (Neman, 2004). Campos e Pecequilo (2003) Mediram a taxa de dose total (externa devido a radiação gama e interna devido a inalação do radônio) recebida por moradores em 7 casas populares em São Paulo, obtendo valor máximo para o inverno com média de $1,68 \mathrm{mSv} \cdot \mathrm{a}^{-1}$.

Foi realizado também um estudo para avaliar exposição ao radônio em residência construída com fosfogesso (Villaverde, 2008) e em cavernas (Alberigi, 2006). Foi mostrado também (Moura, 2005) que as concentrações de ${ }^{238} \mathrm{U},{ }^{232} \mathrm{Th}$ e ${ }^{40} \mathrm{~K}$ e fração de emanação de radônio de rochas magmáticas, utilizadas como ornamentais e de revestimento interno, são influenciadas por características petrográficas.

No Paraná, há poucos estudos medindo a concentração de ${ }^{222} \mathrm{Rn}$ no ar devido a materiais de construção em Curitiba e região metropolitana (Paschuk et al., 2007). Fior (Fior, 2008) estudou a variação da concentração de ${ }^{222} \mathrm{Rn}$ no decorrer da construção de ambientes (células-teste), com bloco cerâmico e de concreto e com a aplicação de materiais como reboco, cal fino e tinta, originados da região metropolitana de Curitiba. Após a aplicação de tinta a óleo e tinta acrílica fosca, tais concentrações diminuíram. Os resultados evidenciam que o revestimento interno das paredes atuou diminuindo a exalação do radônio no interior das células-teste.

\subsection{Estudo da correlação entre concentração de Urânio e emanação de Radônio}

Em princípio, a quantidade de radônio presente em rochas e solos depende da concentração de urânio, contudo há outros fatores importantes na determinação de 
radônio no ar, pois a difusão deste depende da composição mineral e da distribuição de poros das rochas (Faheem et al., 2008). Assim, torna-se necessário fazer também medidas da taxa de exalação de radônio, para se obter uma avaliação mais rigorosa.

Estudos mostraram que a fração de exalação do radônio aumenta com o teor de umidade, com a temperatura (Stranden et al., 1984) e com a diminuição do tamanho do grão (Barton e Ziemer, 1986). Outros estudos mostram comportamento inverso ou nenhum efeito com a diminuição do tamanho do grão (Sakoda et al., 2008). Em um estudo recente (Sakoda et al., 2010), foi mostrado que a fração da emanação de radônio também é influenciada pela composição mineral dos solos ou rochas.

Marocchi e colaboradores (Marocchi et al., 2011) estudaram vinte amostras de materiais de construção, rochas comumente utilizadas como ornamentais, coletadas em companhias locais na Itália. Foram feitas análises por espectrometria gama, fluorescência de raios-X, Difração de raios-X , medida da porosidade e exalação de radônio. Os minerais acessórios radioativos mais comuns determinados nas amostras foram apatita, zircão e alanita e, com menor ocorrência, monazita, torita, torianita, elementos terras raras e óxidos-Zr. Para os radionuclídeos naturais as atividades variaram de $(20 \pm 2) \mathrm{Bq} \cdot \mathrm{kg}^{-1}$ até $(490 \pm 50) \mathrm{Bq} \cdot \mathrm{kg}^{-1}$ para o ${ }^{232} \mathrm{Th}$, de $(12 \pm 2) \mathrm{Bq} \cdot \mathrm{kg}^{-1}$ até $(390 \pm 60) \mathrm{Bq} \cdot \mathrm{kg}^{-1}$ para o ${ }^{226} \mathrm{Ra}$ e de $(240 \pm 7) \mathrm{Bq} \cdot \mathrm{kg}^{-1}$ até $(2000 \pm 70) \mathrm{Bq} \cdot \mathrm{kg}^{-1}$ para o ${ }^{40} \mathrm{~K}$. A taxa de exalação variou de $(0,0007 \pm 0,0002) \mathrm{Bq} \cdot \mathrm{kg}^{-1} \cdot \mathrm{h}^{-1}$ até $(0,64 \pm 0,05) \mathrm{Bq} \cdot \mathrm{kg}^{-1} \cdot \mathrm{h}^{-1}$. Os autores não encontraram uma correlação significativa entre a taxa de exalação do radônio e a concentração de atividade do ${ }^{226} \mathrm{Ra}$, e enfatizam em virtude deste resultado a importância da caracterização de materiais de construção não unicamente em virtude da concentração de atividade de ${ }^{226} \mathrm{Ra}$ mas também das suas propriedades de emanação.

No Brasil, (Moura, 2005) obteve resultados semelhantes, mostrando que o teor de radioatividade natural e consequente teor de emanação de radônio podem ainda ser influenciados por características petrográficas como aspectos composicionais, texturais e estruturais.

Bonotto e colaboradores (Moura et al., 2011) mediram a radioatividade natural em 14 tipos de rochas ígneas brasileiras utilizadas como rochas ornamentais. Por meio da técnica de espectrometria gama foram determinadas as concentrações de atividade do ${ }^{226} \mathrm{Ra},{ }^{232} \mathrm{Th}$ e ${ }^{40} \mathrm{~K}$, e, a partir destes valores, foram estimados os índices dosimétricos $\mathrm{Ra}_{e q}, \mathrm{I}_{\gamma}$ e $\mathrm{H}_{e x}$. Também foi medida a taxa de exalação do radônio. As amostras estudadas são de diferentes ocorrências geológicas do estado de São Paulo e Sudeste de Minas Gerais. As concentrações de atividade variaram de $12,18 \mathrm{~Bq} \cdot \mathrm{kg}^{-1}$ a $251,90 \mathrm{~Bq} \cdot \mathrm{kg}^{-1}$ para o ${ }^{226} \mathrm{Ra}$, de $9,55 \mathrm{~Bq} \cdot \mathrm{kg}^{-1}$ a $347,47 \mathrm{~Bq} \cdot \mathrm{kg}^{-1}$ para o ${ }^{232} \mathrm{Th}$ e de $407,5 \mathrm{~Bq} \cdot \mathrm{kg}^{-1}$ a $1615,0 \mathrm{~Bq} \cdot \mathrm{kg}^{-1}$ para o ${ }^{40} \mathrm{~K}$. A taxa de exalação de radônio variou de 0,24 Bq.m ${ }^{-2} \cdot h^{-1}$ até 3,93 Bq.m ${ }^{-2} \cdot h^{-1}$.

Amaral e colaboradores (Amaral et al., 2012) avaliaram o comportamento 
radiométrico e os padrões de exalação de radônio em 10 tipos de rochas silicáticas exploradas comercialmente como ornamentais nos estados de Minas Gerais e Espírito Santo. As concentrações de urânio medidas variaram de $35,8 \mathrm{~Bq} \cdot \mathrm{kg}^{-1}$ até 456,6 Bq. $\mathrm{kg}^{-1}$ de ${ }^{226} \mathrm{Ra}$. As concentrações de radônio medidas após 25 dias de acumulação variaram de $10 \mathrm{~Bq} \cdot \mathrm{m}^{-3}$ até $2483 \mathrm{~Bq} \cdot \mathrm{m}^{-3}$. Os autores concluíram que, além da concentração de urânio nas rochas, aspectos petrofísicos, como a distribuição de poros também devem ser analisados como parâmetros para quantificar a exalação do radônio. 


\section{CAPÍtulo}

\section{MATERIAIS E MÉTODOS}

\subsection{Amostragem}

Um total de 50 amostras foi obtido na Região Metropolitana de Curitiba (RMC), FIG. 4.1, sendo que duas fábricas que operam na região estudada respondem por quase a totalidade das rochas extraídas no estado do Paraná, para fins de revestimento interno, extraindo e beneficiando as rochas.

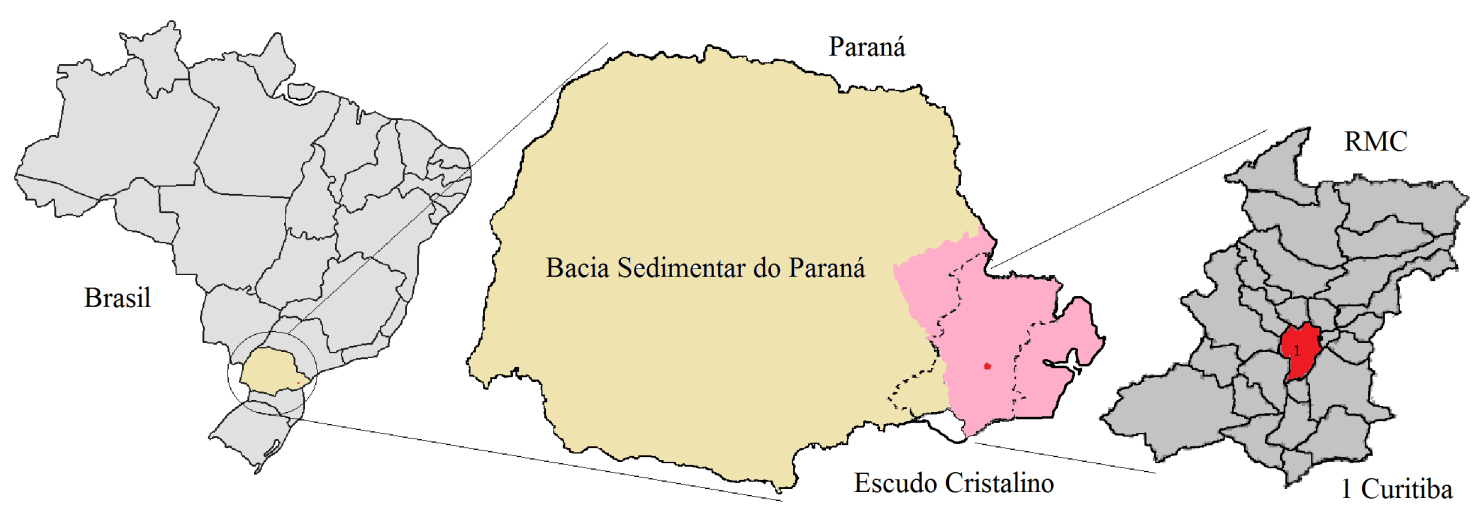

Figura 4.1: Ilustração da área de estudo.

Foram obtidos 34 recortes de chapas com dimensões $15 \mathrm{~cm}$ x $15 \mathrm{~cm} \mathrm{x} 2 \mathrm{~cm}$, largura, comprimento e espessura respectivamente, sendo 21 amostras da fábrica 1 e 13 amostras da fábrica 2, como indicado na TAB. 4.1. Três amostras em forma de brita (utilizadas como agregado), foram obtidas de outras fábricas (TAB. 4.1). 
Tabela 4.1: Amostras de rochas da RMC, obtidas na forma comercial em fábricas da região.

\begin{tabular}{|c|c|c|c|}
\hline \multicolumn{2}{|c|}{ Fábrica 1} & \multicolumn{2}{|c|}{ Fábrica 2} \\
\hline Número(ID) & Código amostra & Número(ID) & Código amostra \\
\hline 1 & $\mathrm{BDA}$ & 22 & SFG2 \\
\hline 2 & BDU1 & 23 & VV \\
\hline 3 & $\mathrm{BN}$ & 24 & MA \\
\hline 4 & $\mathrm{BP}$ & 25 & $P G$ \\
\hline 5 & $\mathrm{CA}$ & 26 & $\mathrm{PP} / \mathrm{TN}$ \\
\hline 6 & $\mathrm{JC}$ & 27 & VI2 \\
\hline 7 & JI & 28 & $\mathrm{RD}$ \\
\hline 8 & PI & 29 & BDU2 \\
\hline 9 & IM1 & 30 & IM2 \\
\hline 10 & MP & 31 & GP \\
\hline 11 & $\mathrm{~PB}$ & 32 & $\mathrm{CN}$ \\
\hline 12 & $\mathrm{PM}$ & 33 & VT2 \\
\hline 13 & $\mathrm{RC}$ & 34 & VDD \\
\hline 14 & SFG1 & \multicolumn{2}{|c|}{ Outras Fábricas } \\
\hline 15 & VB & 35 & BB \\
\hline 16 & VBG & 36 & $\mathrm{RCB}$ \\
\hline 17 & VL & 37 & RPGB \\
\hline 18 & VM & & \\
\hline 19 & VTC & & \\
\hline 20 & VT1 & & \\
\hline 21 & VI1 & & \\
\hline
\end{tabular}

Nas amostras destacadas na TAB. 4.1, o número no final do seu código indica a fábrica em que é produzida. São amostras distintas (provenientes de pedreiras diferentes e extraídas e manufaturadas por fábricas diferentes, em comum apresentam apenas o nome comercial). Ressaltando, o objetivo do trabalho não é fazer uma classificação "geológica" das amostras estudadas, visto que, em termos de nomenclatura, estes nomes comerciais são apenas uma "classificação" faciológica das amostras. Ainda, a extração de uma determinada rocha é continuada ou não de acordo com a sua disponibilidade na pedreira e com a demanda comercial, e estes nomes comerciais são apenas uma forma de buscar a identidade do produto frente aos consumidores. Assim, como este trabalho busca uma avaliação radiológica de rochas extraídas e 
comercializadas na região, o estudo realizou-se considerando-se estes nomes sendo que no caso específico destas cinco amostras, por serem extraídas de pedreiras diferentes e por fábricas diferentes, foram consideradas amostras diferentes com o mesmo nome, possivelmente casos contrários também podem ocorrer, mesma amostra porém com nomes diferentes. Esta discusão sobre classificação e caracterização não é um dos objetivos do trabalho.

Além destas 37 amostras obtidas nas respectivas fábricas responsáveis por sua extração, beneficiamento e distribuição para revendedoras foram obtidas 13 amostras em revendedoras (sem "preocupação" com a fábrica pela qual é produzida, com interesse apenas em estudar a variabilidade da amostragem), TAB. 4.2.

Tabela 4.2: Amostras obtidas em revendedoras locais da RMC para estudo da variabilidade.

\begin{tabular}{cccccc}
\hline \hline Número(ID) & Código amostra & Fábrica & Número(ID) & Código amostra & Fábrica \\
\hline \hline 38 & $(\mathrm{BDU})$ & 1 ou 2 & 45 & $(\mathrm{CA})$ & 1 \\
39 & $(\mathrm{IM})$ & 1 ou 2 & 46 & $(\mathrm{JI})$ & 1 \\
40 & $(\mathrm{PG})$ & 2 & 47 & $(\mathrm{RC})$ & 1 \\
41 & $(\mathrm{SFG})$ & 1 ou 2 & 48 & $(\mathrm{VB})$ & 1 \\
42 & $(\mathrm{VV})$ & 2 & 49 & $(\mathrm{VM})$ & 1 \\
43 & $(\mathrm{VI})$ & 1 ou 2 & 50 & $(\mathrm{VT})$ & 1 ou 2 \\
44 & $(\mathrm{BP})$ & 1 & & & \\
\hline \hline
\end{tabular}

Nesta tabela (TAB. 4.2), a indicação da fábrica foi feita posteriormente (uma vez que pela identificação de cada amostra foi possível "rastrear" sua procedência, fábrica 1 ou 2). Como cinco destas amostras são produzidas pelas duas fábricas, não foi possível identificar inicialmante qual amostra é (1 ou 2), relacionando com a TAB. 4.1.

\subsubsection{Estudo da variabilidade da amostragem}

Em medidas ambientais é importante fazer uma avaliação da amostragem, que pode ser feita por meio de um estudo da variabilidade de algumas amostras, ou seja, coletam-se $\boldsymbol{n}$ alíquotas de uma dada amostra e fazem-se medidas destas, com o objetivo de avaliar se realmente trata-se de uma mesma amostra. Isto fica evidente se o resultado obtido for estatisticamente o mesmo para todas as sub-amostras dentro dos desvios experimentais aceitáveis. Para esta avaliação utilizou-se a distribuição de Student onde duas grandezas são consideradas iguais se estão dentro do intervalo de um dado nível de confiança, equação 4.1, (Barros Neto, 2001).

$$
\bar{x}-t_{N-1} \frac{s}{\sqrt{N}}<\mu<\bar{x}+t_{N-1} \frac{s}{\sqrt{N}}
$$


Onde:

$\bar{x}=$ média amostral

$s \quad=$ desvio padrão amostral

$N=$ número de sub-amostras

$\mu \quad=$ média populacional

\subsection{Espectrometria gama}

\subsubsection{Pré-tratamento e preparo das amostras}

Para a análise por espectrometria gama as amostras, FIG. 4.2 a, foram pré-britadas em um pilão de aço, passadas em uma peneira de 10 Mesh (abertura de $2 \mathrm{~mm}$ ), FIG. $4.2 \mathrm{~b}$, e posteriormente pulverizadas em moinho de recipiente vibratório, FIG. $4.2 \mathrm{c}$ e d (passadas por uma peneira de $60 \mathrm{Mesh}$, abertura de 0,250 mm). Após este preparo elas foram seladas em frascos de polietileno de alta densidade de $100 \mathrm{~mL}$ com batoque e tampa, FIG. 4.2 e e f, e medidas após 30 dias (aproximadamente 8 meias-vidas do ${ }^{222} \mathrm{Rn}$ ), tempo necessário para ser atingido aproximadamente 99,6\% do equilíbrio radioativo secular entre o ${ }^{226} \mathrm{Ra}$ e o ${ }^{222} \mathrm{Rn}$, condição em que as atividades destes isótopos são iguais.

Esta condição de equilíbrio é necessária, pois, as estimativas para a concentração de atividade para o ${ }^{226} \mathrm{Ra}$, foram determinadas considerando os filhos do ${ }^{222} \mathrm{Rn}$, e este por ser um gás nobre, exala facilmente da amostra, tornando necessário que a mesma seja selada por tempo determinado para que o equilíbrio seja reestabelecido. Como a meia-vida do filho $\left({ }^{222} \mathrm{Rn}, \mathrm{t}_{1 / 2}=3,8\right.$ dias $)$ é muito menor que a do pai $\left({ }^{226} \mathrm{Ra}\right.$, $\mathrm{t}_{1 / 2}=1600$ anos) FIG. 1.1, após o recipiente ser selado a concentração de atividade de ${ }^{222} \mathrm{Rn}$ cresce exponencialmente de acordo com sua própria constante de decaimento até atingir o equilíbrio radioativo (Evans, 1979). 


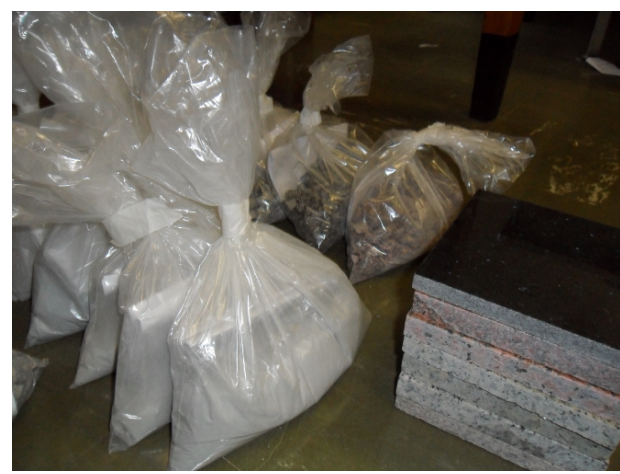

(a)

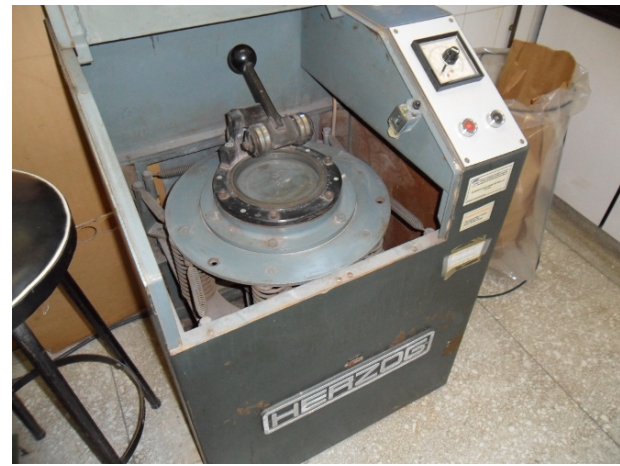

(c)

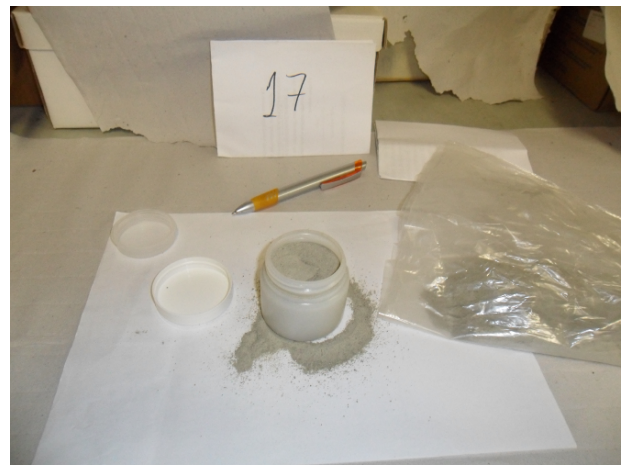

(e)

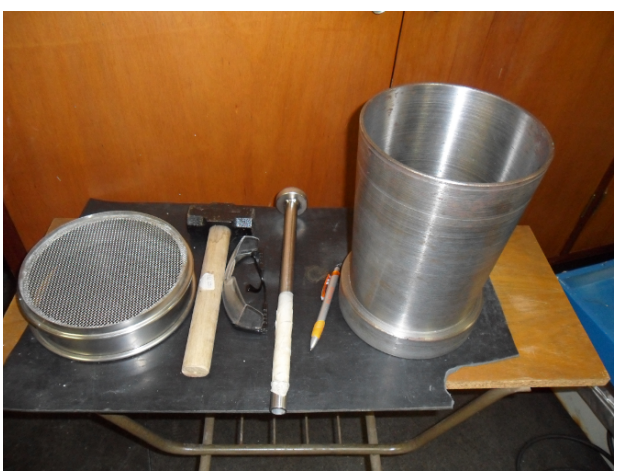

(b)

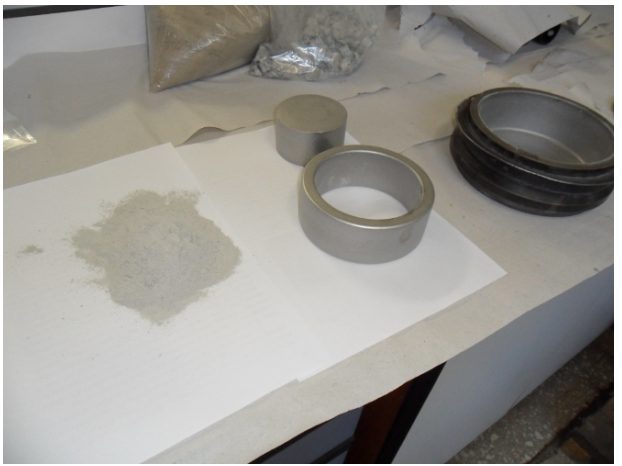

(d)

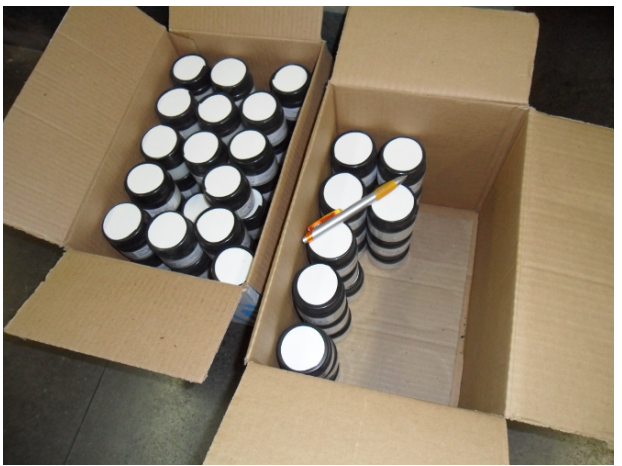

(f)

Figura 4.2: Pré-tratamento das amostras (a) Diferentes etapas de preparação, (b) Pilão de aço e peneira de $2 \mathrm{~mm}$, utilizados na pré-britagem (c) e (d) Moinho vibratório e respectiva "panela" utilizados na pulverização, (e) e (f) Selagem das amostras.

Cada amostra foi preparada em triplicata e medida durante 86000 s, para estas medidas foram utilizados 4 detectores coaxiais de Germânio Hiperpuro (HPGe) com eletrônica padrão associada, sendo:

1. ORTEC série GEM com eficiência relativa de $15 \%$ com resolução efetiva de 2, $8 \mathrm{keV}$ para a transição de $1,33 \mathrm{MeV}$ do ${ }^{60} \mathrm{Co}$; 
2. ORTEC série GEM com eficiência relativa de $15 \%$ com resolução efetiva de 2, $8 \mathrm{keV}$ para a transição de $1,33 \mathrm{MeV}$ do ${ }^{60} \mathrm{Co}$;

3. Faixa estendida (Eurisys Mesures) com eficiência relativa de $15 \%$ e resolução efetiva de $2,1 \mathrm{keV}$ para a transição de $1,33 \mathrm{MeV}$ do ${ }^{60} \mathrm{Co}$;

4. Faixa estendida (Canberra) com eficiência relativa de $25 \%$ e resolução de $2,0 \mathrm{keV}$ para a transição de $1,33 \mathrm{MeV}$ do ${ }^{60} \mathrm{Co}$.

Oitenta e seis por cento das 150 medidas foram realizadas nos detectores 1 (FIG. 4.3) e 2, $7 \%$ no detector 3 e $7 \%$ no detector 4 , estes dois últimos foram utilizados apenas na etapa final das medidas (unicamente para terminar a medidas em tempo hábil). 


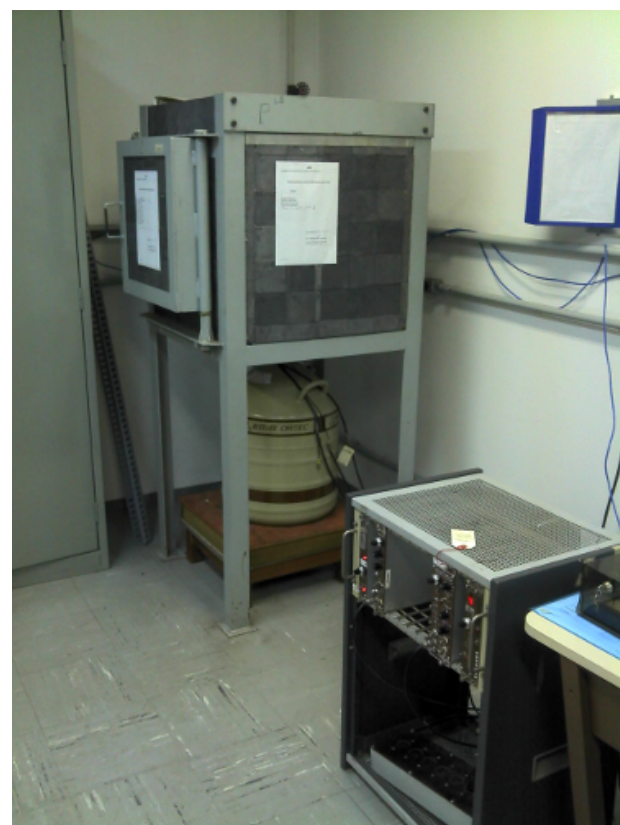

(a) Sistema de medida

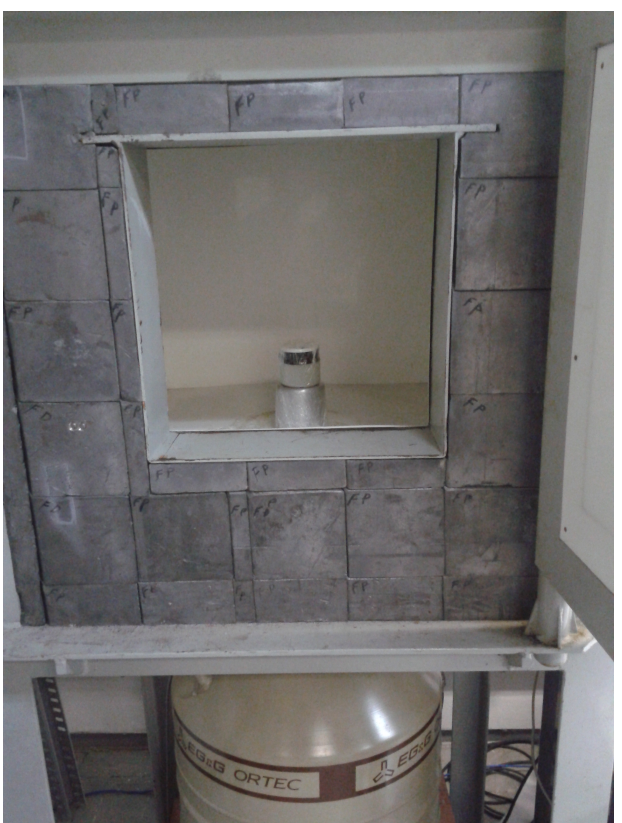

(b) Arranjo experimental

Figura 4.3: (a) Sistema de medida (b) Detector HPGe série GEM Ortec com respectiva blindagem e amostra na geometria de medida.

O analisador multicanal utilizado foi o EG\&G ORTEC 919 Spectrum MASTER $4 \mathrm{k}$, e as análises dos espectros foram realizadas com o programa InterWinner 6.0 (INTERWINNER6.0, 2004). A radiação de fundo foi obtida a partir da medida de um frasco de $100 \mathrm{~mL}$ com água ultrapura e a eficiência do detector foi determinada com uma solução aquosa radioativa multielementar na mesma geometria de medida. Para todas as amostras foram feitas medidas para determinação do fator da autoatenuação, item 4.2.2, estas medidas são importantes, pois a densidade das amostras é maior do que a densidade da solução aquosa radioativa multielementar utilizada para a curva de eficiência.

\subsubsection{Estudo da autoatenuação da radiação gama nas amostras estudadas}

A correção da autoatenuação nas análises das amostras por espectrometria gama torna-se mais importante quanto mais distintas forem as densidades e a composição química das amostras, pois estas refletem características da matriz, as quais deveriam ser também o mais semelhantes possíveis à da amostra utilizada para curva de eficiência. Neste trabalho a densidade da amostra utilizada para curva de calibração é de 1,00 g.cm ${ }^{-3}$ (solução aquosa radioativa multielementar), e as densidades das amostras estudadas variam de 1,57 g.cm ${ }^{-3}$ até 2,02 g.cm ${ }^{-3}$, assim as densidades e as matrizes são diferentes, tornando fundamental, para uma determinação acurada das 
concentrações de atividade, o estudo da autoatenuação.

Neste estudo foram utilizadas 4 fontes pontuais de ${ }^{152} \mathrm{Eu},{ }^{133} \mathrm{Ba},{ }^{60} \mathrm{Co}$ e ${ }^{137} \mathrm{Cs}$, (Ferreira e Pecequilo, 2011) das quais foram selecionadas 17 transições gama de $80 \mathrm{keV}$ a $1408 \mathrm{keV}$, TAB. 4.4, estas transições estão na região de interesse (de $40 \mathrm{keV}$ a 3000 $\mathrm{keV}$ ) para medidas naturais ambientais.

Tabela 4.4: Transições gama selecionadas para o estudo de autoatenuação.

\begin{tabular}{|c|c|c|}
\hline $\begin{array}{c}\text { IAEA Fontes gama } \\
\text { padrão (IAEA, 1982) }\end{array}$ & $\begin{array}{c}\text { Energia }(\mathrm{keV}) \\
(\text { TECDOC-619, 2012) }\end{array}$ & $\begin{array}{c}\text { Intensidade }(\%) \\
(\text { TECDOC-619, 2012) }\end{array}$ \\
\hline \multirow[t]{9}{*}{${ }^{152} \mathrm{Eu}$} & 121,782 & 28,37 \\
\hline & 244,281 & 7,53 \\
\hline & 344,281 & 26,57 \\
\hline & 778,903 & 12,97 \\
\hline & 867,390 & 4,21 \\
\hline & 964,055 & 14,63 \\
\hline & 1085,842 & 10,33 \\
\hline & 1112,087 & 13,54 \\
\hline & 1408,022 & 20,85 \\
\hline \multirow[t]{5}{*}{${ }^{133} \mathrm{Ba}$} & 80,998 & 34,11 \\
\hline & 276,398 & 7,15 \\
\hline & 302,853 & 18,30 \\
\hline & 356,017 & 61,94 \\
\hline & 383,851 & 8,90 \\
\hline \multirow[t]{2}{*}{${ }^{60} \mathrm{Co}$} & 1173,238 & 99,86 \\
\hline & 1332,502 & 99,98 \\
\hline${ }^{137} \mathrm{Cs}$ & 661,660 & 85,10 \\
\hline
\end{tabular}

Os fatores de correção da autoatenuação foram calculados pelo método da transmissão direta descrito por (Cutshall et al., 1983). Neste método, supõe-se que a transmissão de um fóton através da amostra seja igual à transmissão de fótons emitidos pela própria amostra. Este método é válido fazendo-se duas considerações básicas: que fonte, amostra e detector estejam centrados coaxialmente, e que os fótons vindos da amostra incidam perpendicularmente (ou ao menos aproximadamente) no detector, o que é garantido dada a distância detector fonte radioativa (no presente trabalho $63 \mathrm{~mm}$ ) e devido ao uso do colimador (de chumbo com espessura de $8 \mathrm{~mm}$ e diâmetro de furo de $3 \mathrm{~mm}$ ) FIG. 4.4, (Bastos, 2008). 


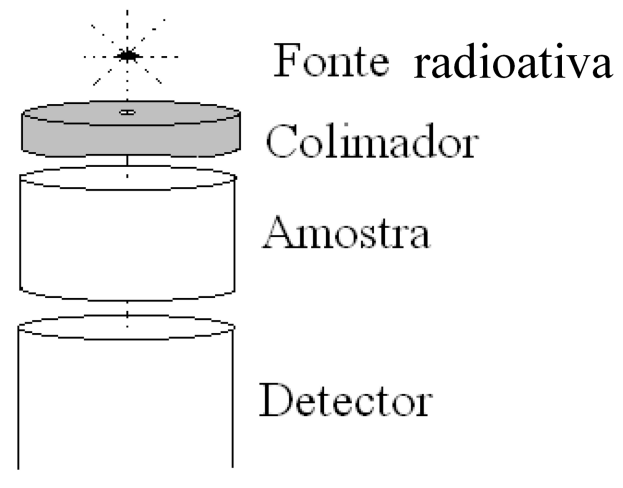

Figura 4.4: Diagrama do arranjo experimental do método de transmissão gama para a correção da autoatenuação nas amostras.

Considerando $\mathrm{T}_{A}$ a intensidade do feixe de fótos (de uma energia específica) atenuado (transmitido através da amostra) e I a intensidade do feixe de fótons não atenuado (incidente na amostra), temos:

$$
T_{A}=I e^{-\mu_{A} L}
$$

Onde $\mu_{A}$ é o coeficiente de atenuação linear total da amostra $\left(\mathrm{cm}^{-1}\right)$, L é a espessura da amostra $(\mathrm{cm})$ (rigorosamente L é a distância percorrida pelo fóton, sem sofrer interação por nenhum dos três processos citados no item 1.3.1, e $e^{-\mu_{A} L}$ é a probabilidade que isto aconteça). Assim, medindo-se a transmissão gama em uma dada amostra e a transmissão gama no padrão, pode-se calcular os fatores da autoatenuação utilizando a equação 4.3, (Cutshall et al., 1983).

$$
f=\left\langle\frac{T_{A}}{T_{P}}\right\rangle=\frac{\left(\frac{T_{A}}{T_{P}}-1\right)}{\ln \left(\frac{T_{A}}{T_{P}}\right)}
$$

Onde $T_{A}$ e $T_{P}$ são as intensidades gamas atenuadas para amostra e para o padrão respectivamente. O fator de correção de autoatenuação da amostra $f=\left\langle\frac{T_{A}}{T_{P}}\right\rangle$ é uma correção na eficiência de detecção e deverá ser igual à razão $\frac{\varepsilon_{A}}{\varepsilon_{P}}$, assim podemos escrever que a eficiência corrigida é dada por $\varepsilon_{A}=f \varepsilon_{P}$, substituindo este valor na equação 4.4, próximo item, obtemos a correção da atividade para cada transição gama considerada. Para tais medidas foi utilizado aparato desenvolvido, para o Laboratório 
de Radiomentria Ambiental (por M. Sc. Marcelo Bessa Nisti), que consiste basicamente de suporte de Lucite e colimador de chumbo, garantindo as condições requeridas pelo modelo de Cutshall et al. (1983).

Para as medidas realizadas para este estudo foi utilizado um detector de Germânio Hiperpuro coaxial série GEM, com eficiência relativa de 20 \% e resolução de $1,8 \mathrm{keV}$ para a transição de $1,33 \mathrm{MeV}$ do ${ }^{60} \mathrm{Co}$, os dados foram adquiridos utilizando-se o software Maestro5.30 para Windows.

\subsubsection{Cálculo da concentração de atividade}

Para medir atividades absolutas, é necessária uma calibração absoluta da eficiência de detecção, esta é feita com fontes de calibração certificadas e com transições gama de energia na região de interesse, utilizando a mesma geometria detector-fonte das análises.

Geralmente, qualquer transição gama emitida por um radionuclídeo filho das séries do ${ }^{238} \mathrm{U}$ e ${ }^{232} \mathrm{Th}$ pode ser utilizada para estimar a atividade do núcleo pai, isto é possível se a série estiver em equilíbrio radioativo (Evans, 1979). A atividade é então derivada da taxa de contagens, conforme equação 4.4.

$$
A\left({ }^{A} X\right)=\frac{C(E)}{P_{\gamma}(E) \varepsilon(E) m t}
$$

Onde:

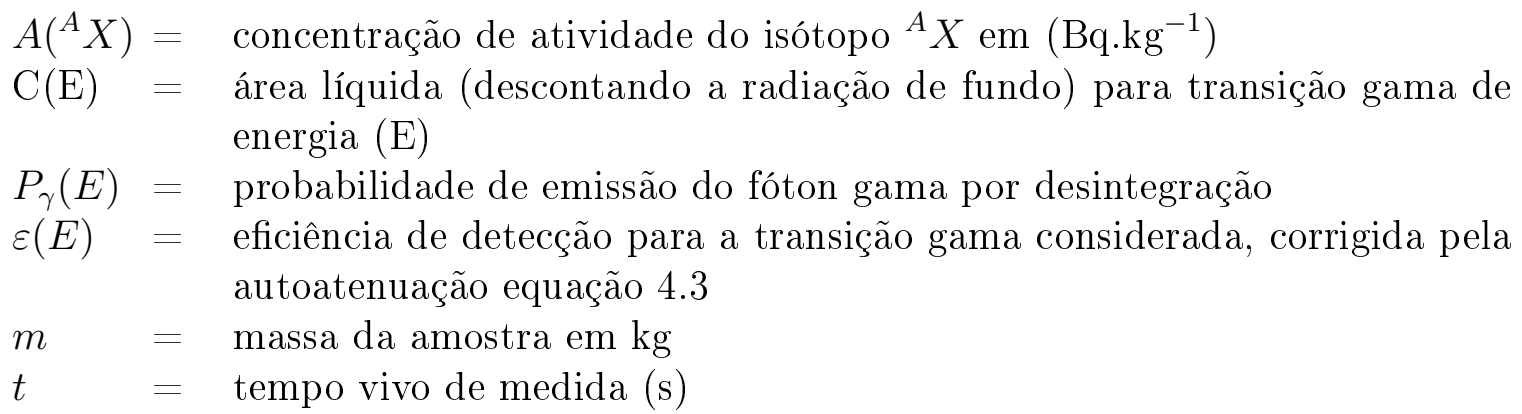

A atividades do ${ }^{40} \mathrm{~K},{ }^{232} \mathrm{Th}$ e do ${ }^{226} \mathrm{Ra}$ foram estimadas pela equação 4.4, utilizando as transições gama apresentadas na TAB. 4.6.

Considerando que as atividades estimadas para cada transição são valores que fazem parte de uma distribuição normal, então o valor mais provável para as atividades finais do ${ }^{232} \mathrm{Th}$ e do ${ }^{226} \mathrm{Ra}$ será dado pela média ponderada pelas respectivas incertezas equação 4.5 . 
Tabela 4.6: Transições gama utilizadas para determinação das concentrações de atividade dos radionuclídeos ${ }^{40} \mathrm{~K},{ }^{232} \mathrm{Th}$ e do ${ }^{226} \mathrm{Ra}$.

\begin{tabular}{ccc}
\hline \hline Radionuclídeos & Isótopos & Transições (keV) \\
\hline \hline${ }^{40} \mathrm{~K}$ & & 1460,8 \\
\hline${ }^{232} \mathrm{Th}$ & ${ }^{228} \mathrm{Ac}$ & 338,40 \\
& & 911,07 \\
& & 964,60 \\
& & 968,91 \\
\hline & ${ }^{212} \mathrm{~Pb}$ & 238,60 \\
& & 300,09 \\
\hline${ }^{226} \mathrm{Ra}$ & ${ }^{212} \mathrm{Bi}$ & 727,33 \\
& & 295,20 \\
& & 351,90 \\
\hline & ${ }^{214} \mathrm{Bi}$ & 609,30 \\
& & 1120,30 \\
& & 1764,50 \\
\hline \hline
\end{tabular}

$$
\bar{A}=\frac{\sum_{i} \frac{A_{i}}{\sigma_{i}^{2}}}{\sum_{i} \frac{1}{\sigma_{i}^{2}}}
$$

Onde $A_{i}$, são as atividades calculadas para cada transição gama e $\sigma_{i}$ suas respectivas incertezas. A incerteza propagada para a atividade final é dada pela equação 4.6 .

$$
\sigma_{\bar{A}}=\frac{1}{\sqrt{\sum_{i} \frac{1}{\sigma_{i}^{2}}}}
$$

Onde $\sigma_{\bar{A}}$ é a incerteza propagada no cálculo da atividade média ponderada e $\sigma_{i}$ são os valores individuais. 
Para verificar se estas médias são representativas dos valores individuais das transições gamas utilizadas, foi aplicado o teste do Qui-quadrado $\left(\chi^{2}\right)$. Este teste é definido por Green e Margerison (1978) como apresentado na equação 4.7.

$$
\chi^{2}=\sum_{i=1}^{n} \frac{\left(x_{i}-\bar{x}\right)^{2}}{\sigma_{i}^{2}}
$$

Onde:

$x_{i}=$ são as estimativas da concentração de atividade para cada transição gama i de um dado radionuclídeo

$\bar{x}=$ concentração de atividade média para cada radionuclídeo estimada pelos valores individuais $x_{i}$ e ponderada pelas respectivas incertezas

$\sigma_{i}=$ incerteza associada à estimativa $x_{i}$

$n=$ número de estimativas

Idealmente, espera-se que $\chi^{2}=0$ caso em que as atividades individuais são iguais à atividade média, porém em caso reais, quanto maior for $\chi^{2}$, menos representativa é a média dos valores individuais. Se o valor calculado de $\chi^{2}$ for maior que os valores críticos, de acordo com um dado nível de significância para $n-1$ graus de liberdade, pode-se concluir que a média calculada não é representativa dos valores individuais (Barros Neto, 2001). 


\section{3 Índices dosimétricos}

Os valores medidos para a concentração de atividade destes radionuclídeos servem então de parâmetros e são utilizados em modelos dosimétricos (Índices Dosimétricos), os quais estabelecem limites máximos permitidos de acordo com a forma e aplicação do material de construção. Neste trabalho foram calculados os três índices, que são amplamente utilizados na literatura, atividade equivalente em rádio $\mathrm{Ra}_{e q}$, e os índices de dose gama externa, $\mathrm{H}_{E X}$ e $\mathrm{I}_{\gamma}$.

\subsubsection{Atividade equivalente em rádio $\left(\mathrm{Ra}_{e q}\right)$}

Como a distribuição dos radionuclídeos nos diferentes tipos de rochas não é uniforme, para representar as atividades de ${ }^{226} \mathrm{Ra},{ }^{232} \mathrm{Th}$ e ${ }^{40} \mathrm{~K}$ em uma única grandeza que leve em conta o risco por radiação, (considerando que as atividades de $370 \mathrm{~Bq} \cdot \mathrm{kg}^{-1}$ de ${ }^{226} \mathrm{Ra}, 259 \mathrm{~Bq} \cdot \mathrm{kg}^{-1}$ de ${ }^{232} \mathrm{Th}$ e $4810 \mathrm{~Bq} \cdot \mathrm{kg}^{-1}$ de ${ }^{40} \mathrm{~K}$ em materiais de construção ocasionem doses similares de radiação gama, cerca de $1,5 \mathrm{mSv}_{\mathrm{a}} \mathrm{a}^{-1}$ ), foi definido o índice denominado "atividade equivalente em rádio" $\left(\mathrm{Ra}_{e q}\right)$ que permite avaliar a soma das atividades do ${ }^{226} \mathrm{Ra},{ }^{232} \mathrm{Th}$ e ${ }^{40} \mathrm{~K}$ em um único índice, a partir da expressão (Beretka e Mathew, 1985):

$$
R a_{e q}=A_{R a}+\left(\frac{370}{259}\right) A_{T h}+\left(\frac{370}{4810}\right) A_{K}=A_{R a}+1,43 A_{T h}+0,077 A_{K}
$$

onde $\mathrm{A}_{R a}, \mathrm{~A}_{T h}$ e $\mathrm{A}_{K}$ são as concentrações de atividade respectivamente do ${ }^{226} \mathrm{Ra},{ }^{232} \mathrm{Th}$ $\mathrm{e}^{40} \mathrm{~K}$, em Bq. $\mathrm{kg}^{-1}$. O valor máximo recomendado de $\mathrm{Ra}_{e q}$ para um novo material de construção é $370 \mathrm{~Bq} \cdot \mathrm{kg}^{-1}$, limitando, assim, o incremento da dose decorrente destes materiais em uma construção a 1,5 mSv.a ${ }^{-1}$ (Stranden, 1976).

\subsection{2 Índice $\left(\mathrm{H}_{E X}\right)$}

Para limitar a dose efetiva anual devida à radiação gama externa de todos os materiais de uma construção a $1,5 \mathrm{mSv} \cdot \mathrm{a}^{-1}$, foi definido o índice $\mathrm{H}_{E X}$, que é calculado pela equação (Beretka e Mathew, 1985),

$$
H_{E X}=\left(\frac{A_{R a}}{370}\right)+\left(\frac{A_{T h}}{259}\right)+\left(\frac{A_{K}}{4810}\right)
$$

onde $\mathrm{A}_{R a}, \mathrm{~A}_{T h}$ e $\mathrm{A}_{K}$ são as concentrações de atividade respectivamente do ${ }^{226} \mathrm{Ra},{ }^{232} \mathrm{Th}$ $\mathrm{e}^{40} \mathrm{~K}$, em Bq. $\mathrm{kg}^{-1}$. Para satisfazer o limite de dose de 1,5 $\mathrm{mSv}^{\mathrm{a}} \mathrm{a}^{-1}$, este índice deve ser $\leq 1$. 


\subsection{3 Índice gama $\left(\mathrm{I}_{\gamma}\right)$}

Para limitar o incremento da dose INDOOR decorrente dos materiais de construção a 1 mSv.a ${ }^{-1}$, a Comissão Européia de Proteção Radiológica por meio do documento EC (1999), baseada no modelo matemático descrito por Markkanen (1995), estabeleceu o Índice Gama $\left(\mathrm{I}_{\gamma}\right)$. Este índice considera também a forma de utilização do dado material de construção. A TAB. 4.8 apresenta os parâmetros usados na derivação deste índice dosimétrico.

Tabela 4.8: Fatores de conversão de concentração de atividade em taxa de dose (EC, 1999).

\begin{tabular}{|c|c|c|c|}
\hline Dimensões do modelo & \multicolumn{3}{|c|}{$(4 \mathrm{~m} \times 5 \mathrm{~m} \times 2,8 \mathrm{~m})$} \\
\hline Espessura e densidade das estruturas & \multicolumn{3}{|c|}{$20 \mathrm{~cm}, 2,35$ g.cm ${ }^{-3}$ (concreto) } \\
\hline Tempo de exposição anual & \multicolumn{3}{|c|}{7000 h ( 291 d) ( 19 h diárias $)$} \\
\hline Conversão de dose & \multicolumn{3}{|c|}{$0,7 \mathrm{~Sv} \cdot \mathrm{Gy}^{-1}$} \\
\hline \multirow[t]{2}{*}{ Radiação de fundo } & \multicolumn{3}{|c|}{$50 \mathrm{nGy} \cdot \mathrm{h}^{-1}$ (média da crosta terrestre) } \\
\hline & \multicolumn{3}{|c|}{ Taxa de dose específica, nGy.h ${ }^{-1}$ por Bq.kg ${ }^{-1}$} \\
\hline Estrutura na construção causando irradiação & ${ }^{226} \mathrm{Ra}$ & ${ }^{232} \mathrm{Th}$ & ${ }^{40} \mathrm{~K}$ \\
\hline Chão, teto e paredes (todas as estruturas) & 0,92 & 1,1 & 0,080 \\
\hline Chão e paredes (teto de madeira) & 0,67 & 0,78 & 0,057 \\
\hline Chão (casa de madeira com chão de concreto) & 0,24 & 0,28 & 0,020 \\
\hline Material superficial (espessura $2 \mathrm{~cm}$, densidade 2, 6 g.cm ${ }^{-1}$ ) & 0,12 & 0,14 & 0,0096 \\
\hline
\end{tabular}

Utilizando os parâmetros da TAB. 4.8, é possível calcular os valores de atividade de cada radionuclídeo que geram a dose de $1 \mathrm{mSv} \cdot \mathrm{a}^{-1}$. O índice gama $\left(\mathrm{I}_{\gamma}\right)$ é definido a partir desses valores, pela equação 4.10, (EC, 1999).

$$
I_{\gamma}=\left(\frac{A_{R a}}{300}\right)+\left(\frac{A_{T h}}{200}\right)+\left(\frac{A_{K}}{3000}\right)
$$

Onde $\mathrm{A}_{R a}, \mathrm{~A}_{T h}$ e $\mathrm{A}_{K}$ são as concentrações de atividade, respectivamente do ${ }^{226} \mathrm{Ra},{ }^{232} \mathrm{Th}$ e ${ }^{40} \mathrm{~K}$, em Bq.kg ${ }^{-1}$, no material de construção. Para este índice são definidos dois limites de dose, o de isenção (os materiais devem ser isentos de todas as restrições relativas à sua radioatividade) e o de controle (a atividade nos materiais deve ser avaliada do ponto de vista de proteção radiológica $(\mathrm{EC}, 1999)$ ). O índice não pode exceder os valores apresentados na TAB. 4.9, dependendo do critério de dose, da maneira e quantidade que é utilizado em uma construção: 
Tabela 4.9: Critérios de dose para materiais de construção (EC, 1999).

\begin{tabular}{ccc}
\hline \hline Critério de dose & $\begin{array}{c}\text { Isenção } \\
\left(0,3 \mathrm{mSv} \cdot \mathrm{a}^{-1}\right)\end{array}$ & $\begin{array}{c}\text { Controle } \\
\left(1 \mathrm{mSv} \cdot \mathrm{a}^{-1}\right)\end{array}$ \\
\hline \hline Materiais estruturais & \\
p. ex. concreto & $\mathrm{I} \leq 0,5$ & $\mathrm{I} \leq 1$ \\
Materiais superficiais & & \\
com uso restrito & $I \leq 2$ & $I \leq 6$ \\
\hline \hline
\end{tabular}

Segundo a Comissão Européia de Proteção Radiológica (EC, 1999), este índice dosimétrico deve ser aplicado apenas como uma ferramenta para identificar materiais que merecem atenção. Qualquer decisão sobre a limitação do uso do material deve ser baseada em uma estimativa de dose muito mais detalhada e realística da aplicação.

\subsection{Taxa de dose e Dose efetiva anual}

\subsubsection{Cálculo da taxa de dose}

Quando um órgão regulador precisa decidir a respeito da aceitabilidade de um determinado material com uma específica aplicação (em termos de dose de radiação), em geral as concentrações de atividade são os parâmetros mais passíveis de serem medidos. Assim, a avaliação da dose é feita para diferentes cenários teóricos de exposição considerando as concentraçãos de atividades dos radionuclídeos de interesse (Markkanen, 1995).

A taxa de dose absorvida, indoor, devido a materiais de construção, é calculada utilizando modelos dosimétricos. Neste trabalho foi adotado o modelo sugerido pela Comissão Européia de Proteção Radiológica no documento (EC, 1999) FIG. 4.5. 


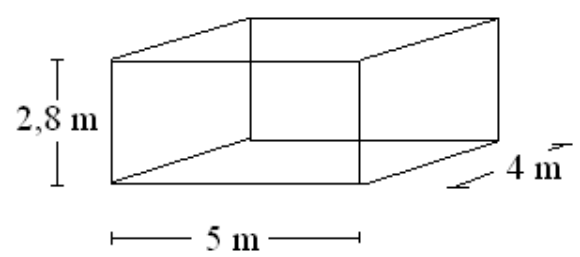

Figura 4.5: Modelo de sala padrão para estimativa da taxa de dose gama externa no ar.

Sendo a taxa de dose absorvida no ar (dentro dessa sala), decorrente de materiais superficiais (espessura $3 \mathrm{~cm}$ e densidade $2,6 \mathrm{~g} . \mathrm{cm}^{-3}$, desconsiderando portas e janelas), dada por:

$$
\dot{D}=0,12 A_{R a}+0,14 A_{T h}+0,0096 A_{K}
$$

Nesta equação $\dot{D}$ é a taxa de dose absorvida no ar em nGy.h ${ }^{-1}$ e $\mathrm{A}_{R a}, \mathrm{~A}_{T h}$ e $\mathrm{A}_{K}$ são as concentrações de atividade respectivamente do ${ }^{226} \mathrm{Ra},{ }^{232} \mathrm{Th}$ e ${ }^{40} \mathrm{~K}$, em Bq. $\mathrm{kg}^{-1}$. Os coeficientes de conversão de atividade em dose foram calculados pelo modelo matemático descrito por (Markkanen, 1995). Este modelo permite a verificação de diversos parâmetros (dimensões da sala modelo, espessura das paredes, e densidade do material), fornecendo desta forma alguns cenários. Dentre estes, o que melhor se aplica ao presente trabalho (rochas utilizadas para revestimento) é o que diz respeito a materiais superficiais, apresentados na última linha da TAB. 4.8, equação 4.11.

Por tratar-se de um programa computacional de implementação não tão trivial, optou-se, pela utilização de um modelo similar e de implementação mais imediata, (Código computacional EDVOS (External gamma Doses Due to Volumetric Sources) desenvolvido por (Máduar, 2000)), com o objetivo de calcular os coeficientes de conversão de atividade em taxa de dose, equação 4.11, para parâmetros de densidade e espessura mais próximos dos reais.

O modelo adotado (Máduar, 2000), descrito aqui de uma forma simplificada, considera uma sala padrão como um conjunto de 2 pares de paredes mais chão e teto, onde calcula-se a dose devido a cada transição gama, proveniente de uma distribuição uniforme de radionuclídeos em um elemento de volume de uma parede. Soma-se então a contribuição dada por todas as transições gama consideradas de todos os radionuclídeos considerados no elemento de volume, integra-se, então, todo o volume da parede, finalmente, é feita a soma de todas as paredes que contribuem para a dose no ponto considerado. O modelo considera também a autoatenuação e contribuição à dose pelo espalhamento dos fótons na parede e no ar (build-up).

A taxa de dose em um determinado ponto dentro desta sala, resultante de 
fótons primários e espalhados provenientes de uma fonte distribuída em um volume $\mathrm{V}$, é calculada usando a expressão.

$$
\dot{D}=\frac{K S}{4 \pi} \sum_{i=1}^{n} I_{i}\left(\frac{\mu_{e n}}{\rho_{a, E_{I}}}\right) E_{i} \int_{V} d V \frac{1}{r^{2}} B\left(E_{i}, \mu_{m, E_{i}} r_{m}\right) e^{\left(-\mu_{m, E_{i}} r_{m}-\mu_{a, E_{i}} r_{a}\right)}
$$

Onde:

$$
\begin{aligned}
\dot{D}= & \text { taxa de dose absorvida no ar }\left(\mathrm{Gy}_{\mathrm{s}}{ }^{-1}\right) \\
K & \text { constante de conversão de unidades de }\left(\mathrm{Bq} \cdot \mathrm{g}^{-1}\right) \mathrm{keV} \text { para }{\mathrm{Gy} \cdot \mathrm{s}^{-1}} \\
& \text { igual a } 1,602 \times 10^{-13} \\
= & \text { concentração de um dado radionuclídeo no volume } \mathrm{V}\left(\mathrm{Bq} \cdot \mathrm{cm}^{-3}\right) \\
S & \text { número de transições gama consideradas } \\
n & \text { probabilidade de emissão para i-ésima transição gama } \\
I_{i} & \text { coeficiente mássico de absorção de energia para o ar para a energia } \\
\left(\frac{\mu_{e n}}{\rho}\right)_{a, E_{i}}= & \mathrm{E}_{i}\left(\mathrm{~cm}^{2} \cdot \mathrm{g}^{-1}\right) \\
= & \text { energia da i-ésima transição } \\
E_{i} & \text { distância do ponto de interesse a cada ponto do volume } \mathrm{V} \text { da fonte } \\
r & (\text { cm) } \\
= & \text { distância percorrida no material absorvedor }(\mathrm{cm}) \\
r_{m} & \text { distância percorrida no ar }(\mathrm{cm}) \\
r_{a} & \text { fator de espalhamento } \\
B & = \\
\rho_{m, E_{i}} & \text { coeficiente de absorção linear no absorvedor, para energia } \mathrm{E}_{i}\left(\mathrm{~cm}^{-1}\right) \\
\rho_{a, E_{i}} & \text { coeficiente de absorção linear no ar, para energia } \mathrm{E}_{i}\left(\mathrm{~cm}^{-1}\right)
\end{aligned}
$$

Os fatores de espalhamento são usualmente dados, tabelados ou calculados por funções empíricas (Máduar e Hiromoto, 2004). Dada a concentração de um determinado radionuclídeo, em um volume definido, pode-se então calcular a taxa de dose no ar em um ponto qualquer de interesse conforme descrito pela equação 4.12. Como a dose é função linear da concentração de atividade do radionuclídeo, pode-se então definir os fatores de conversão de concentração de atividade para dose. Esta relação é expressa pela equação.

$$
\dot{D}=\sum_{i} q_{i} C_{i}
$$

Onde: 
$q_{i}=$ fator de conversão de dose para o radionuclídeo precursor da série de decaimento i (Gy.s ${ }^{-1}$ por Bq.kg ${ }^{-1}$ )

$C_{i}=$ é a concentração de atividade do radionuclídeo precursor da série de decaimento i $\left(\mathrm{Bq} \cdot \mathrm{kg}^{-1}\right)$

Desta forma o fator de conversão $q_{i}$ para cada radionuclídeo ou série radioativa será dado pela equação.

$$
q_{i}=\frac{\dot{D}_{i} \rho}{S_{i}}
$$

Onde:

$\dot{D}=$ componente da taxa de dose no ar devido ao i-ésimo radionuclídeo precursor $\left(\mathrm{Gy}_{\mathrm{s}} \mathrm{s}^{-1}\right)$

$S_{i}=$ razão atividade por volume do radionuclídeo precursor i $\left(\mathrm{Bq} . \mathrm{cm}^{-3}\right)$

$\rho=$ densidade do material $\left(\mathrm{kg} \cdot \mathrm{cm}^{-3}\right)$

Esta expressão pressupõe densidade da parede e concentração de atividade homogêneas, onde i representa uma série de decaimento, a taxa de dose é resultante de todos os radionuclídeos em equilíbrio radioativo com na série (Máduar e Hiromoto, 2004).

Este cálculo envolve funções não passíveis de integração analítica e requer, portanto, a programação computacional, a qual pode incluir ou simplificar determinados parâmetros assim como considerações geométricas e também utilizar métodos diferentes de estimativas de espalhamento e autoatenuação (Stranden, 1976; Markkanen, 1995; Máduar e Hiromoto, 2004).

Foi utilizado o código computacional EDVOS, também para determinar os coeficientes de conversão de dose (para o mesmo modelo de sala), utilizando os parâmetros densidade e espessuras específicos de cada amostra estudada. 


\subsubsection{Cálculo da dose efetiva anual}

A Dose efetiva anual $\left(\mathrm{D}_{\text {ef(gama }}\right)$, considerando um tempo de ocupação de $7000 \mathrm{~h}$ na sala padrão, foi calculado pela equação 4.15 .

$$
D_{e f(g a m a)}=\dot{D}\left(n G y \cdot h^{-1}\right) \times 0,7\left(S v \cdot G y^{-1}\right) \times 7000(h)
$$

Onde $\dot{D}$ é a taxa de dose, 0, 7 é o fator de conversão de taxa de dose para dose efetiva anual e 7000 h é o tempo de exposição considerado no modelo (EC, 1999).

\subsection{Radônio}

\subsubsection{Técnica de detecção}

O radônio no ar pode ser detectado por meio de duas técnicas: detecção ativa e detecção passiva; cada uma destas técnicas sendo utilizada de duas formas: detecção apenas do radônio e detecção do radônio e dos filhos do radônio (Paulo, 1991; Alberigi, 2006). A técnica utilizada neste trabalho para medida de radônio e filhos será a técnica passiva com detectores sólidos de traços nucleares (SSNTD) .

O funcionamento dos detectores SSNTD está baseado na propriedade das partículas carregadas pesadas de interagir com o plástico, deixando um traço latente (da ordem de 50 a $100 \AA$ ). Em sólidos, os traços de partículas carregadas são estreitos $(<50 \AA)$ e estáveis, trata-se de centros de tensão quimicamente reativos, compostos principalmente por átomos deslocados em vez de defeitos eletrônicos. O dano total ao longo do traço é devido ao dano primário resultado da ionização e excitação causado diretamente pelo íon pesado e aos danos secundários causados pelos raios delta em sua passagem próxima do caminho do íon.

Estas causas têm importâncias relativas para sólidos inorgânicos (cristais e vidros) e para sólidos orgânicos (polímeros). Embora não seja definitivamente conhecida qual a importância relativa da ionização primária para polímeros, como em sólidos inorgânicos, a ionização primária é a maior fonte de danos de traços, é provável que ambas, a ionização primária e secundária (e excitação) contribuam em polímeros (Fleischer et al., 1975).

O traço pode ser visualizado sob um microscópio óptico, após ataque químico específico. A geometria do ataque do traço para um caso simples é descrita basicamente por dois processos de ataque: a dissolução química ao longo do traço a uma taxa linear $\mathrm{V}_{T}$; e o ataque geral a toda superfície do detector e a superfície interior do traço atacado a uma taxa menor $\mathrm{V}_{G}$. Este processo cria um cone que tem o traço original como eixo (Fleischer et al., 1975). 
Este modelo supõe que $V_{T}$ é constante ao longo do traço e que $V_{G}$ é constante e isotrópico.

Vários plásticos foram desenvolvidos para detecção de partículas alfa. Cada um desses plásticos tem uma sensibilidade diferente, assim necessitam de um ataque químico adequado. Para medir apenas radônio, deve-se usar uma câmara de difusão, a qual permite apenas a passagem deste, dessa forma o detector registra apenas emissões alfa que foram produzidas pelo radônio e pelos seus filhos gerados no interior da câmara de difusão (Paulo, 1991). Desta maneira, por meio de um fator de calibração, pode-se estabelecer uma relação entre a densidade de traços no detector e a concentração de radônio na câmara.

Por tratar-se do detector com melhor eficiência disponível e apresentar qualidades ópticas ótimas (Paulo, 1991; Silva, 2005; Alberigi, 2011), o CR-39 (Columbia Resin 39), foi o detector SSNTD utilizado. Para medir somente o isótopo ${ }^{222} \mathrm{Rn}$ presente no ar, utilizou-se a câmara de difusão modelo NRPB/SSI, que permite apenas a entrada deste isótopo, barrando os outros e os filhos deste presentes no ar. Esta câmara de difusão consiste de duas partes que se encaixam deixando pequenos "gaps" onde ocorre a difusão do radônio, em poucos minutos (aproximadamente 25 minutos) a concentração no interior desta é igual à concentração externa (Silva, 2005).

Neste trabalho, a determinação do radônio e seus descendentes foi realizada pela técnica de deteç̧ão passiva utilizando detectores SSNTD tipo CR-39, por meio da técnica "Sealed can technique", (Khan et al., 1992; Faheem et al., 2008; Mahur et al., 2008), que consiste basicamente de detectores SSNTD fixados internamente no topo de uma câmara (geralmente cilíndrica) selada.

Esta técnica foi adotada devido à inviabilidade de se reproduzir os cenários de exposição iguais a sala padrão (FIG. 4.5), revestida internamente com cada amostra estudada, para o qual se busca avaliar a dose. Assim, a alternativa foi utilizar esta técnica, que apesar de não representar condições reais, fornece a taxa de exalação de radônio que é utilizada como parâmetro em modelos dosimétricos para estimar a dose em diferentes cenários, com a vantagem de se entrar com uma grandeza (taxa de exalação de radônio) medida em cada amostra.

Para tal medida foi utilizado um recipiente cilíndrico com dimensões de $26,5 \mathrm{~cm} \times 23,5 \mathrm{~cm}$, (altura e diâmetro respectivamente) onde o detector SSNTD adotado, CR-39, é colocado dentro de uma câmara de difusão modelo NRPB/SSI o qual é fixado no topo do recipiente (Orlando et al., 2002); a amostra "ao natural" (um recorte de placa de granito com dimensões $(15 \mathrm{~cm}$ x $15 \mathrm{~cm}$ x $2 \mathrm{~cm})$ comprimento, largura e espessura respectivamente), foi colocada na base do recipiente (FIG. 4.6). Este foi então selado por aproximadamente 30 dias, tempo adotado para integração dos traços buscando uma otimização entre estatística de contagens e tempo de medida. 


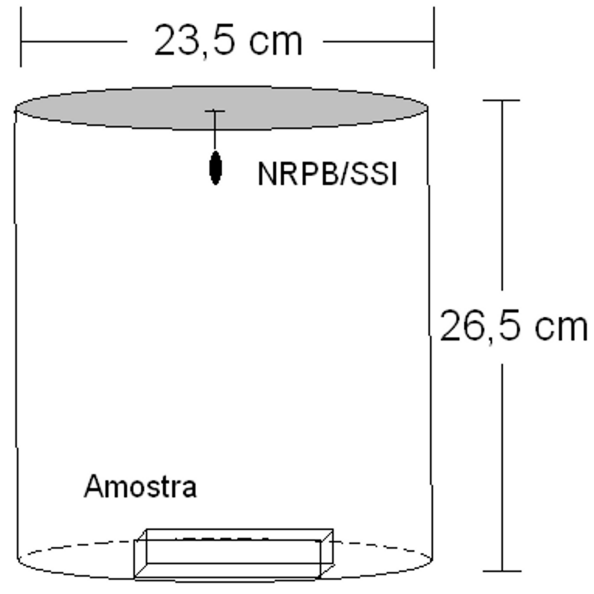

(a)

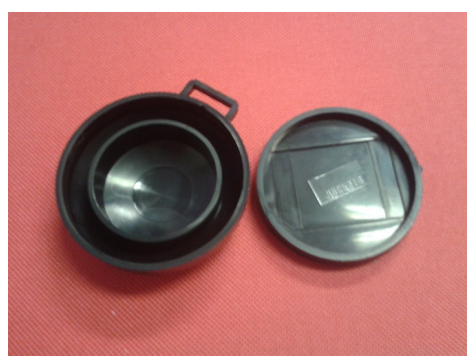

(b)

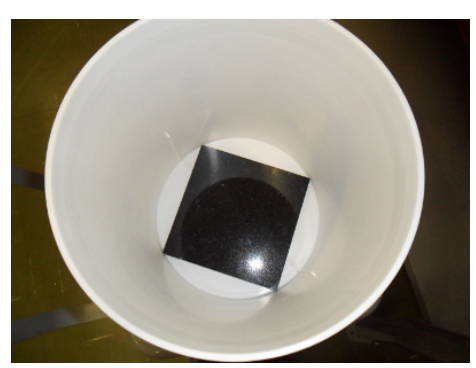

(c)

Figura 4.6: (a) Diagrama ilustrativo da Técnica do recipiente selado (b) Câmara de difusão NRPB e detector CR-39 (c) Amostra no fundo do recipiente de medida.

Após o tempo de contagem, a câmara selada, FIG. 4.6 a, foi aberta e as câmaras de difusão FIG. 4.6 b, foram retiradas e os detectores CR-39 foram, então, no Laboratório de Detectores de Traços Nucleares (LRA/GMR), submetidos a ataque químico padrão, com uma solução $\mathrm{KOH} 30 \%$ a $80{ }^{\circ} \mathrm{C}$ por 5,5 horas em banho-maria com agitação (Orlando et al., 2002) FIG. 4.7 a, para posterior leitura em microscópio óptico FIG. 4.7 b. A densidade de traços (traços.cm ${ }^{-2}$ ) no detector, FIG. 4.7 c, para o cálculo da concentração do radônio, foi determinada a partir da contagem manual dos traços, utilizando o software KS100 versão 3.0 da ZEISS (ZEISS, 1997). 


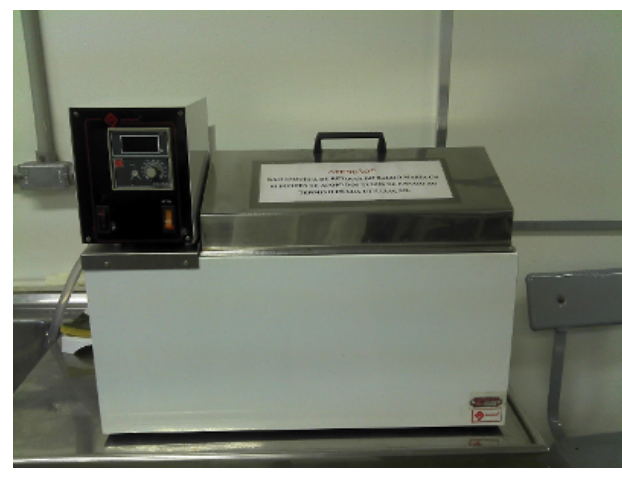

(a)

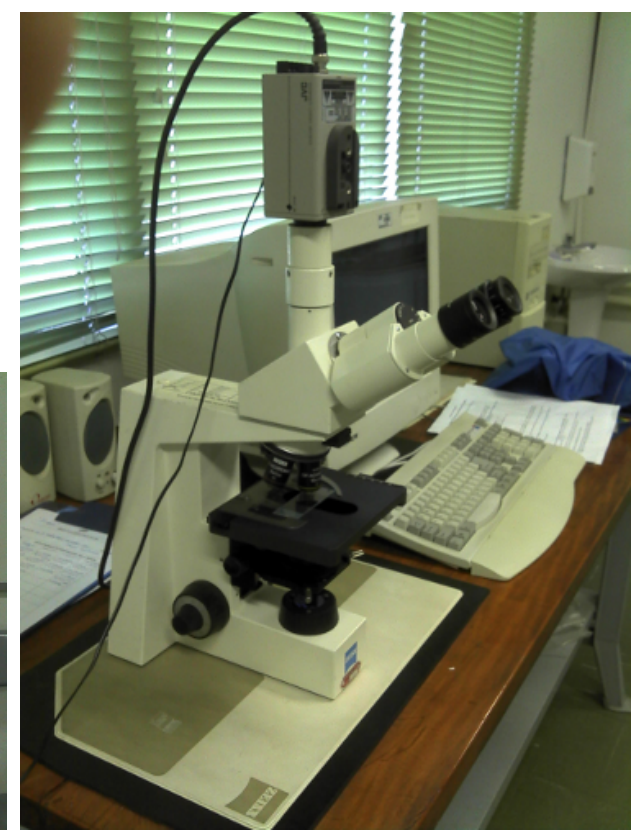

(b)

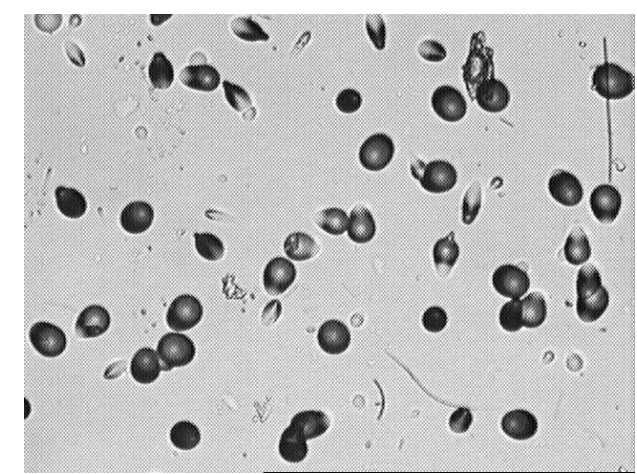

(c)

Figura 4.7: (a) Banho-maria utilizado para revelação, (b) Microscópio ótico Zeiss Axiolab 100, utilizado para contagem dos traços e microcomputador, (c) Detalhe dos traços em um detector CR-39 após revelação, foto de (Alberigi, 2011).

A concentração de radônio no recipiente foi determinada pela equação 4.16 .

$$
C_{R n}=\frac{D}{K t}
$$

Onde:

$C_{R n}=$ concentração de radônio em Bq.m ${ }^{-3}$

$D=$ densidade de traços em (traços por $\mathrm{cm}^{2}$ ) 
$t=$ tempo de exposição em horas

$K=$ eficiência do detector em $\left(\right.$ traços.cm $\left.{ }^{-2}\right) \cdot\left(\mathrm{Bq}^{-1} \cdot \mathrm{m}^{3} \cdot \mathrm{h}^{-1}\right)$

A eficiência do detector foi determinada experimentalmente utilizando-se uma câmara de calibração, FIG. 4.8 a, (com mesmo volume das câmaras utilizadas para as medidas) e uma fonte de fluxo contínuo Pylon modelo RN-1025, FIG. 4.8 b, com atividade nominal de $107,318 \mathrm{kBq}$ de ${ }^{226} \mathrm{Ra}$ (PYLON, 2001).

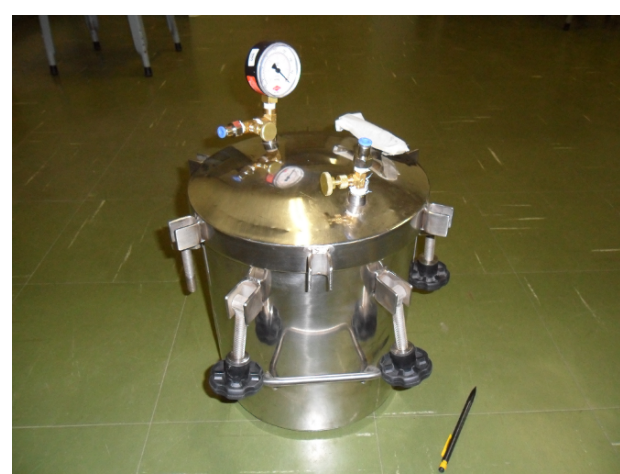

(a)

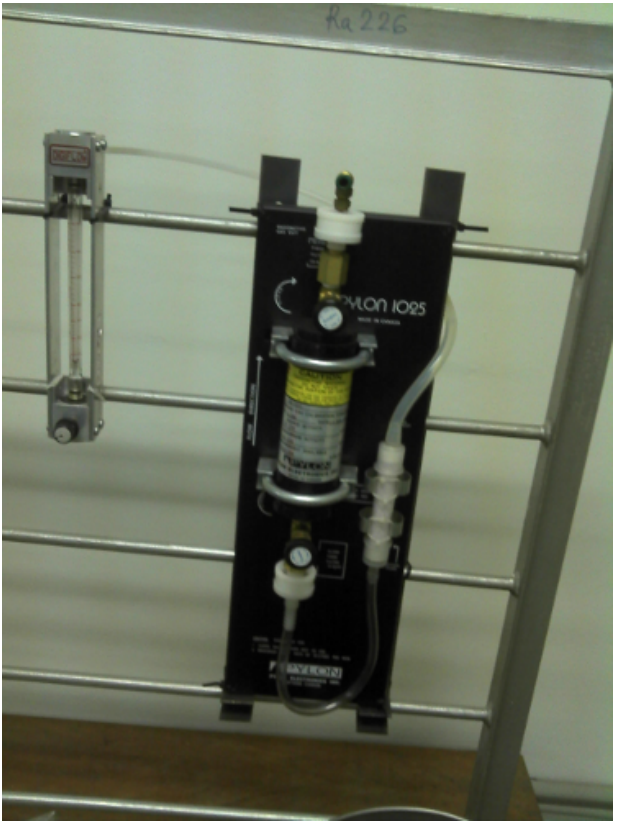

(b)

Figura 4.8: (a) Câmara utilizada para calibração dos detectores CR-39 (b) Fonte de fluxo contínuo Pylon, Rn-1025.

Para este procedimento a fonte Pylon RN-1025 foi operada no modo intermitente, descrito aqui brevemente (PYLON, 2001):

1. "Abre-se", por meio de uma válvula agulha, a cavidade da fonte para liberar todo o radônio concentrado (com auxílio de uma bomba de vácuo);

2. Com a cavidade da fonte "esvaziada de radônio", fecha-se a válvula agulha por tempo determinado de acordo com a concentração de radônio desejada;

3. Após esse tempo abre-se novamente a válvula e com auxílio da bomba de vácuo transfere-se o radônio da sua cavidade para a câmara de calibração;

4. Sela-se a câmara por tempo determinado 
Após a integração, os detectores são revelados e contados e o fator de calibração é determinado pela equação 4.16, a partir da razão entre a densidade de traços $\mathrm{D}$ no detector e a concentração de radônio (conhecida transferida à câmara) $\mathrm{C}_{R n}$ que a causou, considerando o tempo de integração t. Este procedimento foi repedido para diferentes concentrações variando-se também o tempo de integração (buscando boa estatística de densidade de traços sem saturação do detector).

\subsubsection{Taxa de exalação}

A taxa de exalação ${ }^{1}$ de radônio medida por meio da técnica do recipiente selado (Tufail et al., 2000; Mahur et al., 2008) é dada pela equaçao 4.17,

$$
E_{S}=\frac{C(t) \lambda V}{A} \frac{1}{\left[t-\frac{1}{\lambda}\left(1-e^{\lambda t}\right)\right]}
$$

Onde:

$E_{S}=$ taxa de exalação superficial de radônio $\left(\right.$ Bq. $\left.\mathrm{m}^{-2} \cdot \mathrm{h}^{-1}\right)$

$C(t)=$ concentração de radônio integrada medida pelo do SSNTD $\left(\mathrm{Bq} \cdot \mathrm{m}^{-3} \cdot \mathrm{h}^{-1}\right)$

$V=$ volume efetivo de recipiente $\left(\mathrm{m}^{3}\right)$

$A=$ área de exalação da amostra $\left(\mathrm{m}^{2}\right)$

$t=$ tempo de exposição $(\mathrm{h})$

$\lambda=$ constante de decaimento do radônio $\left(\mathrm{h}^{-1}\right)$

Alguns autores também calculam a taxa de exalação por massa (Sonkawade et al., 2008; Marocchi et al., 2011) cuja expressão utilizada aqui, equação 4.18, é a utilizada por Sonkawade, por tratar-se de uma expressão derivada para medidas com detectores SSNTD,

$$
E_{M}=\frac{C(t) \lambda V}{M} \frac{1}{\left[t-\frac{1}{\lambda}\left(1-e^{\lambda t}\right)\right]}
$$

onde $\mathrm{E}_{M}$ é a taxa de exalação por massa em $\left(\mathrm{Bq} \cdot \mathrm{kg}^{-1} \cdot \mathrm{h}^{-1}\right)$ e $\mathrm{M}$ é a massa da amostra.

\footnotetext{
${ }^{1}$ Por exalação de radônio entenda-se a fração de átomos de radônio que exalam através superficie do material considerado, por outro lado a fração de emanação e radônio, que será discutida mais adiante, diz respeito a fração de átomos de radônio ("gerados" no interior de grãos minerais) que saem para os poros, ficando, assim, livres para a difusão neste espaço. Estas definições são discutidas com mais detalhes e com ilustrações por Costa (Costa, 2011).
} 


\subsubsection{Estimativa do incremento da concentração de ${ }^{222} \mathrm{Rn}$ devido ao ${ }^{226} \mathrm{Ra}$ nos materiais de construção e estimativa da fração de emanação}

Todos os materiais utilizados em uma construção que contém ${ }^{226}$ Ra liberam ${ }^{222} \mathrm{Rn}$ no ar, a quantidade liberada depende da concentração de ${ }^{226} \mathrm{Ra}$ no material, da quantidade deste material que é utilizada na construção e da fração de emanação de radônio para este material (grandeza esta que depende de características físicas como densidade, porosidade e composição química do material). Materiais de construção podem então causar um incremento ${ }^{2}$ (considerando que haja outras fontes) na concentração de ${ }^{222} \mathrm{Rn}$ no interior da residência (Markkanen, 1995), este incremento é dado pela equação 4.19,

$$
C_{R n}=\frac{G}{n V}: \text { sendo } G=A E_{S}=\lambda \eta C_{R a} M
$$

Onde:

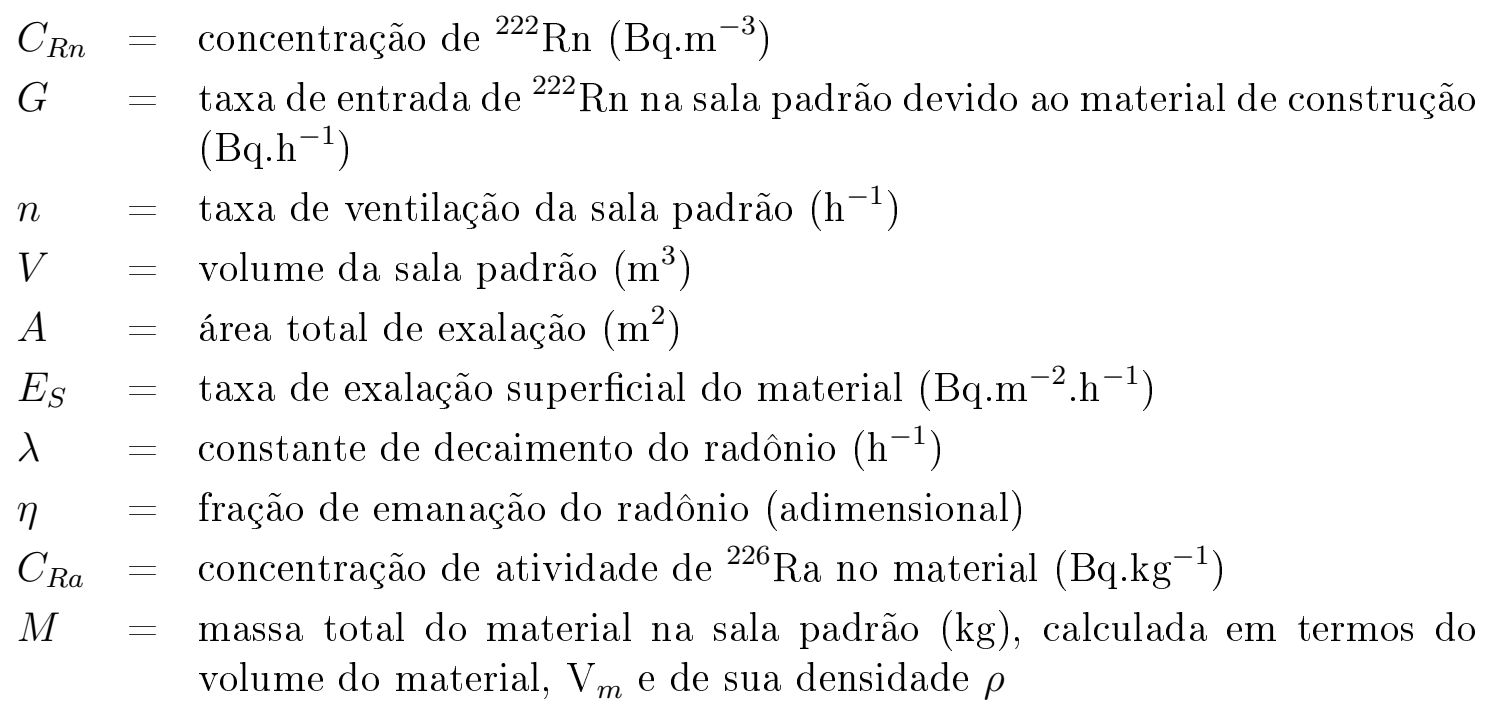

Assim, a taxa de entrada de radônio G na sala padrão, dada pela equação 4.19 pode ser calculada de duas formas: por meio da área de exalação do ${ }^{222} \mathrm{Rn}(A . E s)$; ou por meio da concentração de atividade do ${ }^{226} \mathrm{Ra}$, da massa total do material e da fração de emanação do ${ }^{222} \mathrm{Rn}\left(\lambda . \eta \cdot C_{R a} \cdot M\right)$. Este segundo método pode conduzir a valores superestimados ou subestimados, se os parâmetros utilizados não forem os parâmetros específicos de cada amostra (Markkanen, 1995).

\footnotetext{
${ }^{2}$ Neste trabalho a palavra incremento refere-se apenas ao adicional, de dose ou de concentração de radônio, na sala padrão decorrente da aplicação dos materiais estudados.
} 
Para comparar os resultados medidos com valores teóricos foi utilizada uma expressão matemática simplificada para estimar a taxa de exalação de radônio (exalação teórica, rigorosamente trata-se de um modelo empírico) em materiais de construção dada pela equação 4.20, por (UNSCEAR, 2000).

$$
E_{t e}=C_{R a} \lambda \eta \rho l \tanh \left(\frac{L}{l}\right)
$$

Onde:

$E_{T e}=$ taxa de exalação "teórica" do material $\left(\right.$ Bq.m $\left.{ }^{-2} \cdot h^{-1}\right)$

$C_{R a}=$ concentração de atividade de ${ }^{226} \operatorname{Ra}$ no material $\left(\mathrm{Bq} \cdot \mathrm{kg}^{-1}\right)$

$\lambda=$ constante de decaimento do radônio $\left(\mathrm{h}^{-1}\right)$

$\eta=$ fração de emanação do radônio (adimensional)

$\rho=$ densidade do material de construção $\left(\mathrm{kg} \cdot \mathrm{m}^{-3}\right)$

$l=$ comprimento de difusão efetiva no material $(\mathrm{m})$

$L=$ meia espessura do material usado $(\mathrm{m})$

Sendo $l$ dado por:

$$
l=\sqrt{\frac{D_{e}}{\lambda}}
$$

Onde $D_{e}$ é o coeficiente de difusão efetiva do radônio no material $\left(\mathrm{m}^{2} \cdot \mathrm{h}^{-1}\right)$. Dada a inexistência destes valores para as amostras estudadas, para este cálculo foi adotado o valor $3,6 \times 10^{-4}\left(\mathrm{~cm}^{2} . \mathrm{s}^{-1}\right)$ para concreto (fazendo a conversão de unidades), dado por (Stranden e Berteig, 1980).

A fração de emanação $f$ foi determinada pela razão entre taxa de exalação de radônio (E) e a concentração de atividade do ${ }^{226} \mathrm{Ra}\left(\mathrm{C}_{R a}\right)$ descrita por (Marocchi et al., 2011), e dada pela equação:

$$
f=\frac{E}{C_{R n} \lambda_{R n}}
$$

Onde $\lambda_{R n}$ é a constante de decaimento do radônio $\mathrm{em}^{-1}$. 


\subsection{Cálculo da dose efetiva anual devida ao radônio}

A dose efetiva anual decorrente do incremento da concentração de radônio em uma residência, causado pelos materiais de construção, $\mathrm{D}_{e f(R n)}$, é calculada multiplicando-se a $\mathrm{C}_{R n}$ pelo fator de conversão de concentração para dose efetiva, equação 4.23.

$$
D_{e f(R n)}=C_{R n} \times 20 \frac{\mu S v}{B q m^{-3}}
$$

Onde este fator de conversão foi derivado considerando um tempo de exposição anual de $7000 \mathrm{~h}$ (7000 h anuais dentro da sala padrão, e fator de equilíbrio de 0,5$)$ (Markkanen, 1995).

O fator de equilíbrio é uma grandeza adimensional que diz respeito ao equilíbrio radioativo entre o radônio e seus filhos no ambiente (considerado). Em um ambiente selado este valor é 1, indicando equilíbrio total, em condições reais isto não ocorre pois o radônio tem comportamento diferente dos seus filhos, (devido, por ex., ao efeito de plate-out, à presença de aerosóis e coeficiente de difusão (Paulo, 1991)).

\subsection{Análise dos principais óxidos componentes por fluorescência de raios $\mathrm{X}$}

Com o objetivo de avaliar a correlação entre os principais elementos químicos presentes nas amostras com a concentração de atividade de ${ }^{226} \mathrm{Ra}$ e concentração de radônio nas mesmas foi realizada pelo Laboratório de Fluorescência de raios X (CQMA/IPEN), uma análise semiquantitativa, pelo método de parâmetros fundamentais, de Fluorescência de raios $\mathrm{X}$ por dispersão de comprimento de onda, WDXRF. Para esta análise foi utilizado o espectrômetro modelo RIX 3000, Rigaku, 1996, tubo de Rh com todos os acessórios necessários para a análise (Scapin, 2003).

Pelo método de parâmetros fundamentais é possível realizar análises químicas semi-quantitativas sem uma curva de calibração, para tal as intensidades de raios X, de um elemento químico de uma amostra, de composição conhecida, são correlacionadas com a sensibilidade instrumental e número atômico do elemento. Essas informações são armazenadas em uma biblioteca para todos os elementos medidos. Assim, os elementos não medidos são determinados por interpolação. Este método juntamente com a biblioteca de sensibilidade fornece então resultados precisos e exatos e permitem análises químicas de materiais desconhecidos, para mais detalhes sobres este método e preparação das amostras para as medidas consultar (Scapin, 2003). 
Os resultados desta análise foram tabulados a partir do relatório emitido pelo (CQMA/IPEN) e utilizando-se o software Statistica9 (2009), foi realizada a análise de agrupamento (dendograma), utilizando como parâmetros as concentrações dos óxidos determinadas para as amostras pela técnica WDXRF.

\subsection{Ensaios Físicos}

Para verificar uma possível correlação entre densidade e porosidade das amostras com a sua taxa de exalação de radônio, estas grandezas foram determinadas utilizando-se a norma técnica NBR 15845:2010 (ABNT, 2010) por meio das equações 4.24 e 4.25 respectivamente,

$$
\begin{gathered}
\rho_{a}=\frac{M_{\text {sec }}}{\left(M_{\text {sat }}-M_{\text {sub }}\right)} 1000 \\
\eta_{a}=\frac{\left(M_{\text {sat }}-M_{\text {sec }}\right)}{\left(M_{\text {sat }}-M_{\text {sub }}\right)} 100
\end{gathered}
$$

Considerando a densidade da água igual a $1000 \mathrm{~kg} \cdot \mathrm{m}^{-3}$, sendo:

$$
\begin{aligned}
\rho_{a} & =\text { densidade aparente }\left(\mathrm{kg} \cdot \mathrm{m}^{-3}\right) \\
\eta_{a} & =\text { porosidade aparente }(\%) \\
M_{\text {sec }} & =\text { massa seca }(\mathrm{kg}) \\
M_{\text {sat }} & =\text { massa saturada }(\mathrm{kg}) \\
M_{\text {sub }} & =\text { massa submersa }(\mathrm{kg})
\end{aligned}
$$

Para as pesagens foi utilizada uma balança analítica adaptada para pesagem hidrostática, e nove corpos de prova para cada amostra FIG. 4.9.

O procedimento para as pesagens consiste de três etapas, descritas de forma resumida a seguir:

1. secagem dos corpos de prova em estufa, por $24 \mathrm{~h}$ a $70{ }^{\circ} \mathrm{C}$, para pesagem seca;

2. submersão dos corpos de prova em água, por período de 40 h (ou fervura em água por 2 horas), para pesagem na condição submersa;

3. logo após a pesagem submersa, secagem dos corpos com flanela úmida para pesagem saturada. 


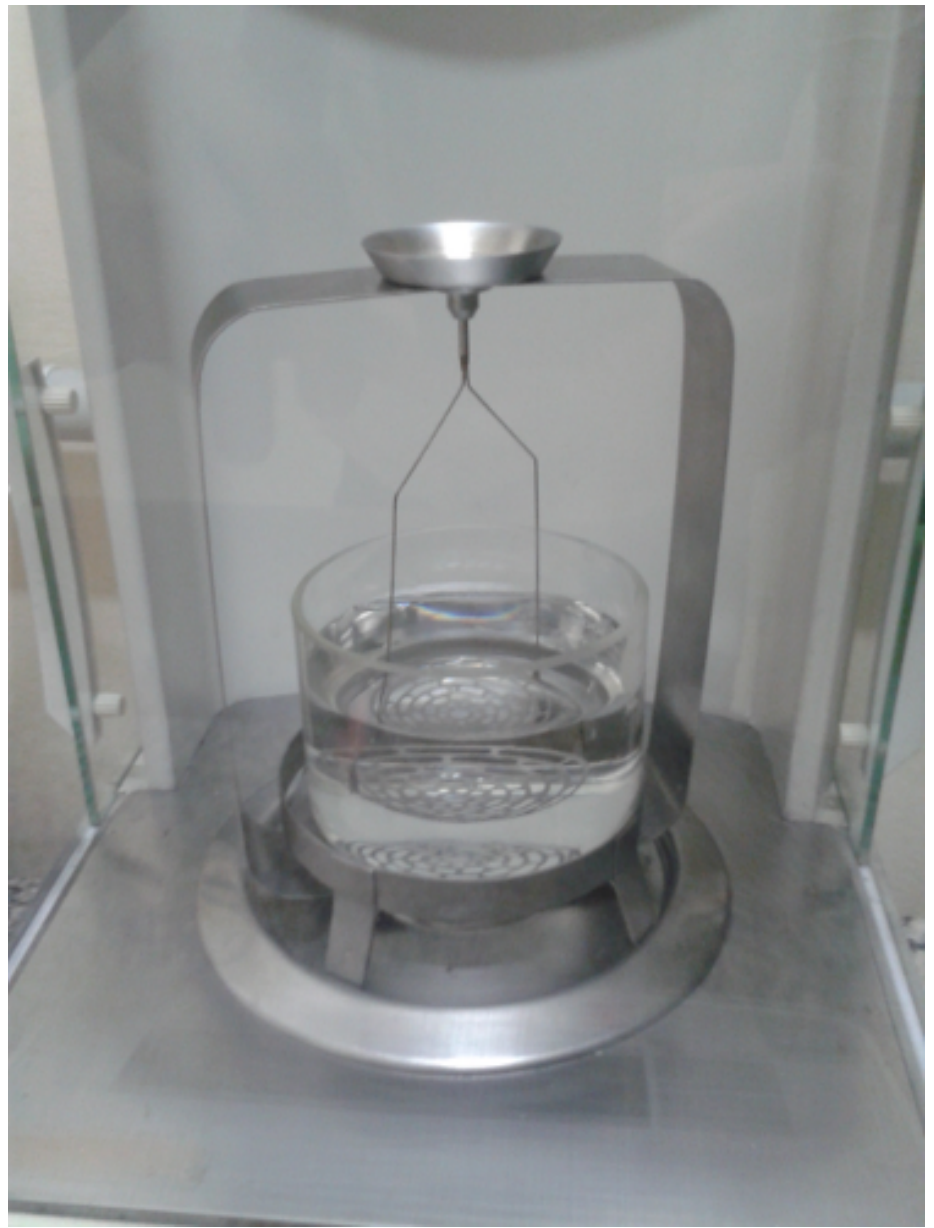

(a)

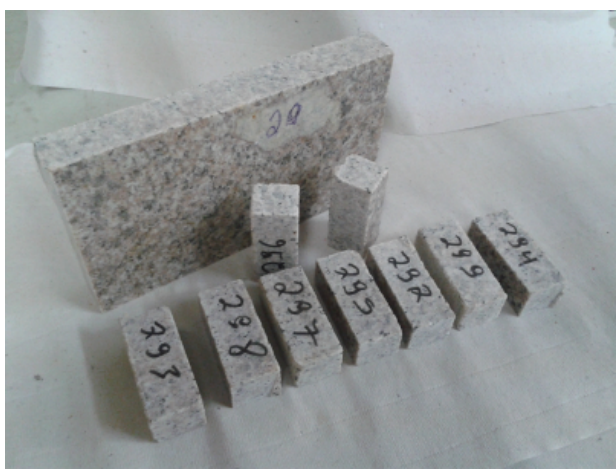

(b)

Figura 4.9: (a) Detalhe da balança adaptada para pesagem hidrostática (b) Corpos de prova de uma das amostras.

Os resultados para cada amostra, foram, então reportados como a média aritmética e respectivo desvio padrão das medidas destes corpos de prova. 


\section{CAPÍTUlO}

\section{RESULTADOS}

Neste capítulo, são apresentadas as concentrações de atividade do ${ }^{226} \mathrm{Ra},{ }^{40} \mathrm{~K}$ e ${ }^{232}$ Th determinadas por espectrometria gama de alta resolução, a taxa de exalação do ${ }^{222} \mathrm{Rn}$ pela técnica de detecção passiva com SSNTD, os resultados dos ensaios físicos para determinação da densidade e porosidade das amostras, e os resultados da análise por Fluorescência de raios X. São discutidas também as possíveis correlações entres os resultados destas 4 análises.

\subsection{Concentração de atividade por Espectrometria Gama de alta resolução}

As análises por espectrometria gama foram realizadas utilizando-se 4 detectores de germânio Hiperpuro (HPGe), item 4.2.1. A curva de eficiência para cada um deles foi determinada a partir de uma solução aquosa radioativa multielementar na mesma geometria das medidas e a radiação de fundo foi determinada utilizando-se água ultrapura na mesma geometria, na FIG. 5.1 é apresentado o espectro da amostra 34, que foi obtido em $86 \mathrm{ks}$.

Sendo as densidades "clássicas"1 das rochas estudadas maiores que a da solução multielementar, e com ampla faixa de variação de $1,57 \mathrm{~g} . \mathrm{cm}^{-3}$ até $2,02 \mathrm{~g} \cdot \mathrm{cm}^{-3}$, e por apresentarem composições químicas diferentes, faz-se necessário realizar um estudo de autoatenuação para correção da eficiência e, por conseguinte, para uma determinação precisa das concentrações de atividades.

\footnotetext{
${ }^{1}$ Aqui o termo densidade "clássica" refere-se ao valor obtido da razão entre a massa da amostra dentro do frasco de Polietileno utilizado para a medida e o respectivo volume.
} 
5.1 - Concentração de atividade por Espectrometria Gama de alta resolução 71

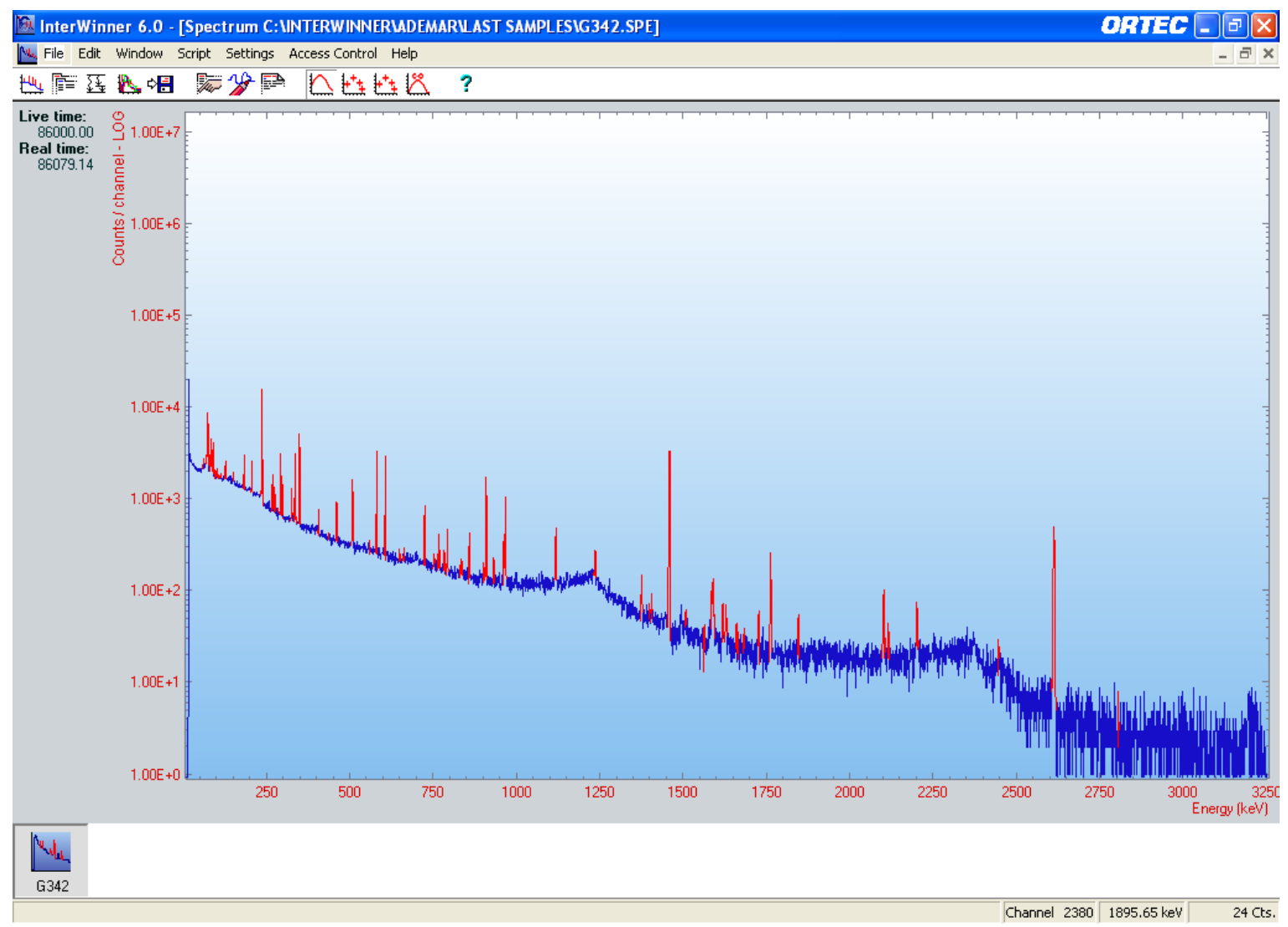

Figura 5.1: Espectro de raios gama da amostra 34 em contagem de 86 ks.

\subsubsection{Medida da autoatenuação}

Conforme descrito no item 4.2.2 foram obtidos 17 fatores de correção na região de interesse para cada amostra. Esses pontos foram ajustados (sem ponderação instrumental) pelo software QtiPlot0.9.8.8 (2011) (como exemplificados para a amostra 1 na FIG. 5.2 e para a amostra 24 na FIG. 5.3). A partir do ajuste, foi realizada a correção para cada transição gama utilizada na determinação da concentração de atividade dos radionuclídeos medidos. 


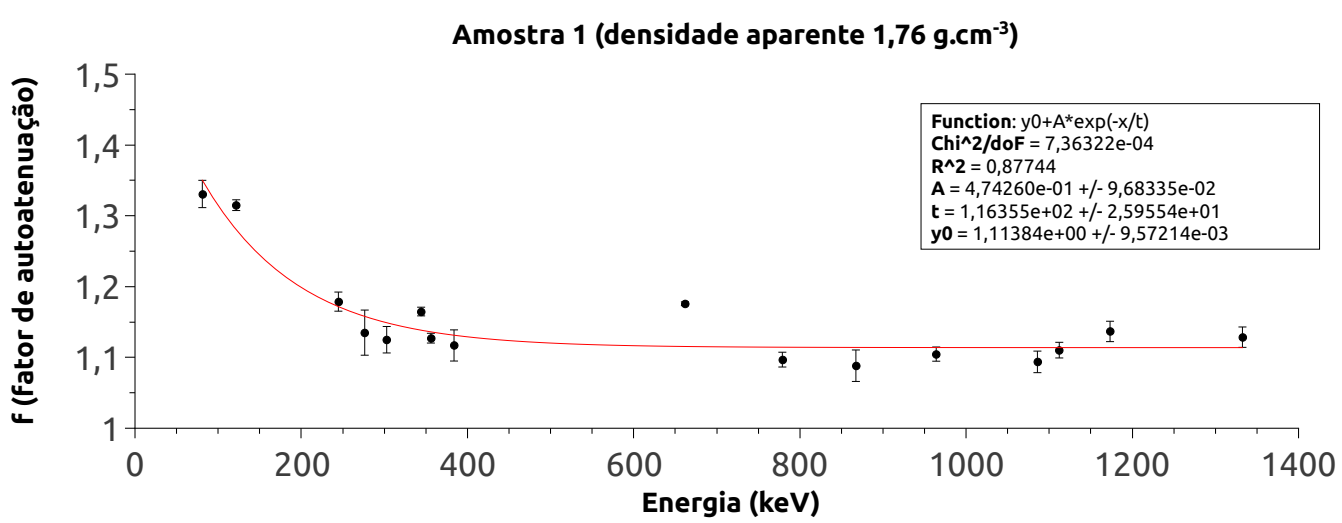

Figura 5.2: Fatores de autoatenuação e ajuste da curva para a amostra 1.

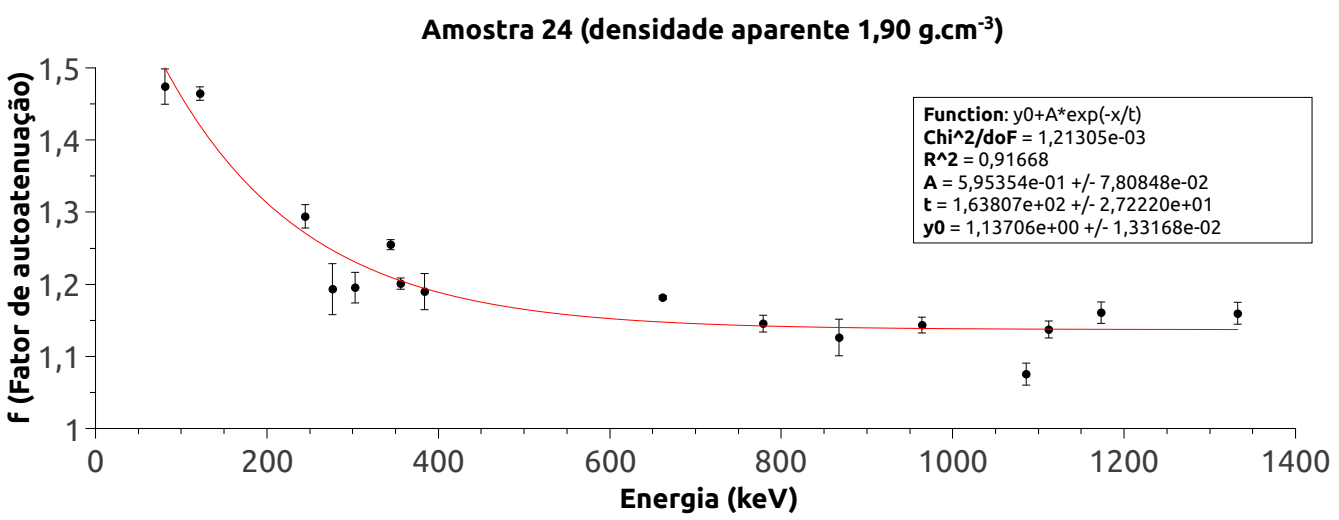

Figura 5.3: Fatores de autoatenuação e ajuste da curva para a amostra 24 .

Estes resultados FIG. 5.2 e 5.3 mostram que o fator de autoatenuação varia com a energia e também com a densidade das amostras, para uma variação de $7 \%$ na densidade da amostra, o fator, para energia de $1332,5 \mathrm{keV}$, variou de $2 \%$ e para energia de 80,99 $\mathrm{keV}$ de $10 \%$.

Fatores de autoatenuação e curvas de ajustes semelhantes foram obtidos para todas as amostras estudadas. Como cada amostra possui uma densidade aparente diferente das demais, nas FIG. 5.4 e 5.5 são justapostos os resultados obtidos para as amostras de 1 a 50 , ordenados por densidade aparente. 


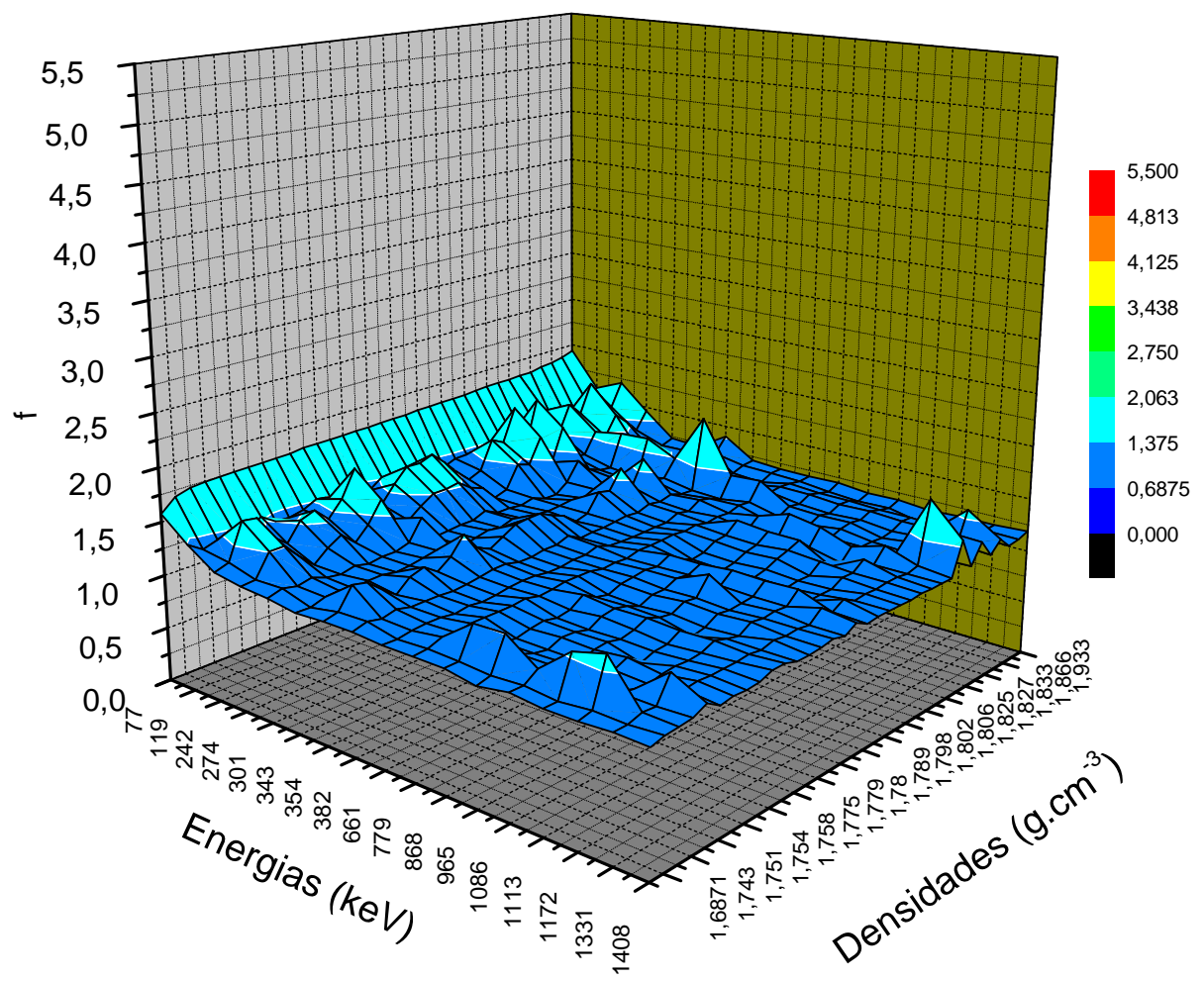

Figura 5.4: Fatores de autoatenuação medidos em função da energia para todas as amostras de rochas da RMC.

Na FIG. 5.5, pode-se observar que o fator $f$ foi ajustado em função da energia e não em função da densidade (considerando que houvesse uma dependência maior destes fatores com a densidade, esperaríamos um comportamento menos "rugoso" deste gráfico em função das densidades.

Como descrito no item 1.3.1, a interação da radiação gama com matéria (neste caso a autoatenuação) depende da energia dos fótons e do número atômico do meio. Esta segunda dependência, comparando-se as FIG. 5.4 e 5.5, parece estar implícita (conforme esperado teoricamente) com a não dependência com a densidade. $\mathrm{Na}$ realidade, a atenuação depende do número atômico $\mathrm{Z}$ do meio em que é atenuado, neste caso, este meio (a amostra) é uma mistura de muitos elementos, de tal forma que a atenuação depende do $\mathrm{Z}$ médio ponderado pela concentração do elemento. Assim, a autoatenuação é dependente da energia da densidade e principalmente da composição química das amostras. 


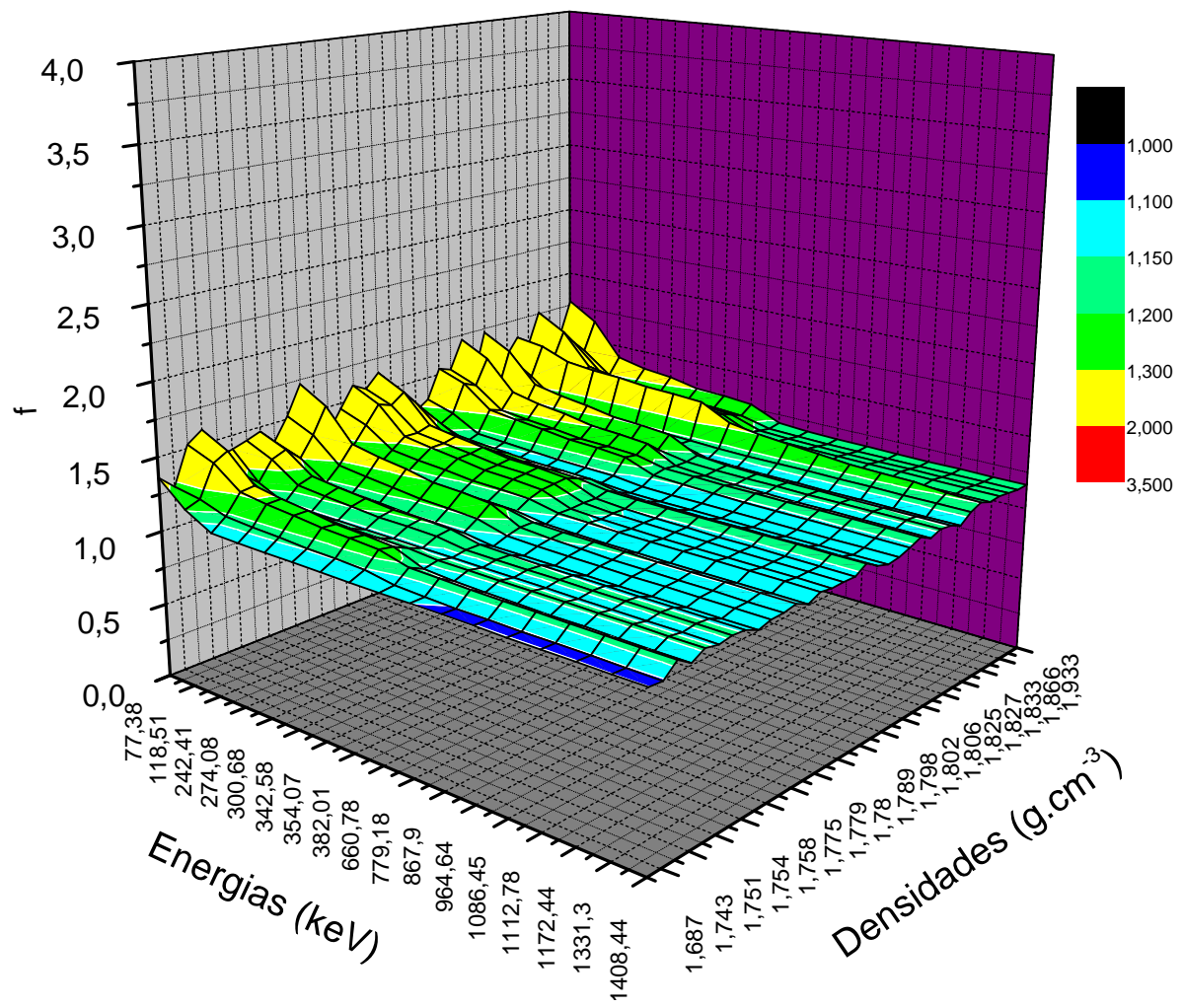

Figura 5.5: Ajustes dos fatores de autoatenuação em função da energia para todas as amostras de rochas da RMC.

\subsubsection{Qui-quadrados $\left(\chi^{2}\right)$}

Na figura a seguir, pode-se observar os valores calculados para os Qui-quadrados conforme equação 4.7, descrita no item 4.2.3.

Pode-se observar na FIG. 5.6 que das 100 estimativas realizadas (50 para o tório e 50 para o rádio) apenas $4(4 \%)$ estão fora deste intervalo ${ }^{2}$ indicando que as estimativas individuais são representativas do valor médio neste nível de significância.

\footnotetext{
${ }^{2}$ Valores de quiquadrado entre 0 e 5,02 este intervalo foi obtido considerando $n=2$, ou seja, duas estimativas para a atividade de tório e rádio, estas estimativas foram realizadas utilizando os radionulídeos apresentados na (TAB. 4.6) por meio de suas respectivas transições, onde para o tório foram agrupadas (em uma única estimativa, apenas para este cálculo ) as transições do ${ }^{212} \mathrm{~Pb}$ e ${ }^{212} \mathrm{Bi}$ por estarem próximos na série de decaimento FIG. 1.3
} 


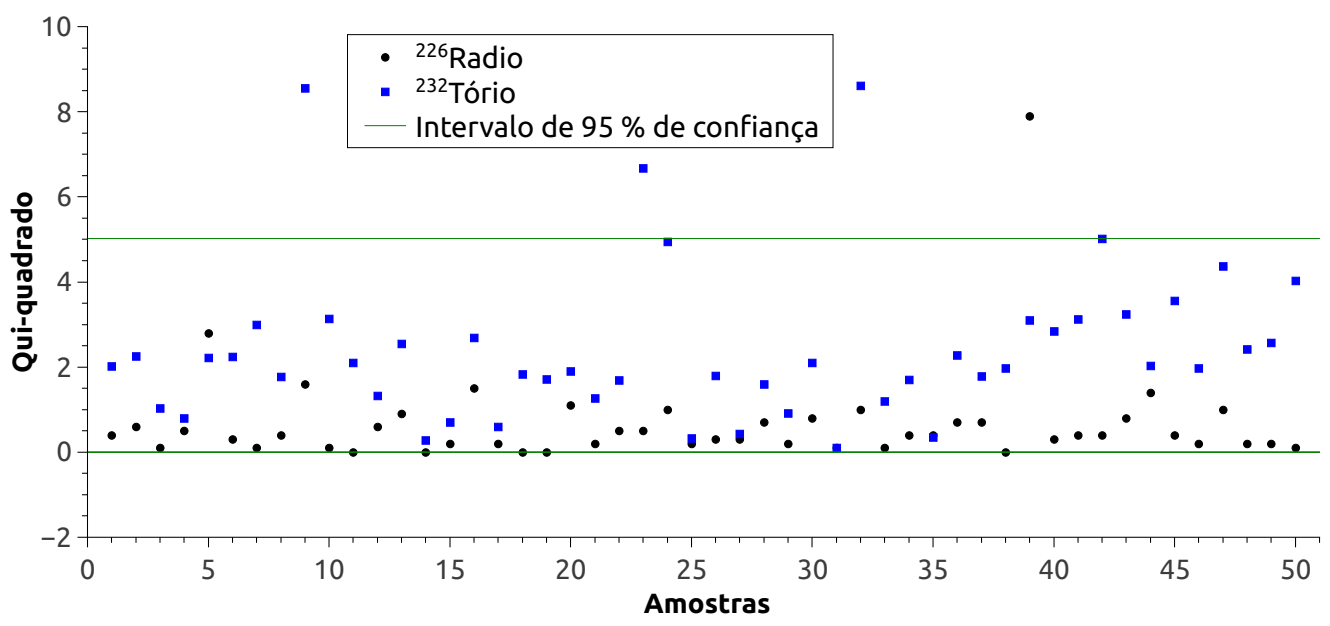

Figura 5.6: Valores de Qui-quadrado determinados para as estimativas do ${ }^{226} \mathrm{Ra}$ e do ${ }^{232} \mathrm{Th}$, considerando $n=2$, (estas estimativas foram realizadas considerando dois radionuclídeos TAB. 4.6).

\subsubsection{Concentrações de atividades do ${ }^{40} \mathrm{~K},{ }^{232} \mathrm{Th}$ e ${ }^{226} \mathbf{R a}$}

Os valores calculados para as concentrações de atividades, corrigidos pelo fator de autoatenuação, do ${ }^{40} \mathrm{~K},{ }^{232} \mathrm{Th}$ e ${ }^{226} \mathrm{Ra}$, conforme descrito no item 4.2.3 são apresentados nas FIG. 5.7, 5.8 e 5.9. 


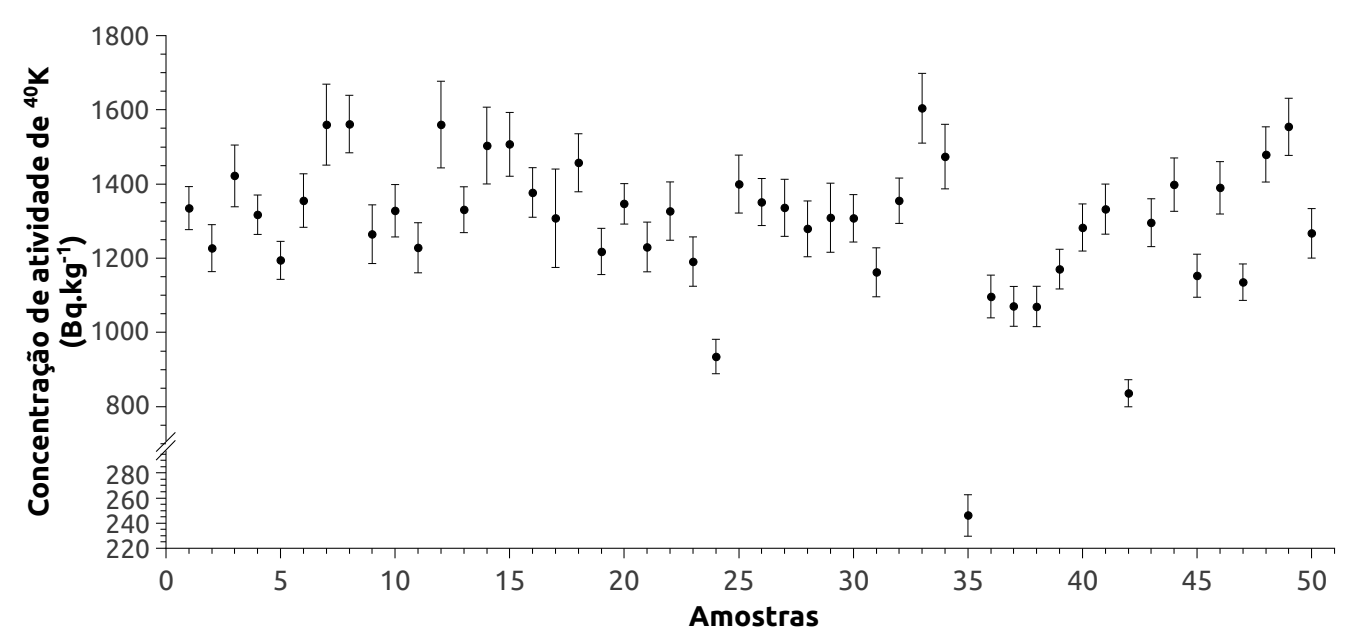

Figura 5.7: Concentração de atividades de ${ }^{40} \mathrm{~K}$ nas amostras de rochas obtidas na RMC.

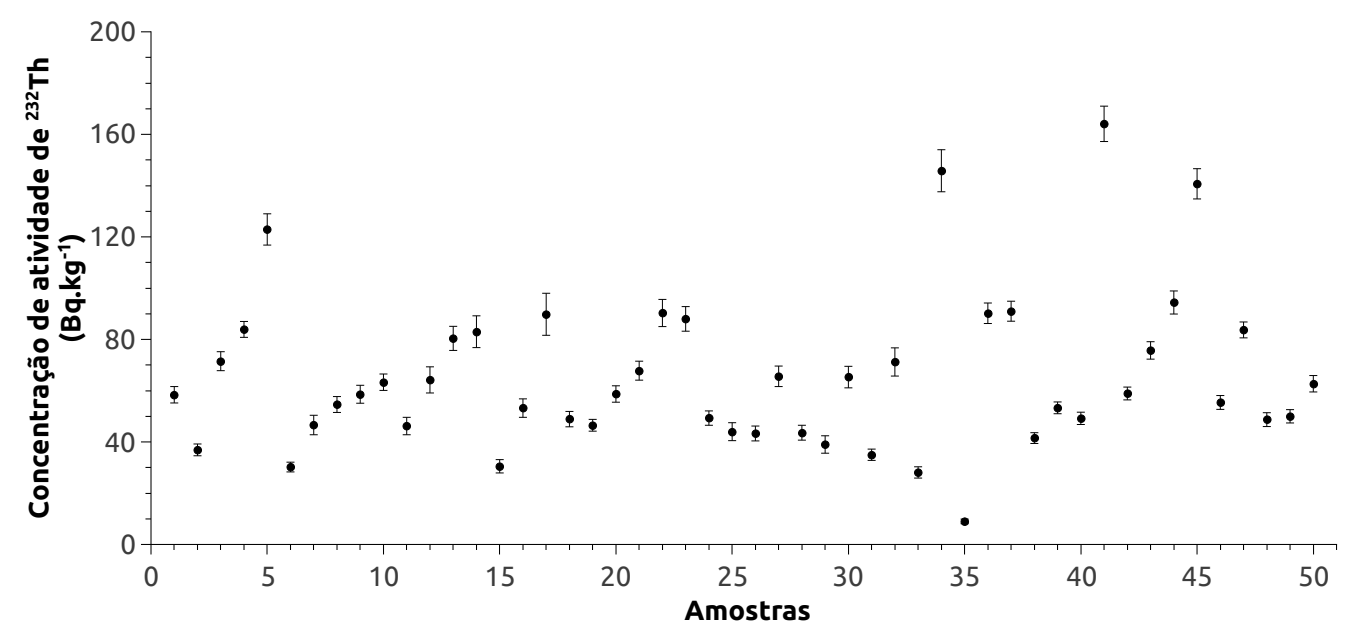

Figura 5.8: Concentração de atividades de ${ }^{232}$ Th nas amostras de rochas obtidas na RMC. 


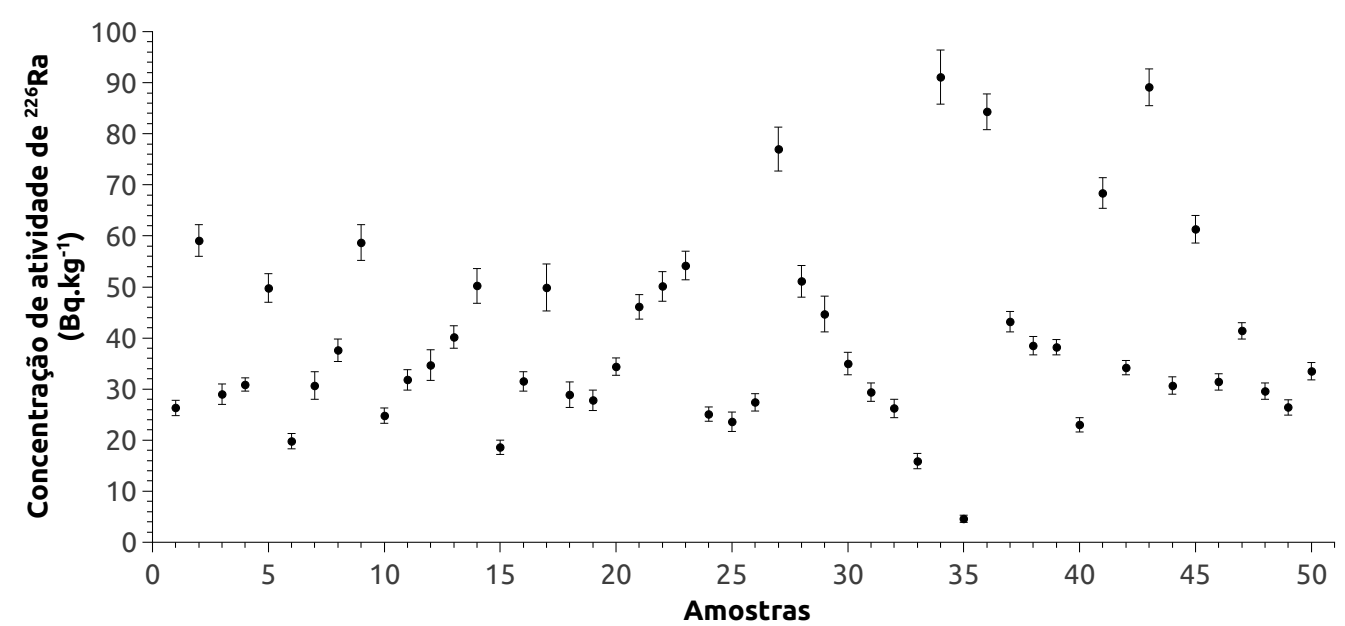

Figura 5.9: Concentração de atividades de ${ }^{226}$ Ra nas amostras de rochas obtidas na RMC.

As concentrações de atividade variaram de $(246 \pm 17) \mathrm{Bq} \cdot \mathrm{kg}^{-1}$ até $(1604 \pm 94)$ Bq. $\mathrm{kg}^{-1}$ para o ${ }^{40} \mathrm{~K}$, de $(9 \pm 1) \mathrm{Bq} \cdot \mathrm{kg}^{-1}$ até $(164 \pm 7) \mathrm{Bq} \cdot \mathrm{kg}^{-1}$ para o ${ }^{232} \mathrm{Th}$ e de $(5 \pm 1)$ Bq. $\mathrm{kg}^{-1}$ até $(91 \pm 5) \mathrm{Bq} \cdot \mathrm{kg}^{-1}$ para o ${ }^{226} \mathrm{Ra}$. Estes valores estão dentro das faixas de variação dos resultados na literatura obtidos para rochas graníticas utilizadas na construção civil TAB. 5.1.

Tabela 5.1: Resultados reportados na literatura e neste trabalho para concentrações de atividade em rochas.

\begin{tabular}{|c|c|c|c|c|c|c|c|c|}
\hline \multirow{3}{*}{$\begin{array}{c}\text { Região } \\
\text { estudada }\end{array}$} & \multirow{3}{*}{$\begin{array}{c}\text { Número } \\
\text { de amostras }\end{array}$} & \multicolumn{6}{|c|}{ Concentração de atividade $\left(\mathrm{Bq} \cdot \mathrm{kg}^{-1}\right)$} & \multirow[t]{2}{*}{ Referência } \\
\hline & & \multicolumn{2}{|c|}{${ }^{40} \mathrm{~K}$} & \multicolumn{2}{|c|}{${ }^{232} \mathrm{Th}$} & \multicolumn{2}{|c|}{${ }^{226} \mathrm{Ra}$} & \\
\hline & & 92 & 4155,9 & 7,5 & 344,6 & 9,2 & 192,5 & (Turhan, 2008) \\
\hline Itália & 20 & $(240 \pm 7)$ & $(2000 \pm 70)$ & $(20 \pm 2)$ & $(490 \pm 50)$ & $(12 \pm 2)$ & $(390 \pm 60)$ & (Marocchi et al., 2011) \\
\hline Brasil $^{3}$ & 110 & $(190 \pm 63)$ & $(2029 \pm 95)$ & $(4 \pm 4)$ & $(449 \pm 122)$ & $(5 \pm 4)$ & $(169 \pm 39)$ & (Anjos et al., 2005) \\
\hline SP e MG & 14 & 407,5 & 1615 & 9,55 & 347,47 & 12,18 & 251,90 & (Moura, 2005) \\
\hline Paraná & 37 & $(246 \pm 17)$ & $(1604 \pm 94)$ & $(9 \pm 1)$ & $(156 \pm 8)$ & $(5 \pm 1)$ & $(91 \pm 5)$ & Este estudo \\
\hline
\end{tabular}

\subsubsection{Variabilidade}

Foram obtidas para este estudo 13 amostras, conforme descrito no item 4.1, das quais cinco amostras são extraídas por ambas as fábricas 1 e 2, e 8 por apenas uma das fábricas. Assim, optou-se por realizar este estudo em duas etapas, primeiro para estas

\footnotetext{
${ }^{3}$ Este estudo envolveu dez estados brasileiros, mais detalhes deste e dos outros citados são apresentados no item 3 .
} 
5 amostras, depois para as 8, os resultados são apresentados nas FIG. 5.10 e 5.11.

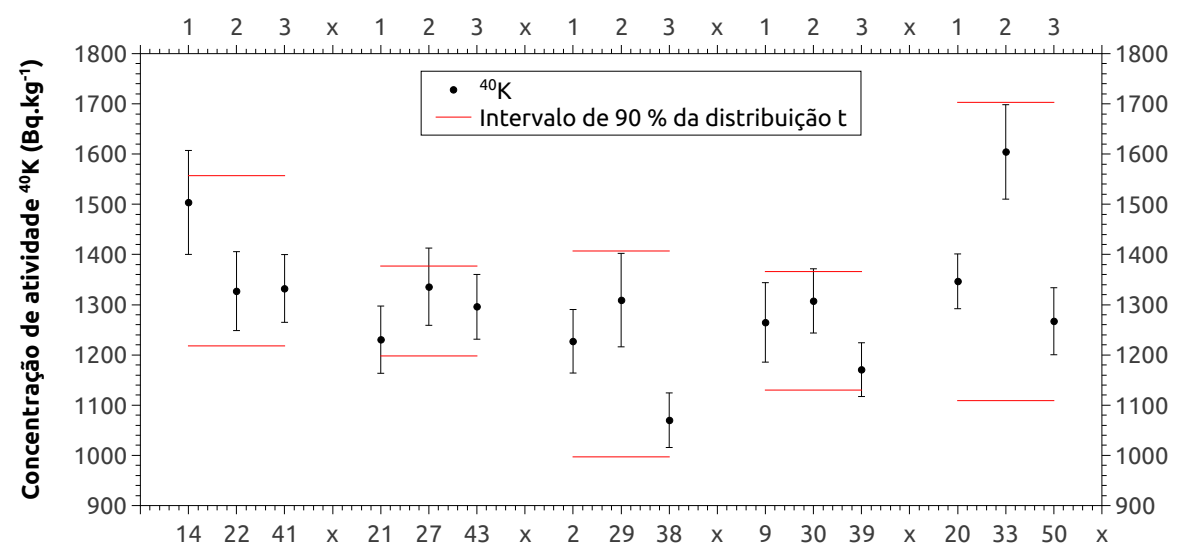

(a)

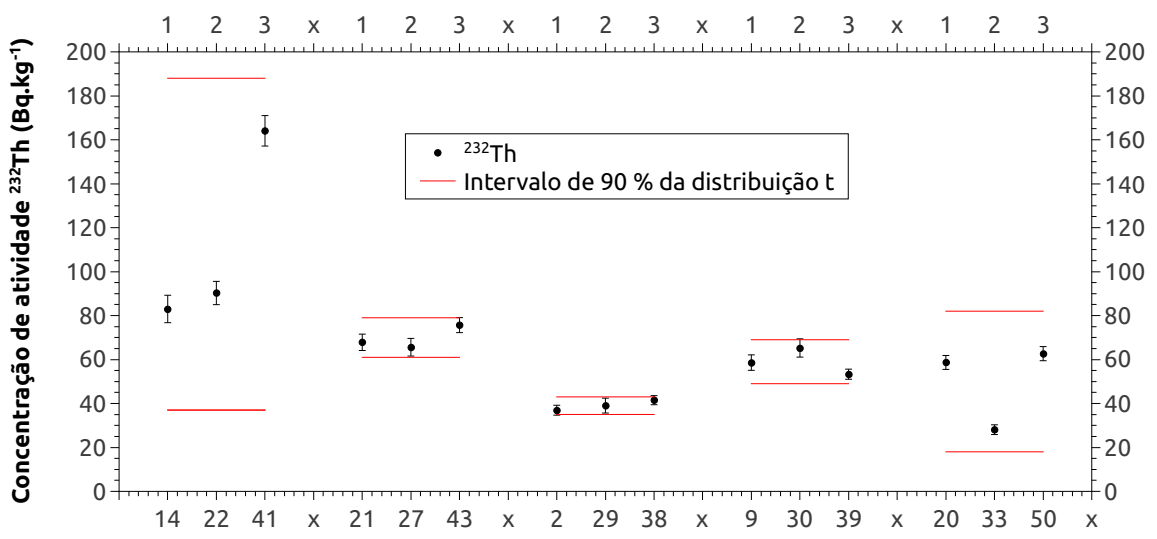

(b)

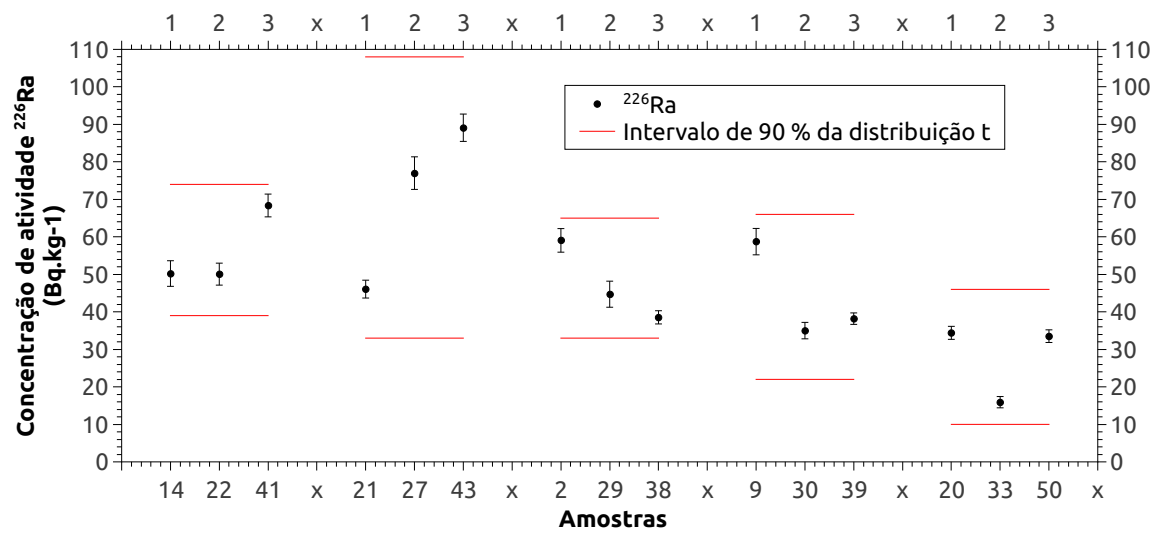

(c)

Figura 5.10: Resultados do estudo da variabilidade para as 5 amostras extraídas pelas duas fábricas utilizando os radioisótopos (a) ${ }^{40} \mathrm{~K}$ (b) ${ }^{232} \mathrm{Th}$ e (c) ${ }^{226} \mathrm{Ra}$. 


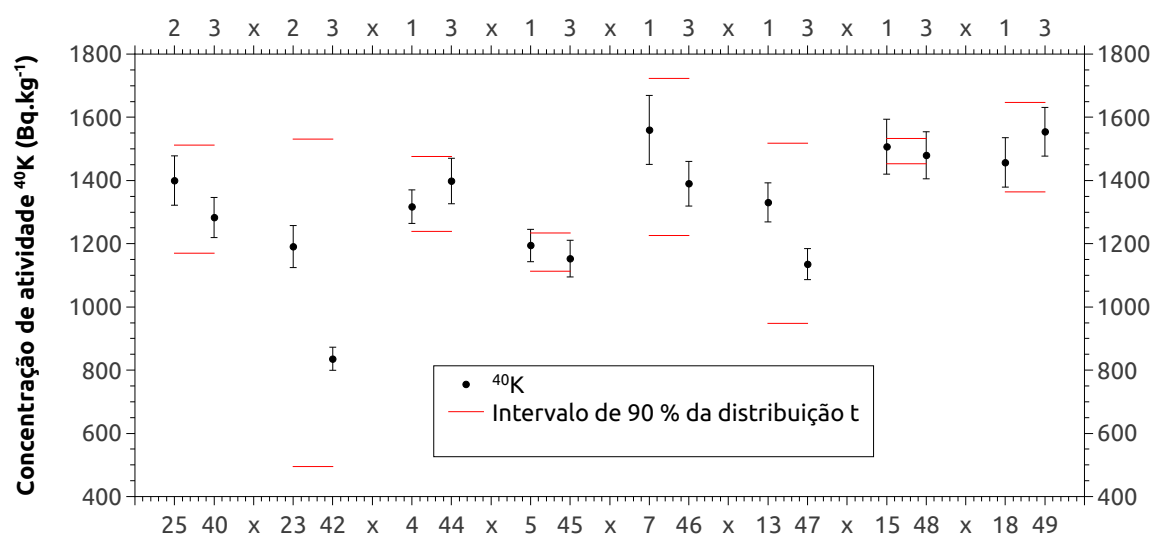

(a)

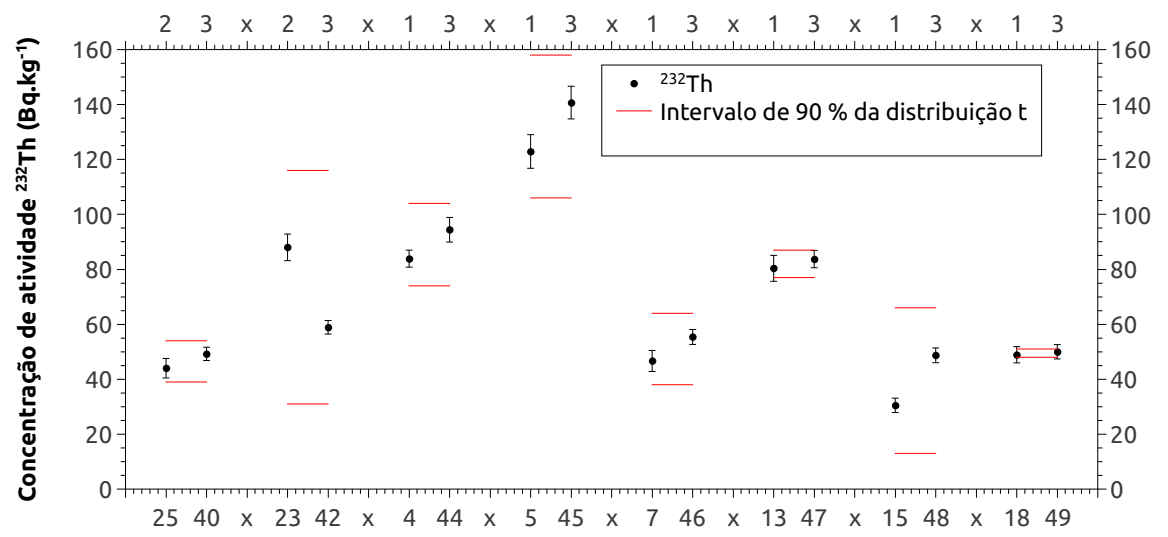

(b)

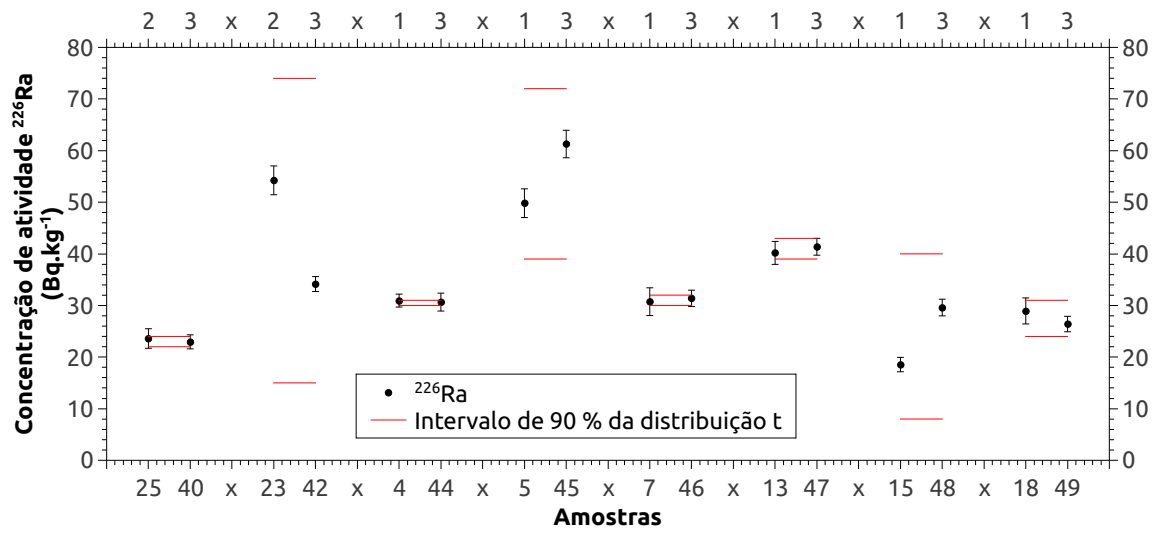

(c)

Figura 5.11: Resultados do estudo da variabilidade para as 8 amostras utilizando os radioisótopos (a) ${ }^{40} \mathrm{~K}$ (b) ${ }^{232} \mathrm{Th}$ e (c) ${ }^{226} \mathrm{Ra}$. 
Onde a numeração, 1 e 2 na parte superior de cada gráfico das FIG. 5.10 e 5.11, indica a fábrica de procedência (TAB. 4.1) e o número 3 indica a amostra obtida para o estudo da variabilidade (TAB. 4.2), as barras indicam o intervalo de confiança de $90 \%$ da distribuição de Student.

Na FIG. 5.10 os intervalos de confiança da distribuição de Student foram obtidos para 2 graus de liberdade, pois foram medidas apenas três amostras. Os resultados mostram que o intervalo de $90 \%$ de confiança, dos três radionuclídeos, em todas as amostras os valores estão dentro do intervalo, isto significa que, em termos dos valores medidos de concentrações de atividade dos radionuclídeos ${ }^{226} \mathrm{Ra},{ }^{232} \mathrm{Th}$ e ${ }^{40} \mathrm{~K}$, as sub-amostras estudadas fazem parte de uma mesma amostra com $90 \%$ de confiança. Na FIG. 5.11, pode-se observar que para o intervalo de $90 \%$ de confiança da distribuição t, considerando os três radionuclídeos quantificados, todas as amostras também estão dentro do intervalo, assim, as sub-amostras estudadas fazem parte de uma mesma amostra com $90 \%$ de confiança.

Este intervalo foi calculado pela equação 4.1, que considera o desvio padrão da média dividido por $\sqrt{N}$, onde $\mathrm{N}$ é o número de amostras. No primeiro estudo $N=3$ (FIG. 5.10) e no segundo caso $N=2$ (FIG. 5.11). Assim, o intervalo para estes estudos é fortemente influenciado pelo fator $\sqrt{N}$, além dos desvios padrões de cada média. Portanto, para obter-se um intervalo, cujo valor tenha influência menor de $\sqrt{N}$, uma redução no número de diferentes amostras estudadas (3 ou 4 ao invés de 13 por ex.) em substituição a um aumento do número de sub-amostras (6 ou 7 ao invés de 2 por ex.) seria mais eficiente para as amostras estudadas, mas, por outro lado, perderia informação a respeito da amostragem geral. 


\subsection{5 Índices Dosimétricos}

Para avaliar a dose externa foram calculados os índices dosimétricos que utilizam como parâmetros os valores obtidos de concentrações de atividades do ${ }^{40} \mathrm{~K},{ }^{232} \mathrm{Th}$ e ${ }^{226} \mathrm{Ra}$. Os resultados calculados para os índices $\mathrm{Ra}_{e q}, \mathrm{H}_{E X}$ e $\mathrm{I}_{\gamma}$ conforme descrito no item 4.3 são mostrados nas FIG. 5.12, 5.13 e 5.14, respectivamente.

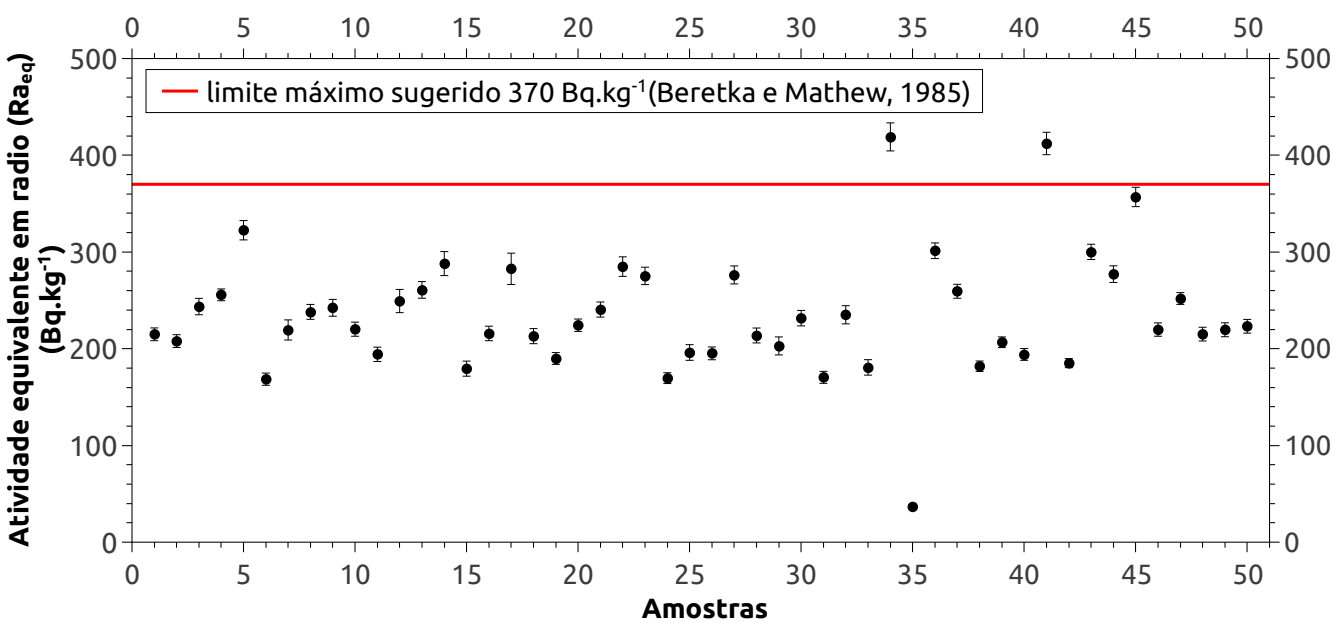

Figura 5.12: Valores calculados para o indice Atividade Equivalente em Rádio para as rochas estudadas.

Na FIG. 5.12, pode-se observar que a amostra 34 e a amostra 41 estão acima do limite máximo sugerido (370 Bq. $\left.\mathrm{kg}^{-1}\right)$, indicando que todas as demais amostras podem ser utilizadas como novos materiais de construção, segundo este critério, (no caso da amostra cujo valor está acima, mais estudos são necessários para avaliar sua aplicação).

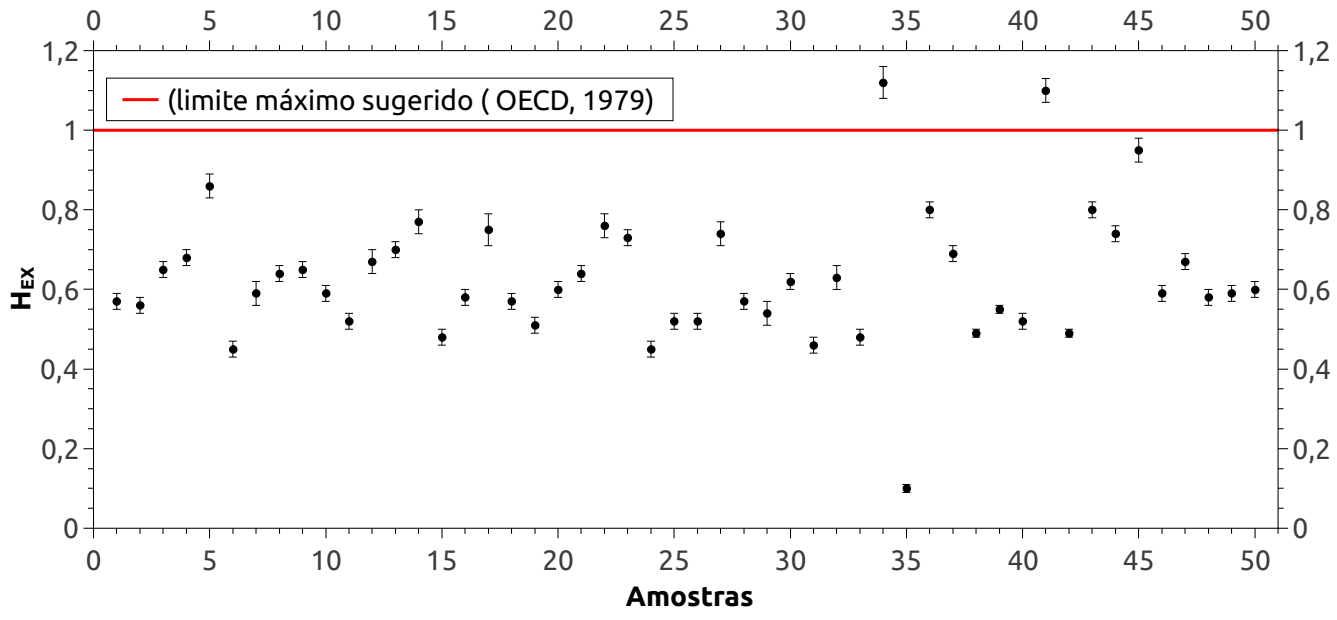

Figura 5.13: Valores calculados para o Índice externo para as rochas estudadas.

Novamente na FIG. 5.13, somente as amostras 34 e 41 apresentam um valor 
maior que o limite máximo sugerido $H_{E X} \leq 1$, indicando que a dose efetiva anual devido à radiação gama externa, para todas as outras amostras, está abaixo de 1,5 $\mathrm{mSv}$.

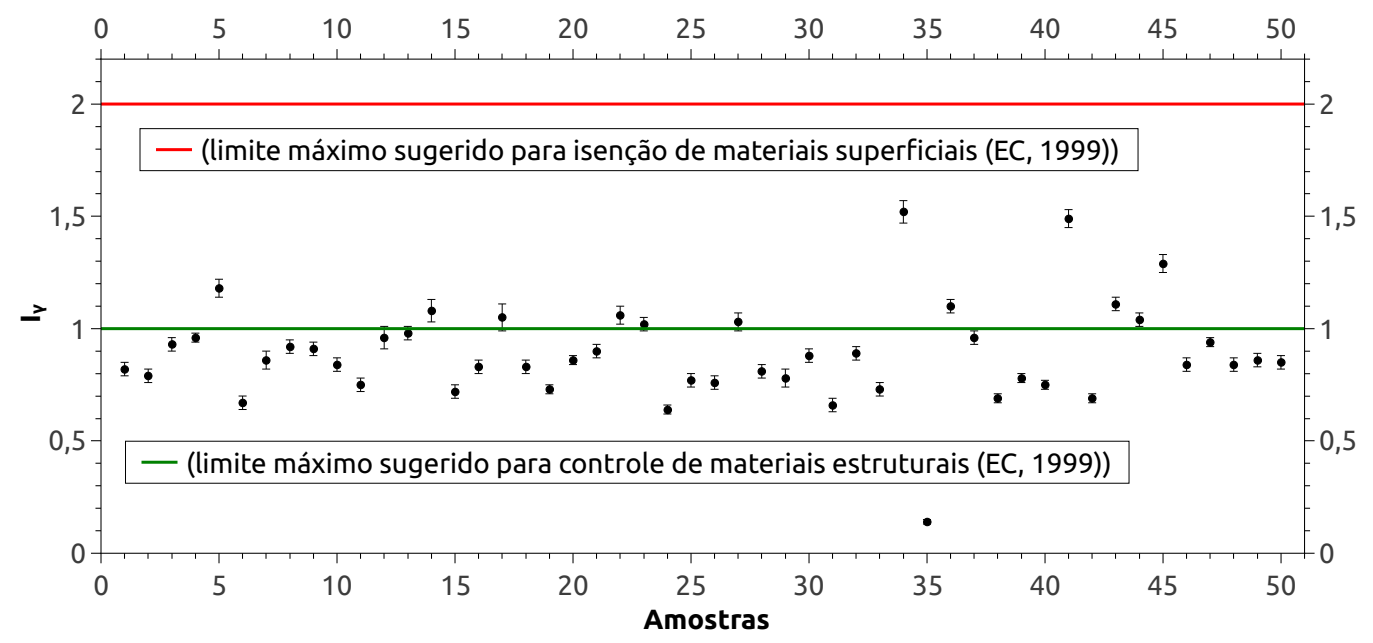

Figura 5.14: Valores calculados para o Índice gama.

O índice gama $\left(\mathrm{I}_{\gamma}\right)$ calculado possui dois critérios de avaliação, que dependem do tipo de aplicação; como o principal objetivo deste trabalho é avaliar a aplicação superficial, todas as amostras analisadas estão abaixo do critério de isenção para materiais com este tipo de aplicação $\mathrm{I}_{\gamma} \leq 2$, FIG. 5.14. Mesmo considerando-se o critério de controle para materiais com aplicação estrutural $\mathrm{I}_{\gamma} \leq 1$, somente 8 amostras ${ }^{4}$ $(5,14,17,22,23,27,34$ e 36) estão acima deste nível. Dentre estas, 7 tem valores menores que 1,18 , próximo do valor limite, e a amostra 34 tem valor 1,52, indicando que para uma aplicação (estrutural) há necessidade de uma avaliação mais específica em termos radiológicos principalmente da amostra 34 .

\subsubsection{Taxa de Dose absorvida no ar}

As taxas de dose absorvida no ar foram calculadas segundo o modelo sugerido pela Comissão Européia de Proteção Radiológica (EC, 1999), considerando uma sala com dimensões $4 \mathrm{~m}$ x $5 \mathrm{~m}$ x 2,8 8 , para materiais superficiais com espessura de $3 \mathrm{~cm}$ e densidade de $2,6 \mathrm{~g} \mathrm{~cm}^{-3}$, conforme descrito no item 4.4.1. Os valores foram obtidos pela equação 4.11, e estão apresentados na FIG. 5.15.

\footnotetext{
${ }^{4}$ Considerando apenas as 37 amostras distintas (TAB. 4.1), sem considerar as amostras obtidas para estudo da variabilidade.
} 


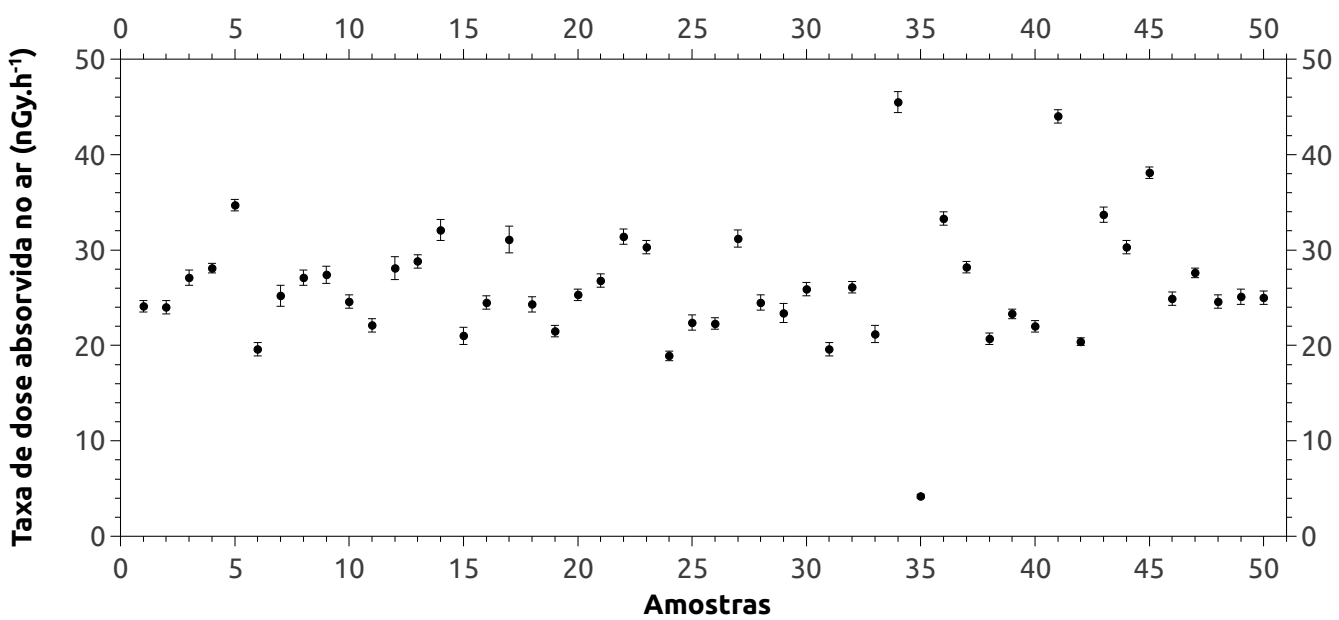

Figura 5.15: Taxa de dose Absorvida no ar dentro da sala padrão (4 m x $5 \mathrm{~m}$ x 2,8 m), decorrente da utilização da rochas estudadas com resvestimento interno.

O resultado mostra que os valores variam de $(4,2 \pm 0,2)$ nGy.h ${ }^{-1}$ até $(46 \pm 1)$ nGy.h ${ }^{-1}$, estes resultados estão dentro da faixa de variação dos resultados obtidos por Anjos (Anjos et al., 2011), cuja faixa é de 4, $4 \mathrm{nGy} \cdot \mathrm{h}^{-1}$ até $120 \mathrm{nGy} \cdot \mathrm{h}^{-1}$.

Utilizando o programa computacional EDVOS, descrito por Máduar (2000) citado no item 4.4.1, para calcular os coeficientes (nas mesmas dimensões e densidade), a nova equação de taxa de dose é dada por,

$$
\dot{D}=0,097 A_{R a}+0,13 A_{T h}+0,0094 A_{K}
$$

Onde pode-se observar que o coeficiente com variação mais significativa em relação ao obtido por Markkanen (1995) foi o da série do ${ }^{226}$ Ra. A FIG. 5.16 apresenta a comparação entre os resultados obtidos pelos modelos aplicados, equações 4.11 e 5.1, para cada amostra estudada. 


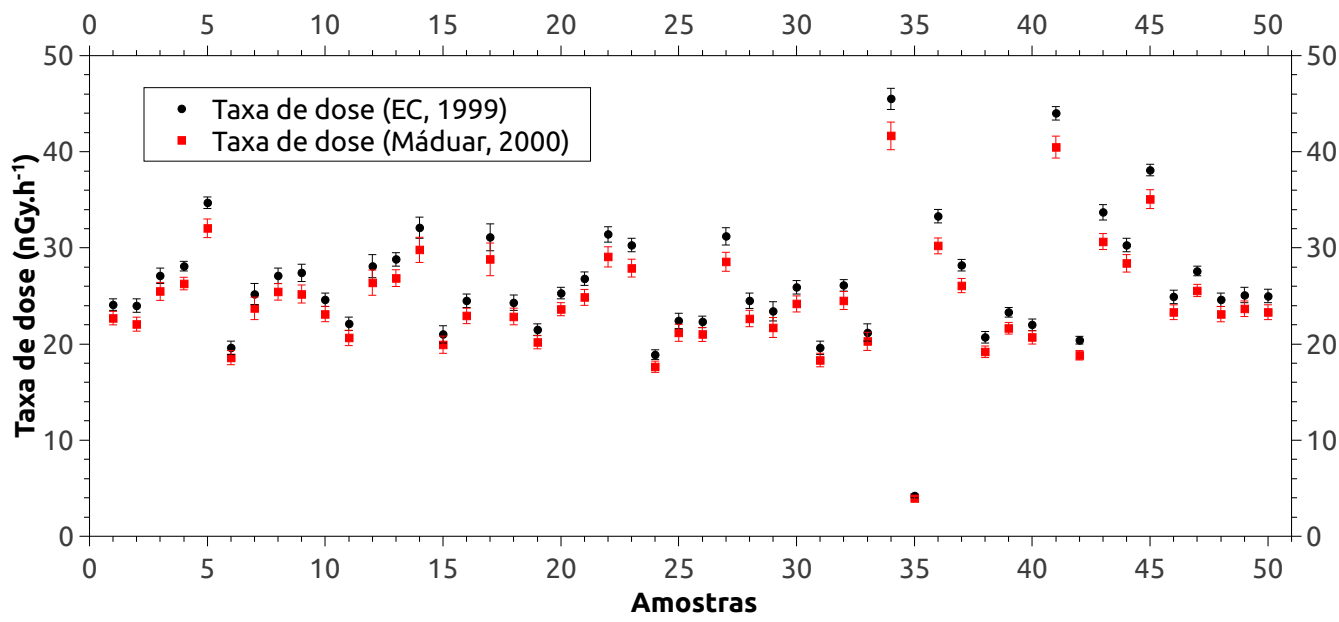

Figura 5.16: Resultados para Taxa de dose Absorvida no ar dentro da sala padrão (4 m x 5 m x 2,8 m), obtidos pelos modelos descritos em (EC, 1999; Máduar, 2000) decorrente da utilização das rochas estudadas como revestimento interno.

Estes resultados (FIG. 5.16), foram calculados segundo modelos que consideram espessura de $3 \mathrm{~cm}$ e densidade de $2,6 \mathrm{~g} \cdot \mathrm{cm}^{-3}$. As espessuras das amostras deste trabalho são de $2 \mathrm{~cm}$, assim os resultados são superestimados (o que é justificável em termos de proteção radiológica). Por outro lado, as densidades das amostras estudadas são variadas com valores menores e maiores que o valor adotado no modelo. Assim, para obter um valor de dose específico devido a cada granito (e comparar com os resultados anteriores) considerando sua densidade e espessura de $2 \mathrm{~cm}$, para uma sala padrão com as mesmas dimensões do modelo de (EC, 1999), foi utilizado o programa EDVOS para calcular os coeficientes de conversão de dose para cada granito. Os resultados obtidos para as três situações descritas são mostrados na FIG. $5.17^{5}$.

\footnotetext{
${ }^{5}$ As linhas ligando os pontos, que aparecerem nesta figura e em outras adiante, foram utilizadas apenas para facilitar a visualização dos resultados.
} 


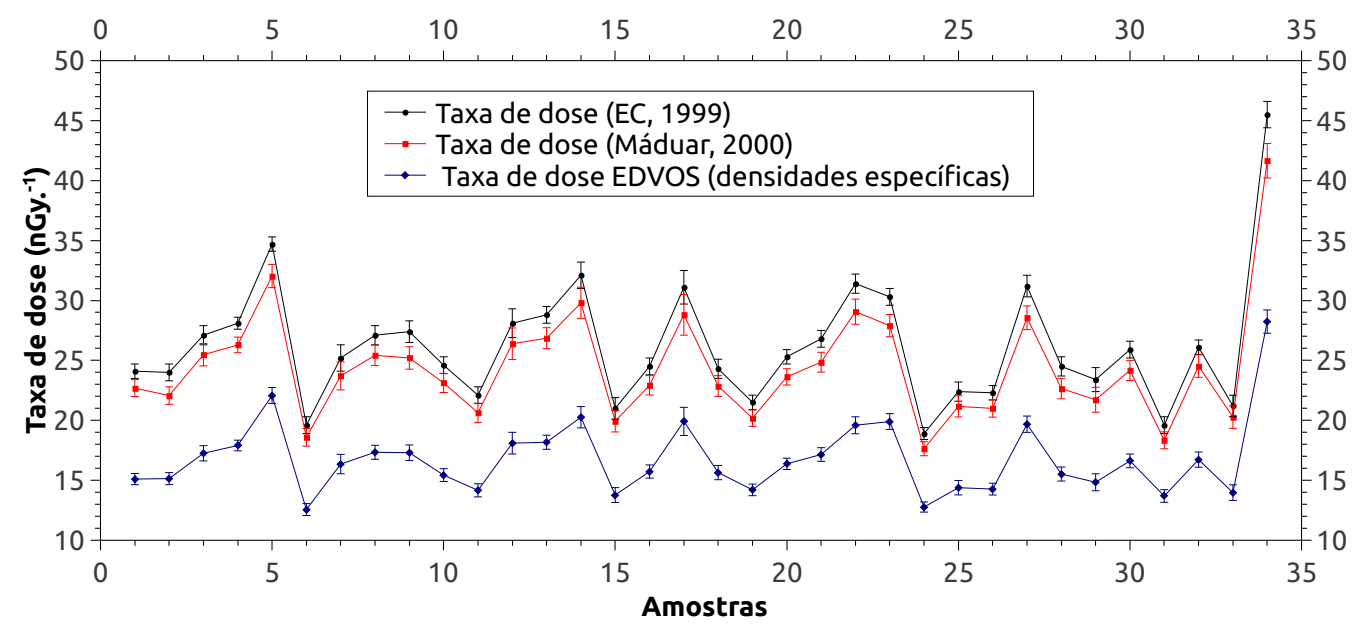

Figura 5.17: Comparação dos valores de taxa de dose calculados em três situações diferentes.

Este resultado mostra que o programa EDVOS, gera como saída um fator de conversão menor (mesmo para dimensões iguais), portanto uma taxa de dose também menor, em média da ordem de $7 \%$. Isso pode ser atribuído ao fato de que o programa EDVOS procura utilizar pressupostos mais realistas, em lugar daqueles que maximizam as doses, como é prática usual em aplicações radiológicas.

Já para os resultados considerando espessura de $2 \mathrm{~cm}$ e as densidades de cada amostra, os valores de taxa de dose são, na média, $36 \%$ menores que o valor do modelo (EC, 1999). Esta diferença deve-se a dois fatores, primeiro o modelo gera $7 \%$ (conforme discutido no parágrafo anterior) e os demais $29 \%$ são devido ao incremento que a variação da espessura (de $1 \mathrm{~cm}$ ) e também as densidades, causam no valor final, neste caso uma redução de $50 \%$ da espessura reduz a taxa de dose em $29 \%$.

O resultado para a verificação da variação dos coeficientes de conversão de dose com a espessura é apresentado na FIG. 5.18.

Este resultado mostra a variação dos coeficientes em função da espessura da parede, para uma densidade de $2,6 \mathrm{~g} . \mathrm{cm}^{-3}$. Observa-se que a variação de 2 para $3 \mathrm{~cm}$ tem um incremento significativo para os componentes do ${ }^{232} \mathrm{Th}$ e ${ }^{226} \mathrm{Ra}$ de aproximadamente $31 \%$, este resultado mostra que para a faixa de variação de espessura de $0,5 \mathrm{~cm}$ a $5 \mathrm{~cm}$ a dose aumenta linearmente, pois os efeitos de autoatenuação para estas espessuras não são importantes. Assim a dose aumenta porque aumenta a quantidade de material contribuindo com a dose. Este comportamento, bem como numa faixa de variação maior de espessura, são discutidos com mais detalhes por Máduar e Hiromoto (2004), onde os autores mostram que para uma variação de espessura de $40 \mathrm{~cm}$ para $60 \mathrm{~cm}$ ha um incremento no fator de conversão de apenas $4 \%$. 


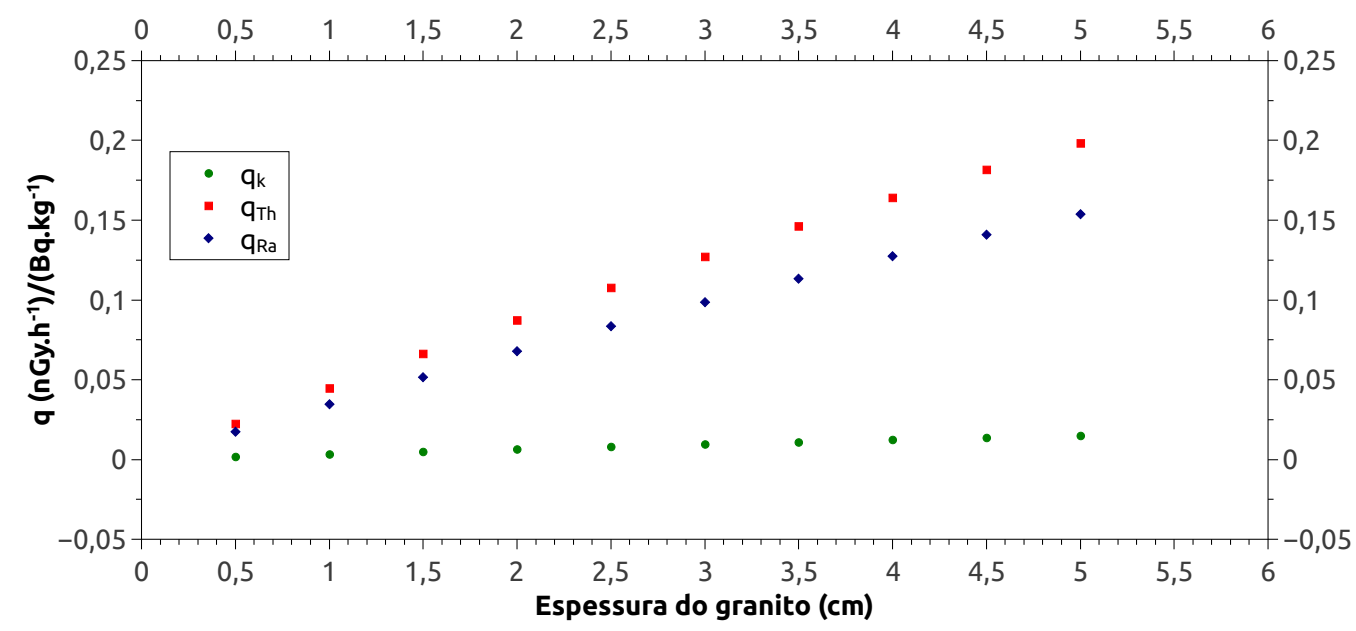

Figura 5.18: Fatores de conversão de dose em função da espessura da parede, calculados pelo programa EDVOS, para as rochas estudadas.

\subsection{Radônio}

A inalação do radônio é a principal responsável pela exposição interna devido a materiais de construção, portanto, o conhecimenoto da taxa de exalação do ${ }^{222} \mathrm{Rn}$, para materiais de construção, é um parâmetro relevante na estimativa da dose interna. Para estimar a concentração de radônio utilizando-se detectores sólidos de traços nucleares é necessário conhecer a eficiência de detecção destes. Assim, foi determinado experimentalmente a eficiência do detector CR-39 (utilizado neste trabalho) para a geometria de medida, conforme descrito no item 4.5.1, o resultado é apresentado na FIG. 5.19, a seguir.

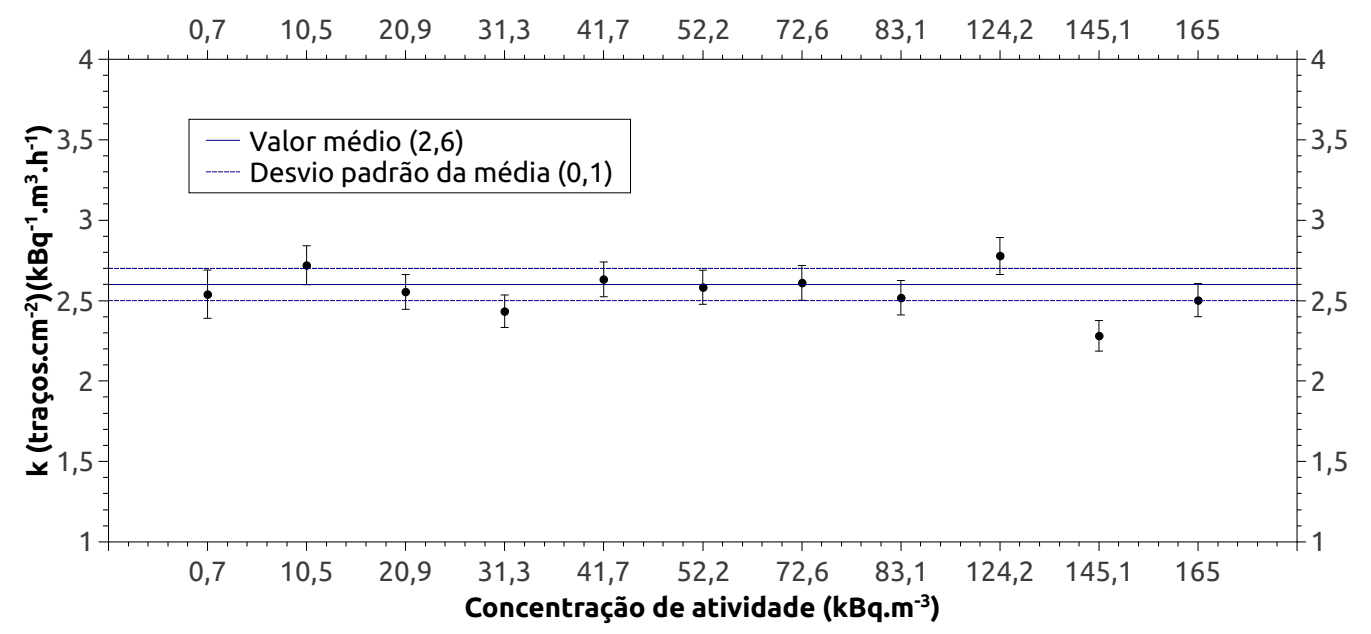

Figura 5.19: Fator de calibração (eficiência de detecção) dos detectores CR-39, determinados experimentalmente para a geometria de medida. 
O valor médio utilizado na determinação da concentração, com o respectivo desvio padrão obtido foi de $(2,6 \pm 0,1)\left(\right.$ traços.cm $\left.{ }^{-2}\right)\left(\mathrm{kBq}^{-1} \cdot \mathrm{m}^{3} \cdot \mathrm{h}^{-1}\right)$.

Na FIG. 5.20 são apresentados os resultados da concentração de radônio, (na câmara selada), determinados pela equação 4.16, conforme descrito no item 4.5.1, estes valores são as médias aritméticas e respectiva incerteza de três medidas.

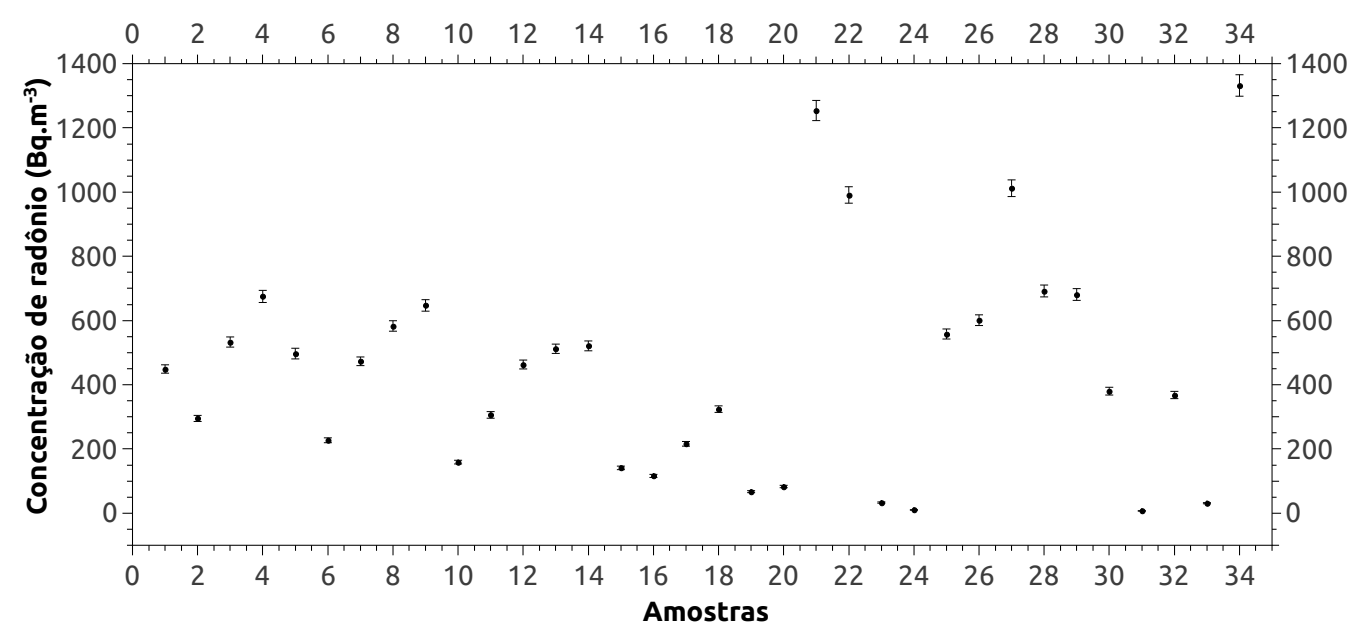

Figura 5.20: Concentração de radônio na câmara selada.

Este estudo foi realizado para 34 amostras, pois três amostras são utilizadas como agregados. A concentração medida variou de $(7 \pm 1)$ Bq.m ${ }^{-3}$ até $(1332 \pm 33) \mathrm{Bq} \cdot \mathrm{m}^{-3}$. Estes resultados obtidos pela técnica do recipiente selado são os valores a partir dos quais se obtém a taxa de exalação de radônio das amostras, valores estes que são intrínsicos de cada amostra e só são influênciados por mudanças de condições muito drásticas (como tratamento da superfície da rocha por ex.).

Na FIG. 5.21 e 5.22 a seguir são apresentados os resultados para a taxa de exalação superficial e taxa de exalação por massa, usando as equações 4.17 e 4.18 respectivamente, que foram calculadas a partir dos valores médios determinados para a concentração do radônio. 


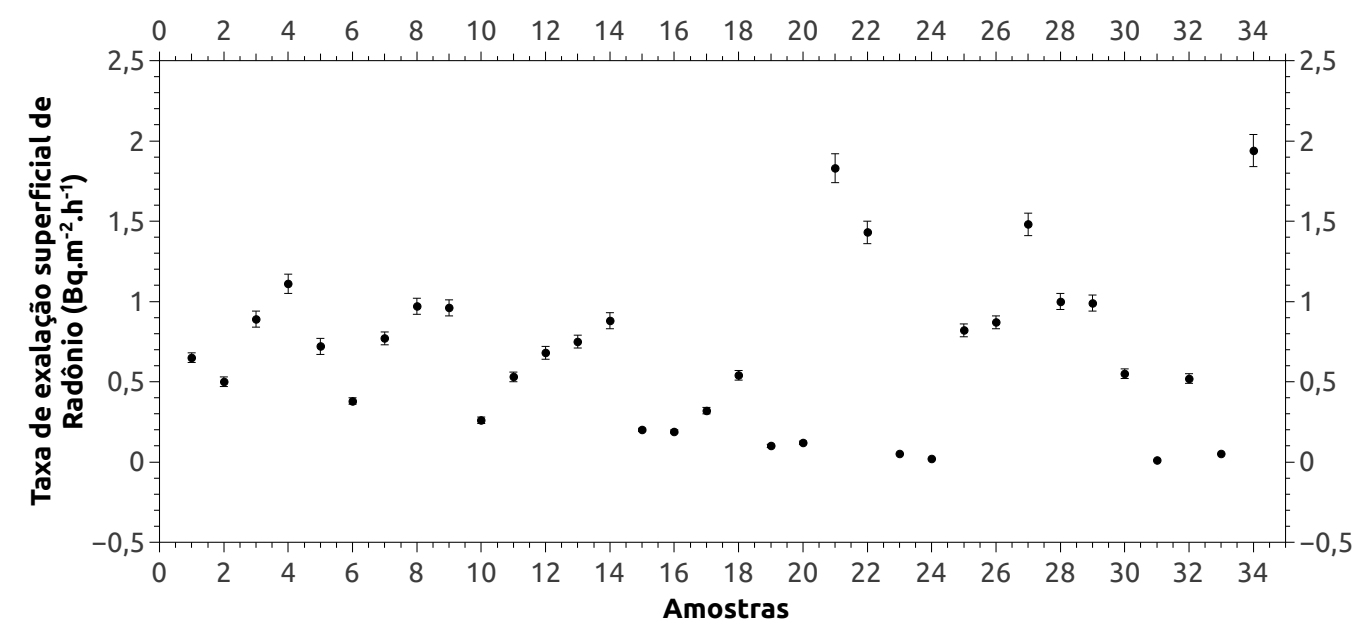

Figura 5.21: Taxa de exalação superficial de radônio das amostras de rochas estudadas.

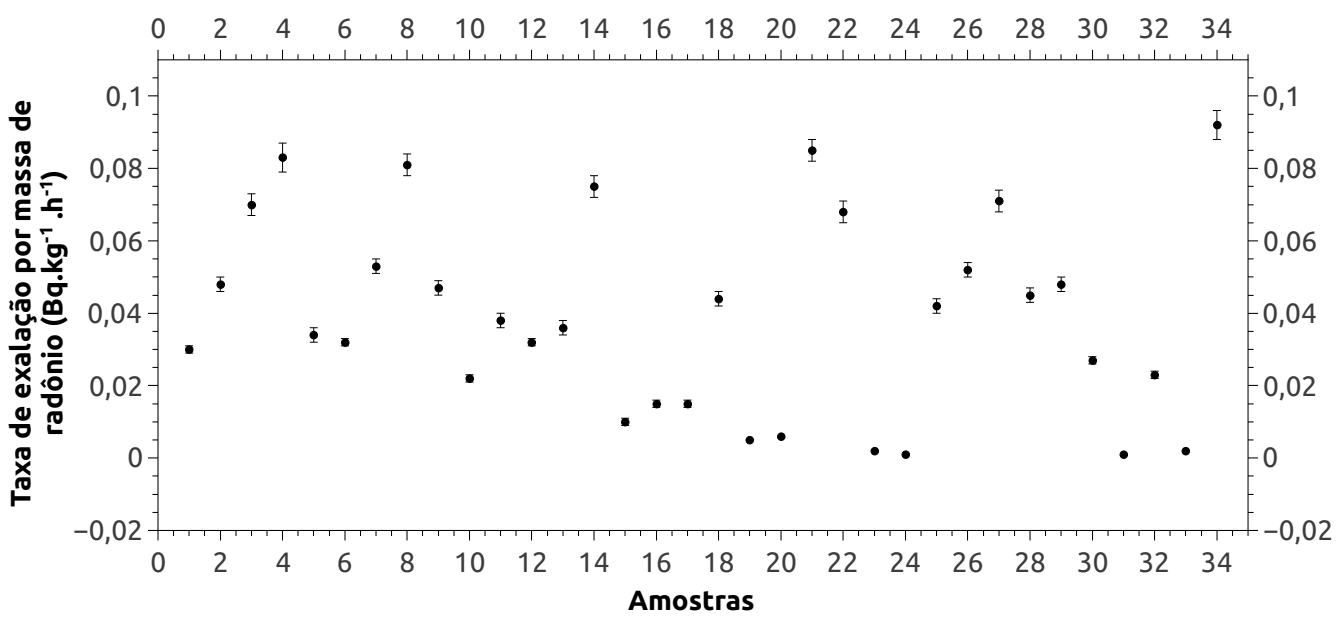

Figura 5.22: Taxa de exalação de radônio por massa das amostras de rochas estudadas.

Os valores calculados para a taxa de exalação superficial variaram de $(0,011 \pm 0,001)$ Bq.m ${ }^{-2} \cdot h^{-1}$ até $(1,9 \pm 0,1)$ Bq.m ${ }^{-2} \cdot h^{-1}$. Resultados semelhantes foram obtidos por Moura et al. (2011); os autores mediram, em uma câmara fechada, utilizando detectores de traços nucleares CR-39, a radioatividade natural em 14 tipos de rochas ígneas brasileiras utilizadas como rochas ornamentais dos estados de São Paulo e Rio de Janeiro, obtendo taxa de exalação superficial de radônio, variando de 0,24 Bq.m ${ }^{-2} \cdot h^{-1}$ até $3,93 \mathrm{~Bq} \cdot \mathrm{m}^{-2} \cdot \mathrm{h}^{-1}$.

A taxa de exalação por massa medida variou de $(0,0010 \pm 0,0001) \mathrm{Bq} \cdot \mathrm{kg}^{-1} \cdot \mathrm{h}^{-1}$ até $(0,092 \pm 0,004) \mathrm{Bq} \cdot \mathrm{kg}^{-1} \cdot \mathrm{h}^{-1}$, resultados estes na mesma faixa de resultados obtidos por Marocchi na Itália (Marocchi et al., 2011) que mediram, utilizando uma câmara de íons de eletreto E-PERM, 20 rochas ornamentais comumente utilizadas como materiais de construçao, cujos resultados variaram de $(0,0007 \pm 0,0002) \mathrm{Bq} \cdot \mathrm{kg}^{-1} \cdot \mathrm{h}^{-1}$ 
até $(0,64 \pm 0,05) \mathrm{Bq} \cdot \mathrm{kg}^{-1} \cdot \mathrm{h}^{-1}$.

\subsubsection{Fração de Emanação e concentração de radônio na sala padrão}

Os resultados apresentados, neste item, foram calculados utilizando as equações descritas no item 4.5.3, para um modelo de sala padrão, FIG. 4.5, cujas dimensões são $(4,0 \times 5,0 \times 2,8) \mathrm{m}$ e com espessura de $2 \mathrm{~cm}$, considerando revestimento apenas das paredes (sem considerar teto e chão). A fração de emanação e a concentração de radônio são calculadas a partir da razão entre taxa de exalação de radônio e concentração de ${ }^{226}$ Ra no material de construção.

Para fazer uma comparação com o valor medido, a taxa de exalação também foi calculada por um modelo matemático simplificado, equação 4.20, (UNSCEAR, 2000), onde foram utilizados os valores tabelados da literatura $\eta=0,2 \mathrm{e}$ $D_{e}=3,6 \times 10^{-4} \cdot \mathrm{cm}^{2} \cdot \mathrm{s}^{-1}$, (fazendo a conversão de unidades) que são respectivamente a fração de emanação de radônio em concreto e coeficiente de difusão específica do radônio em concreto (UNSCEAR, 2000; Markkanen, 1995). Esta comparação é mostrada na FIG. 5.23.

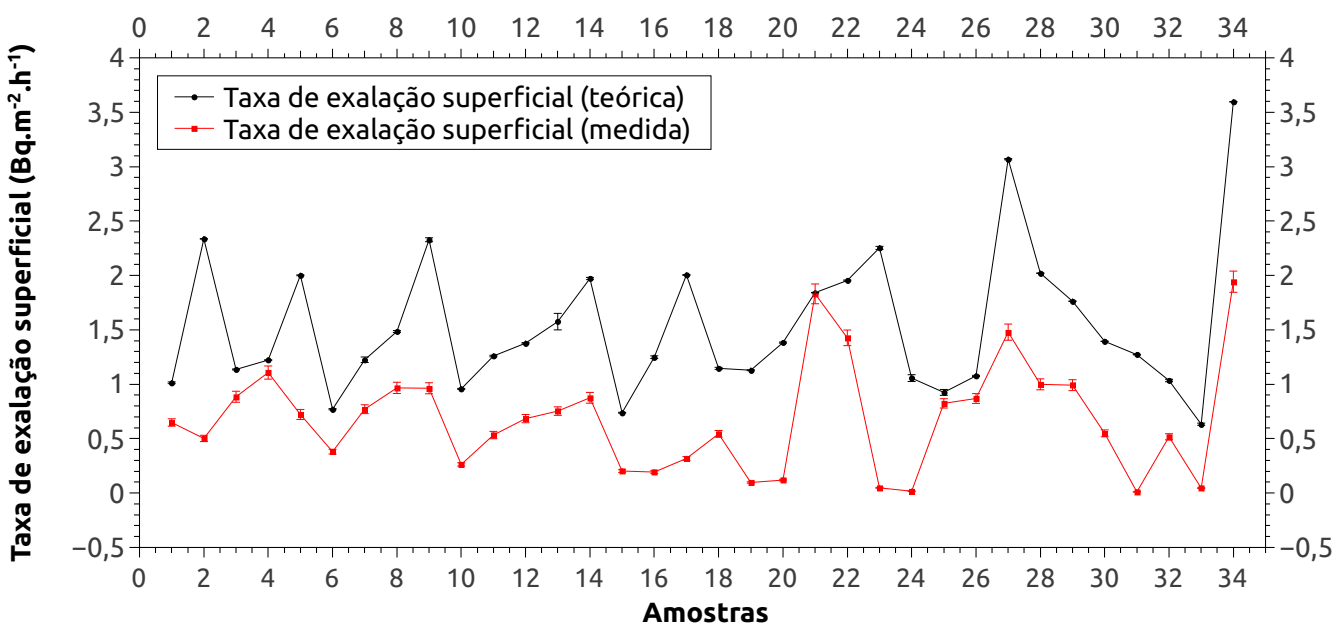

Figura 5.23: Valores teóricos e valores experimentais de taxa de exalação superficial de radônio das rochas estudadas.

Pode-se notar que os valores teóricos (determinados a partir da concentração de atividade de ${ }^{226} \mathrm{Ra}$ e da densidade de cada amostra), apesar de estarem, em sua grande maioria, acima dos valores medidos, (pode estar relacionado ao fato de dois parâmetros utilizados no cálculo (equação 4.20) serem para concretos com densidade menor 2,35 g.cm ${ }^{-3}$, porosidade maior e sem variação na composição química), apresentam 
no geral o mesmo comportamento dos dados experimentais.

Na FIG. 5.24, a seguir são plotados os valores teóricos e experimentais para a fração de emanação que foram calculados conforme (Marocchi et al., 2011), pela equação 4.22 multiplicados por um fator de conversão de unidades ${ }^{6}$.

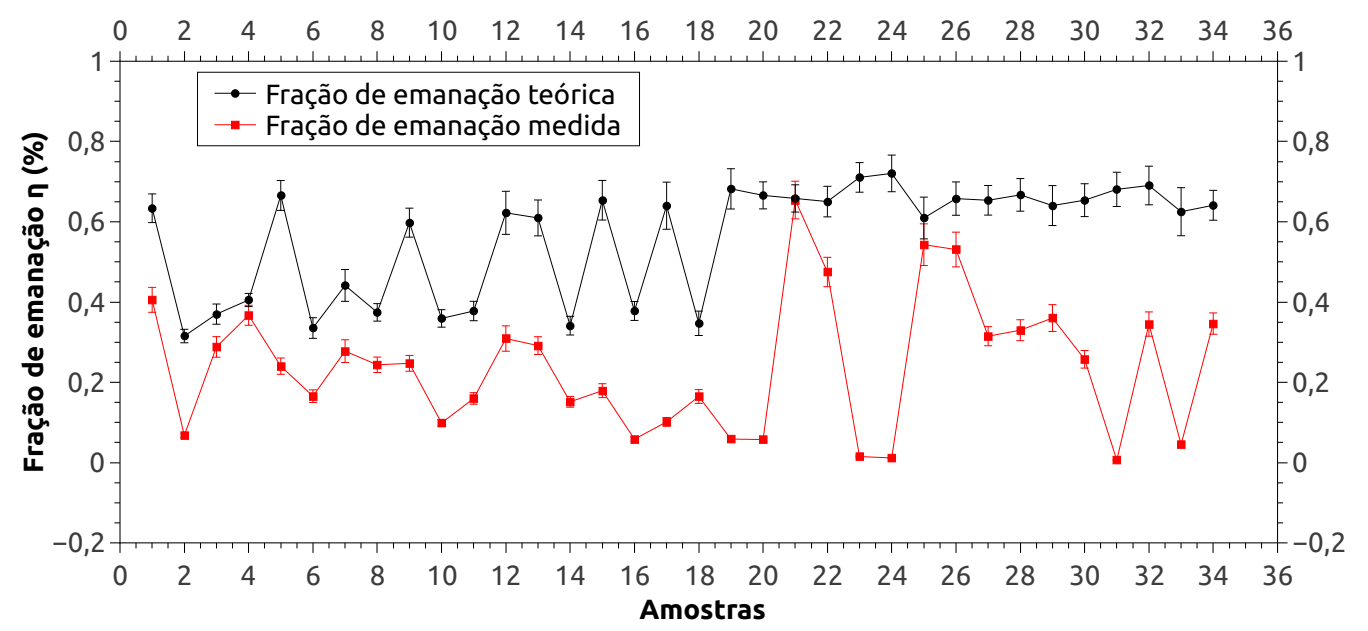

Figura 5.24: Fração de emanação valores teóricos e valores medidos para a rochas estudadas.

Os valores foram estimados pela equação 4.22, onde o valor medido foi calculado a partir da taxa de exalação superficial medida e da concentração de atividade de ${ }^{226} \mathrm{Ra}$ medida $\mathrm{C}_{R a}$, e os valores teóricos, foram calculados pela mesma equação, porém foi utilizada taxa de exalação teórica determinada pela equação 4.20. Os resultados para os valores medidos variaram de $(0,0062 \pm 0,0008) \%$ até $(0,65 \pm 0,05) \%$.

O comportamento dos valores teóricos e experimentais na FIG. 5.24, é menos semelhante que o comportamento dos valores teóricos e experimentais mostrados na FIG. 5.23. Este resultado indica, considerando que esta última figura é "basicamente" a primeira normalizada pela concentração de concentração de atividade de ${ }^{226} \mathrm{Ra}$, que a fração de emanação medida sofre mais influência de fatores físicos das amostras (que variam, em relação ao do teórico que é fixo) como densidade e composição química por exemplo.

Uma vez determinada a taxa de exalação superficial de radônio, (por meio de uma medida ou de um modelo teórico), de uma rocha que é utilizada como revestimento interno em residências, pode-se simular a concentração de radônio que esta rocha causa no interior desta residência, pela equação 4.19, de qualquer dimensão, conhecendo a área total revestida por esta rocha. Para este cálculo, pode-se escolher qualquer cenário (desde todo interior revestido, até apenas uma parte de uma parede por exemplo).

\footnotetext{
${ }^{6} \mathrm{Na}$ equação 4.22 a taxa de exalação é dada em Bq. $\mathrm{kg}^{-1} \cdot \mathrm{h}^{-1}$, e para este cálculo utilizamos a taxa de exalação superficial cuja unidade é em Bq.m ${ }^{-2} \cdot \mathrm{h}^{-1}$.
} 
Optou-se aqui por determinar o incremento da concentração de ${ }^{222} \mathrm{Rn}$ na sala padrão, FIG. 4.5, revestida com os granitos em todas as paredes (exceto teto e chão), os resultados para este cálculo comparando o valor medido (obtido utilizando a taxa de exalação medida na equação 4.19 e o valor teórico, utilizando a taxa de exalação teórica) são apresentados na FIG. 5.25.

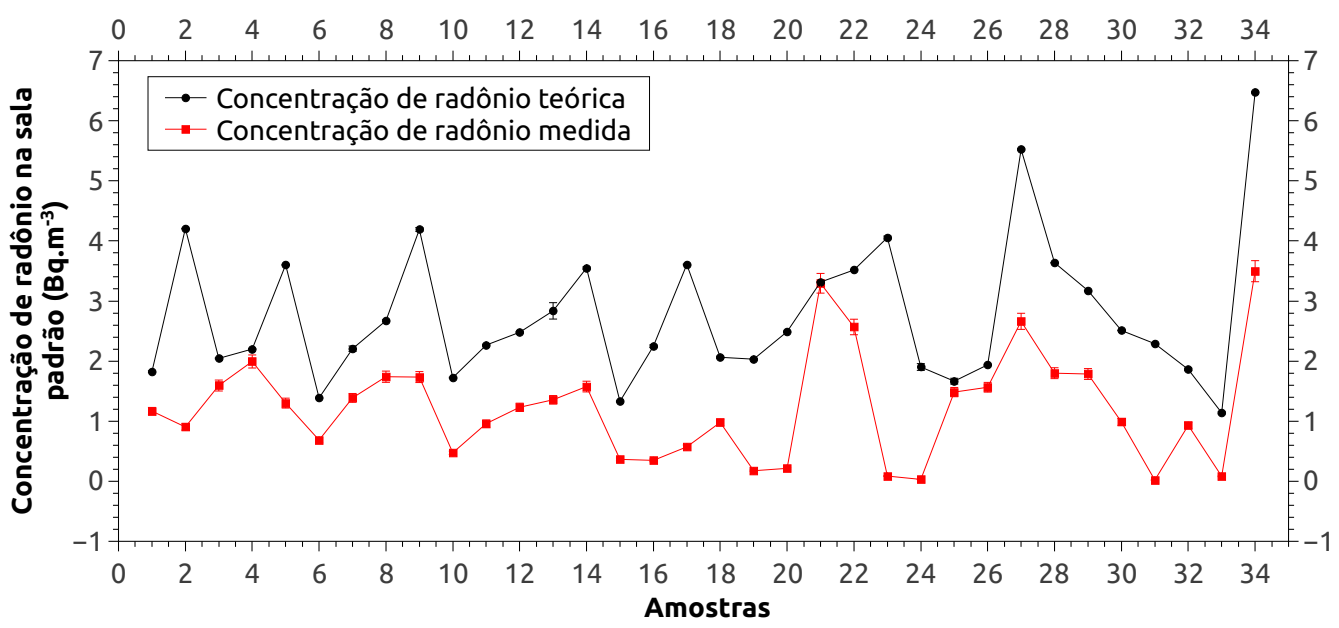

Figura 5.25: Incremento de concentração de radônio na sala padrão (valor teórico e valor medido) devido ao revestimento interno com as rochas estudadas.

Os resultados medidos variaram de $(0,02 \pm 0,002) \mathrm{Bq} \cdot \mathrm{m}^{-3}$ até $(3,5 \pm 0,2) \mathrm{Bq} \cdot \mathrm{m}^{-3}$, este é o incremento de concentração de radônio na sala padrão decorrente apenas do revestimento interno com estas amostras, considerando uma taxa de ventilação de $0,5 \mathrm{~h}^{-1}$. Estes valores ${ }^{7}$ estão abaixo do limite máximo permitido sugerido pela Comissão Européia de Proteção Radiológica (EC, 1999) que é de $200 \mathrm{~Bq} \cdot \mathrm{m}^{-3}$.

Pode-se notar que o comportamento dos valores teóricos e valores medidos é semelhante, sendo que os primeiros obtiveram valores maiores, e as possíveis causas já foram citadas no início deste item.

Em geral concentrações de radônio no ar $(O U T D O O R)$ próximo a superfície da crosta são altamente variáveis; valores reportados na literatura de concentrações de ${ }^{222} \mathrm{Rn}$ cobrem uma ampla faixa de variação a qual é influenciada principalmente pelo contexto geológico do local, típica faixa varia de 0,7 Bq.m ${ }^{-3}$ até $35 \mathrm{~Bq} \cdot \mathrm{m}^{-3}$ (Kathren, 1998). Valores mais altos de concentrações de ${ }^{222} \mathrm{Rn}$ são reportados na literatura para locais fechados, como minas e cavernas. Alberigi (2011) mediu concentrações de ${ }^{222} \mathrm{Rn}$ em cavernas brasileiras obtendo faixa de variação de $132 \mathrm{~Bq} \cdot \mathrm{m}^{-3}$ até $9456 \mathrm{~Bq} \cdot \mathrm{m}^{-3}$. Silva (2005) mediu em 170 residências da cidade de São Paulo concentrações de ${ }^{222} \mathrm{Rn}$ obtendo variação de $11 \mathrm{~Bq} \cdot \mathrm{m}^{-3}$ a $109 \mathrm{~Bq} \cdot \mathrm{m}^{-3}$. Valores típicos de concentrações de ${ }^{222} \mathrm{Rn}$ (INDOOR) em residências decorrente apenas de materiais de construçao são de

\footnotetext{
${ }^{7}$ Ressaltando que são a fração da concentração total de radônio (INDOOR) decorrente apenas das rochas de revestimento interno.
} 
10 Bq. ${ }^{-3}$ a 20 Bq.m ${ }^{-3}$ (EC, 1999).

\subsubsection{Dose efetiva anual na sala padrão devido à radiação gama e ao radônio}

Na FIG. 5.26, a seguir, é apresentado o resultado da estimativa da dose efetiva anual em uma sala padrão decorrente da exposição externa à radiação gama (conforme descrito no item 4.4 .2 pela equação 4.15$)^{8}$ e da exposição interna pela inalação do radônio (conforme descrito no item 4.6 pela equação 4.23 ).

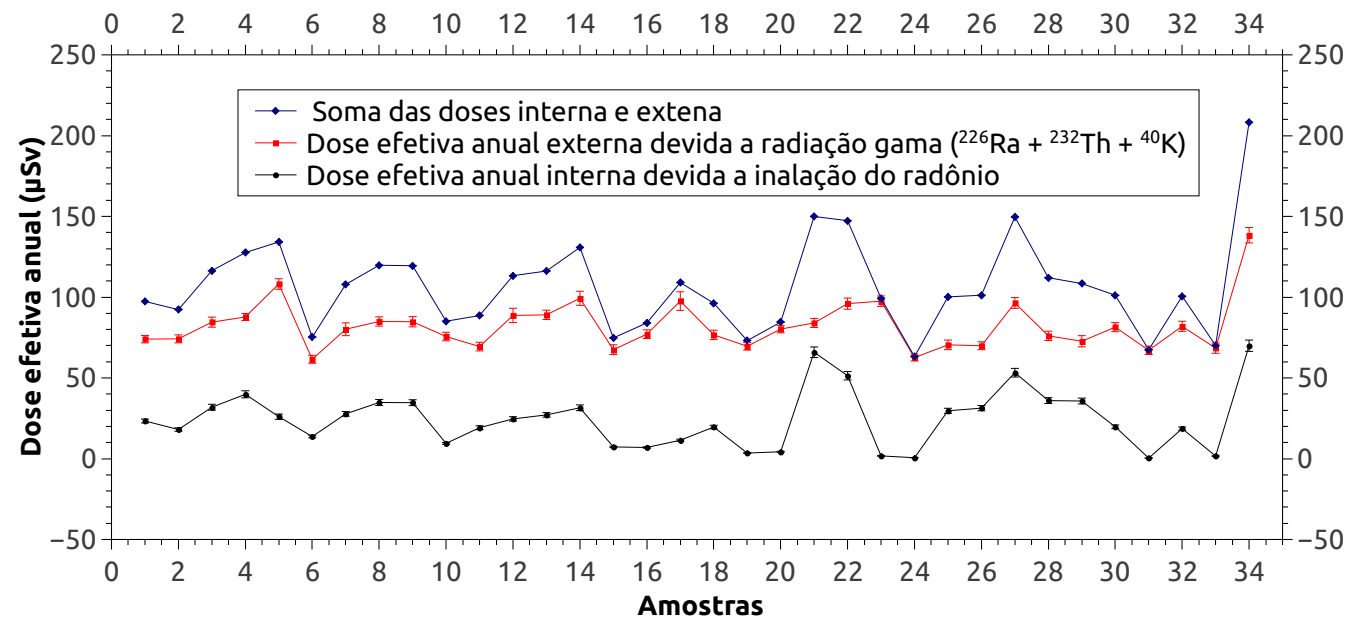

Figura 5.26: Incremento da dose efetiva anual causado pelo revestimento interno de uma sala padrão devido a radiação gama externa e a inalação do radônio.

Este resultado mostra o incremento total da dose efetiva anual em uma sala padrão, onde todas as paredes são revestidas com as rochas estudadas. Os valores estimados para a contribuição em virtude da inalação do radônio variaram de $(0,39 \pm 0,04) \mu \mathrm{Sv}^{-\mathrm{a}^{-1}}$ a $(70 \pm 4) \mu \mathrm{Sv}^{-\mathrm{a}^{-1}}$ e a contribuição em virtude da dose externa gama de $(62 \pm 3) \mu \mathrm{Sv} \cdot \mathrm{a}^{-1}$ a $(138 \pm 5) \mu \mathrm{Sv} \cdot \mathrm{a}^{-1}$.

Na FIG. 5.26, observa-se que o comportamento dos valores obtidos para a dose interna e a externa é semelhante, onde esta primeira é na média (28\%) menor que a dose externa, a soma destas duas contribuições variou de $(63 \pm 1) \mu \mathrm{Sv}$ a $(208 \pm 1) \mu \mathrm{Sv}$; estes valores estão abaixo do limite máximo permitido ao público que é de $1 \mathrm{mSv}$, lembrando que este é apenas a estimativa do incremento da dose em razão dos materiais de revestimento. Em um estudo semelhante, avaliando a contribuição de uma combinação de mármores e cerâmicas como materiais de acabamento (revestimento, em uma sala padrão) Shweikani e Raja (2009) obtiveram valores máximos de $20 \mu \mathrm{Sv}$ e $35 \mu \mathrm{Sv}$ para

\footnotetext{
${ }^{8}$ Neste cálculo foi utilizado o valor de taxa de dose específica que foi cálculada a partir das densidades específicas de cada amostra e considerando sua espessura de $2 \mathrm{~cm}$.
} 
dose interna e externa respectivamente.

A dose efetiva anual interna foi calculada para um modelo de sala com as mesmas dimensões que o modelo utilizado para calcular a dose efetiva anual externa e considerando o mesmo tempo de exposição anual $(7000$ h). Para este cálculo foram considerados uma taxa de ventilação de $0,5 \mathrm{~h}^{-1}$ na determinação da concentração de radônio na sala e um fator de equilibrio de 0,5 na determinação da dose. A dose externa foi calculada, utilizando-se a taxa de dose específica estimada para cada granito (considerando suas densidades e espessuras reais), assim, na FIG. 5.26, pode-se verificar a contribuição de cada uma dessas doses ao incremento total da dose causada pela aplicação (no cenário descrito) para cada amostra.

\subsection{Análise dos principais elementos componentes por fluorescência de raios $\mathrm{X}$}

Por meio da técnica de fluorescência de raios $\mathrm{X}$, foi realizada um análise semiquantitativa, conforme descrito no item 4.7, em $30 \operatorname{amostras}^{9}$, com o objetivo de avaliar as concentrações relativas dos óxidos principais de cada amostra. Os 14 óxidos principais mais frequentes nas amostras foram $\mathrm{SiO}_{2}, \mathrm{Al}_{2} \mathrm{O}_{3}, \mathrm{Na}_{2} \mathrm{O}, \mathrm{K}_{2} \mathrm{O}, \mathrm{Fe}_{2} \mathrm{O}_{3}$, $\mathrm{CaO}, \mathrm{MgO}, \mathrm{TiO}_{3}, \mathrm{P}_{2} \mathrm{O}_{5}, \mathrm{MnO}, \mathrm{NiO}, \mathrm{ZnO}, \mathrm{Rb}_{2} \mathrm{O}$ e $\mathrm{SO}_{3}$.

Para avaliar a similaridade destas 30 amostras em termos destes óxidos quantificados, foi realizada uma análise de agrupamento (clusters), utilizando o software Statistica9 (Statistica9, 2009). Para esta análise é fornecida uma matriz onde as linhas (casos) são as amostras e as colunas (variáveis) são as concentrações relativas dos óxidos principais componentes determinados por XRF, o resultado é apresentado na FIG. 5.27.

Este resultado mostra que, quanto à composição, estas amostras são divididas em três grupos (considerando a distância de separação, eixo das ordenadas na FIG. 5.27 , de $80 \%)^{10}$ por "grau" de semelhança da direita para a esquerda G1, G2 e G3. O grupo 1, que compreende 17 amostras (56,6\% do total analisado) é subdivido em dois subgrupos menores (G1,1 e G1,2), separados por uma distância de $30 \%$ e com 10 e 7 amostras, respectivamente. O G2 compreende 10 amostras (33,3\% do total) e está separado do G1 por uma distância de $84 \%$, é constituído por dois subgrupos G2, 1 e G2, 2 com 4 e 6 amostras, respectivamente, e separados por uma distância de $20 \%$. O G3 é constituído por 3 amostras (10\% do total) e está separado do G1 por uma distância de $70 \%$ e do G2 por $16 \%$, assim, pode-se considerar que ele está mais

\footnotetext{
${ }^{9}$ Este estudo foi realizado em apenas 30 das 37 amostras distintas por problemas operacionais

${ }^{10}$ Fazendo-se um "corte" na altura de $80 \%$ no eixo das ordenadas, obtém-se três ramos do agrupamento.
} 
5.3 - Análise dos principais elementos componentes por fluorescência de raios X94

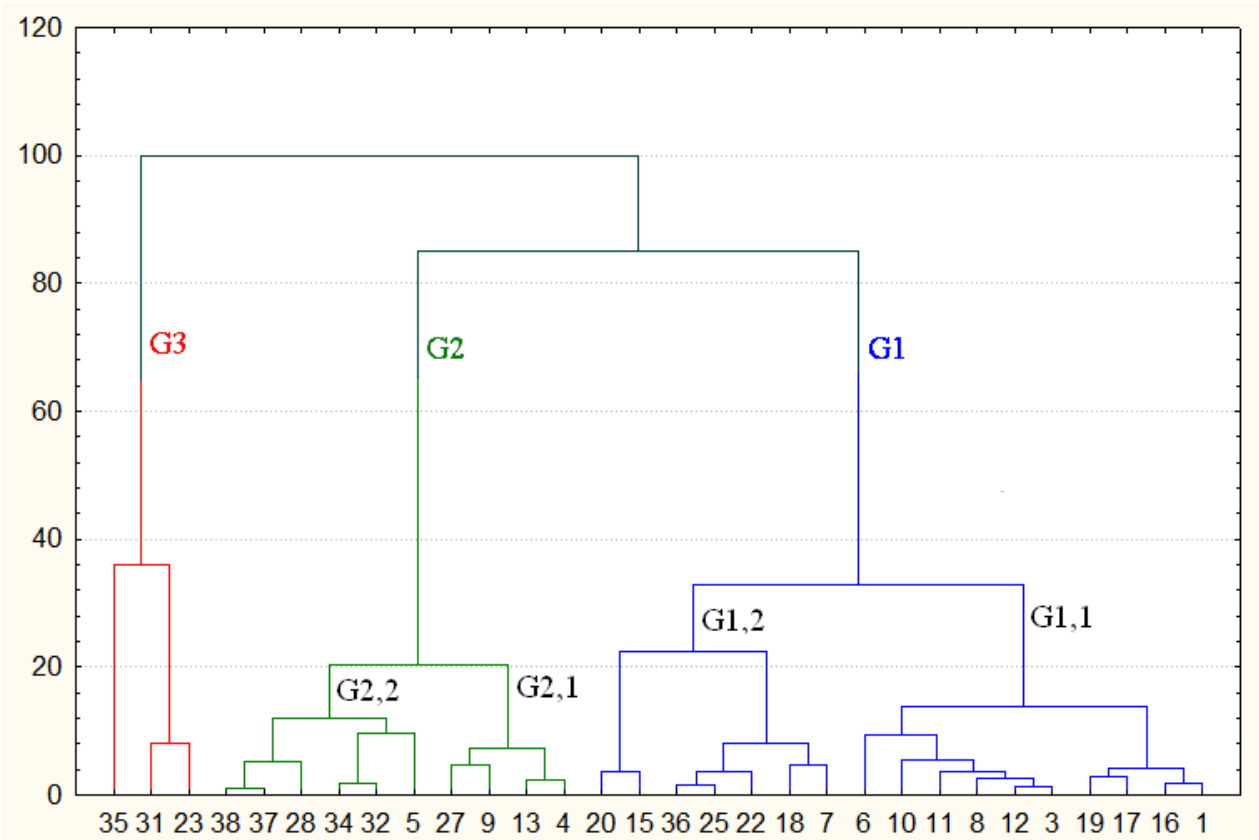

Figura 5.27: Análise por agrupamento dos óxidos principais constituintes das amostras de rochas estudadas.

próximo do G2 que do G1.

O objetivo desta análise é verificar se estes grupos tem correlação com a concentração de ${ }^{226} \mathrm{Ra}$, com a taxa de exalação de radônio ${ }^{222} \mathrm{Rn}$, com os índices físicos e com a fração de emanação, discussões estas que são retomadas no item 5.5.

Na FIG. 5.28, a seguir, são plotados em pizza, em termos do teor composicional, 4 amostras, extremos dos agrupamentos descritos anteriormente. 
Teor composicional das amostras
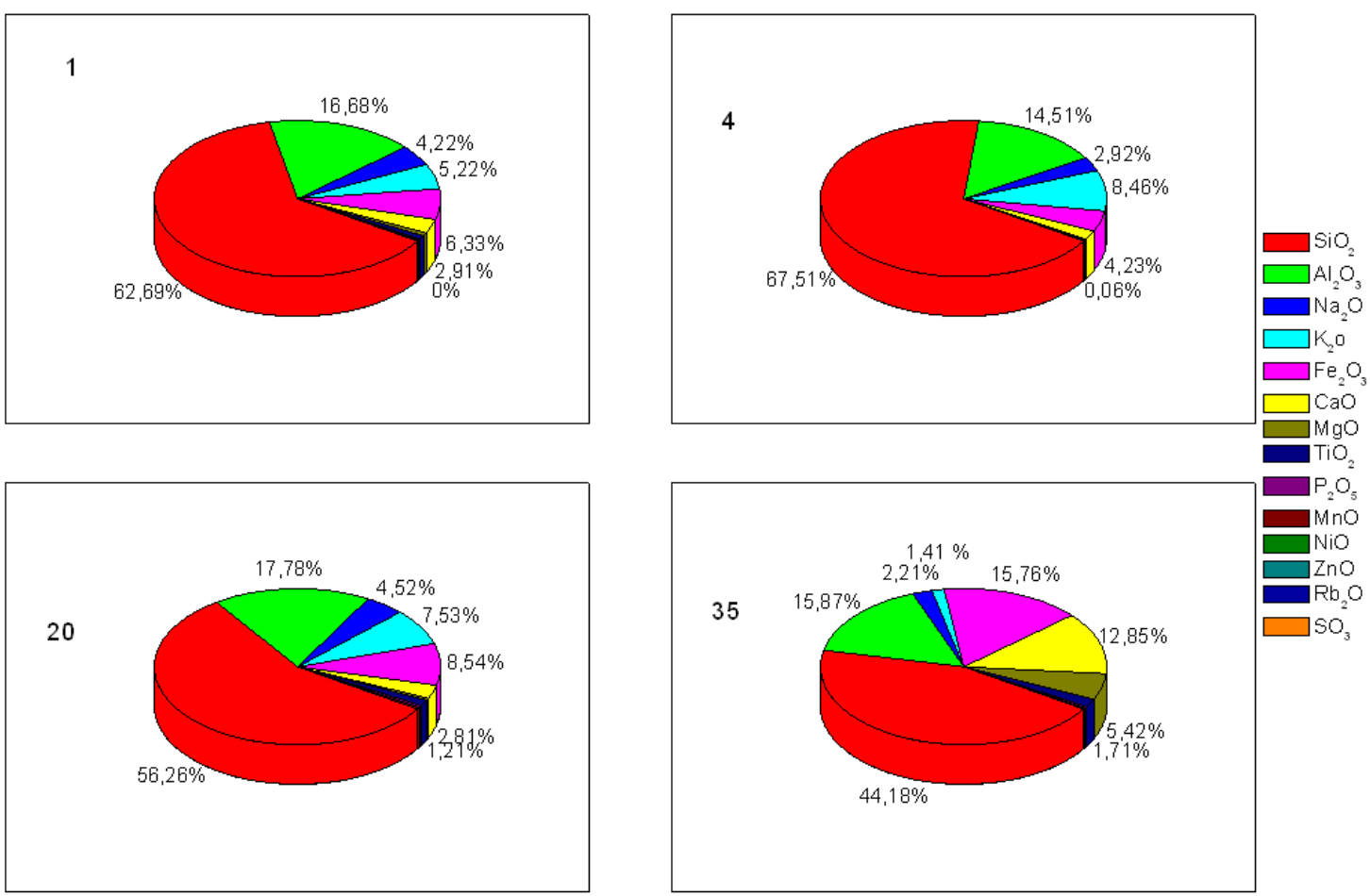

Figura 5.28: Teor em (\%) de óxidos nas amostras 1, 4, 20 e 35 extremos do dendograma.

A amostra 1 e 35 fazem parte dos extremos de todo o agrupamento e as amostras 4 e 20 são extremos entre os dois grupos (G1 e G2) e estão aproximadamente no centro do agrupamento todo. Nesta figura (FIG. 5.28) pode-se observar que a principal diferença em termos de concentração de óxido é devido ao óxido de silício $\mathrm{SiO}_{2}$, cuja concentração nas amostras extremas do dendograma é de aproximadamente 19 \%, as variações para os demais óxidos são menores. 


\subsection{Propriedades físicas}

Os resultados obtidos para os valores de densidade aparente e porosidade aparente, conforme descrito no item 4.8, são apresentados nas FIG. 5.29 e 5.30 a seguir.

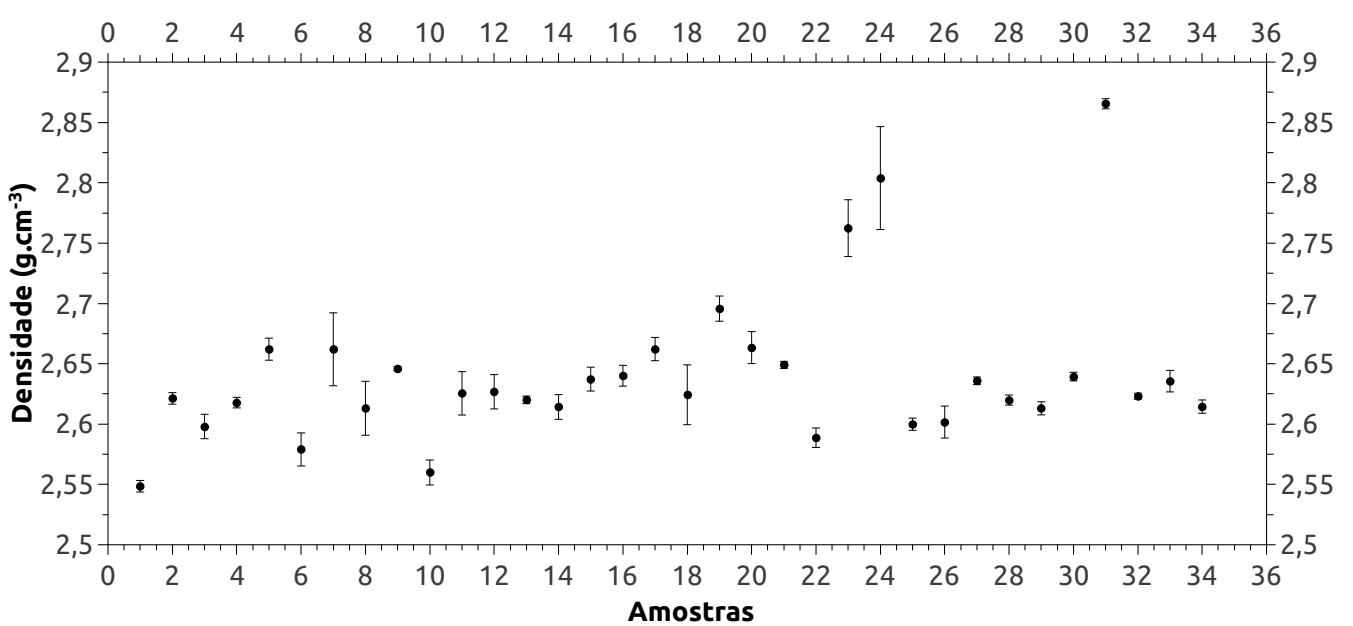

Figura 5.29: Densidade aparente das amostras medidas conforme norma ABNT (2010).

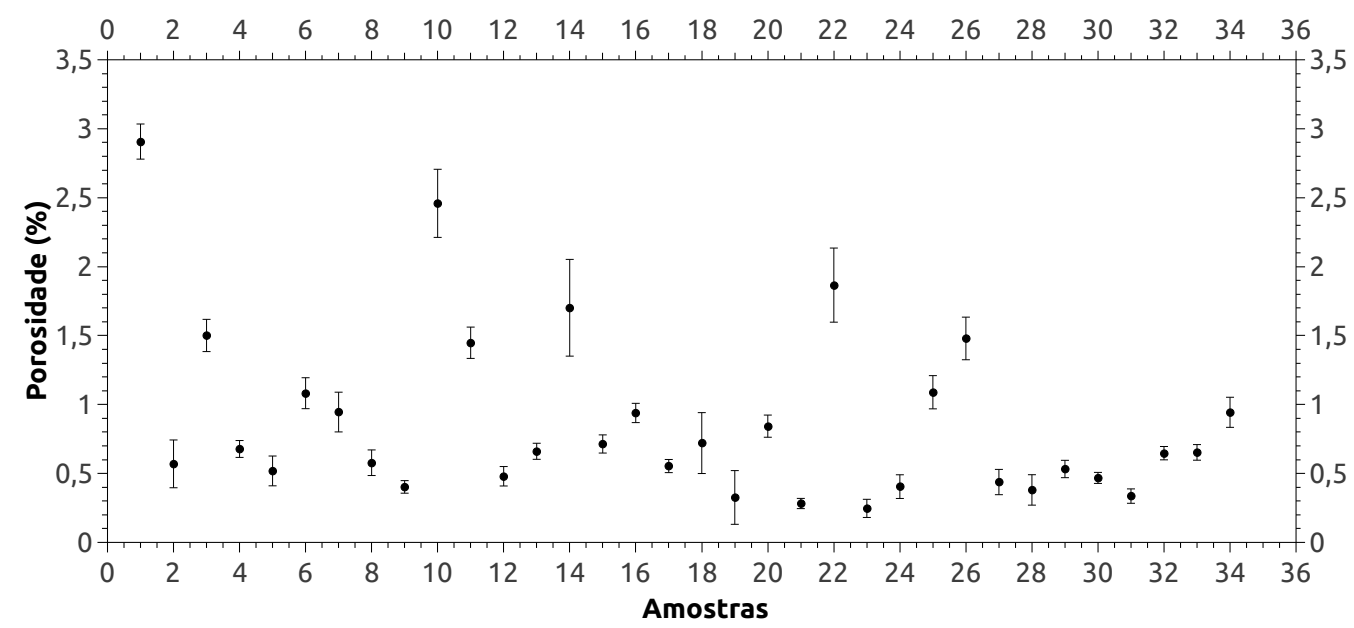

Figura 5.30: Porosidade aparente das amostras medidas conforme norma ABNT (2010).

Estes resultados mostram que as densidades das amostras variam de $(2,548 \pm 0,005)$ g.cm ${ }^{-3}$ até $(2,865 \pm 0,004)$ g.cm ${ }^{-3}$, valores esperados uma vez que a densidade de rochas é uma média ponderada pelas concentrações dos minerais constituintes e as rochas ígneas estudadas apresentam concentrações em torno de $60 \%$ de $\mathrm{SiO}_{2}$ (quartzo), cuja densidade é $2,65 \mathrm{~g} \cdot \mathrm{cm}^{-3}$. As porosidades medidas variam de $(0,25 \pm 0,07) \%$ até $(2,9 \pm 0,1) \%$, faixa de variação semelhante à obtida por (Marocchi et al., 2011) que determinou a porosidate total com porosímetro de mercúrio para amostras de granitos, gabros, sianitos, riolitos e gnaisses, entre outras, obtendo 
faixa de variação para estes de $0,2 \%$ até 1,9\%.

\subsection{Correlações entre ${ }^{226} \mathrm{Ra},{ }^{222} \mathrm{Rn}$, principais óxidos componentes e propriedades físicas}

\subsubsection{Radônio vs (Rádio, Tório e Potássio)}

Determinadas a concentração de ${ }^{226} \mathrm{Ra}$, a concentração de radônio, a taxa de exalação superficial e por massa, o objetivo deste tópico é estudar possíveis correlações entre estes parâmetros para as amostras. Os resultados são mostrados nas FIG. 5.31, 5.32 e 5.33 a seguir,

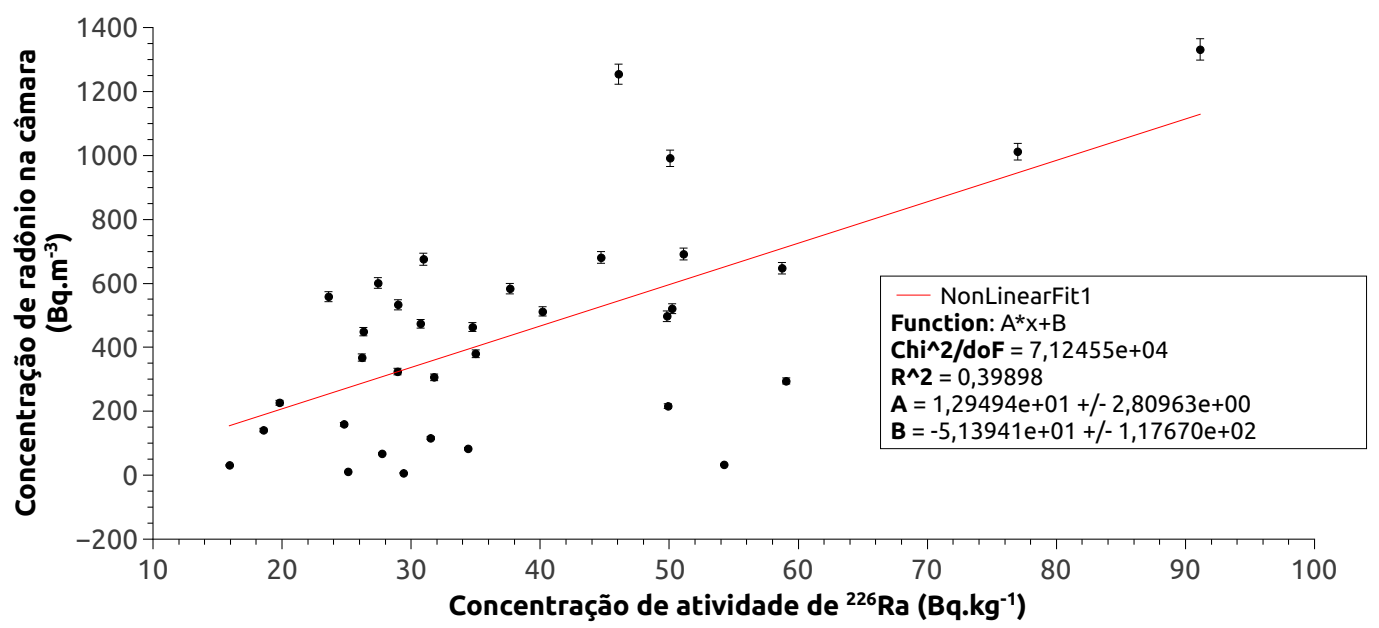

Figura 5.31: Concentração de ${ }^{222} \mathrm{Rn}$ na câmara em função da concentração de atividade do ${ }^{226} \mathrm{Ra}$ nas amostras de rocha estudadas. 


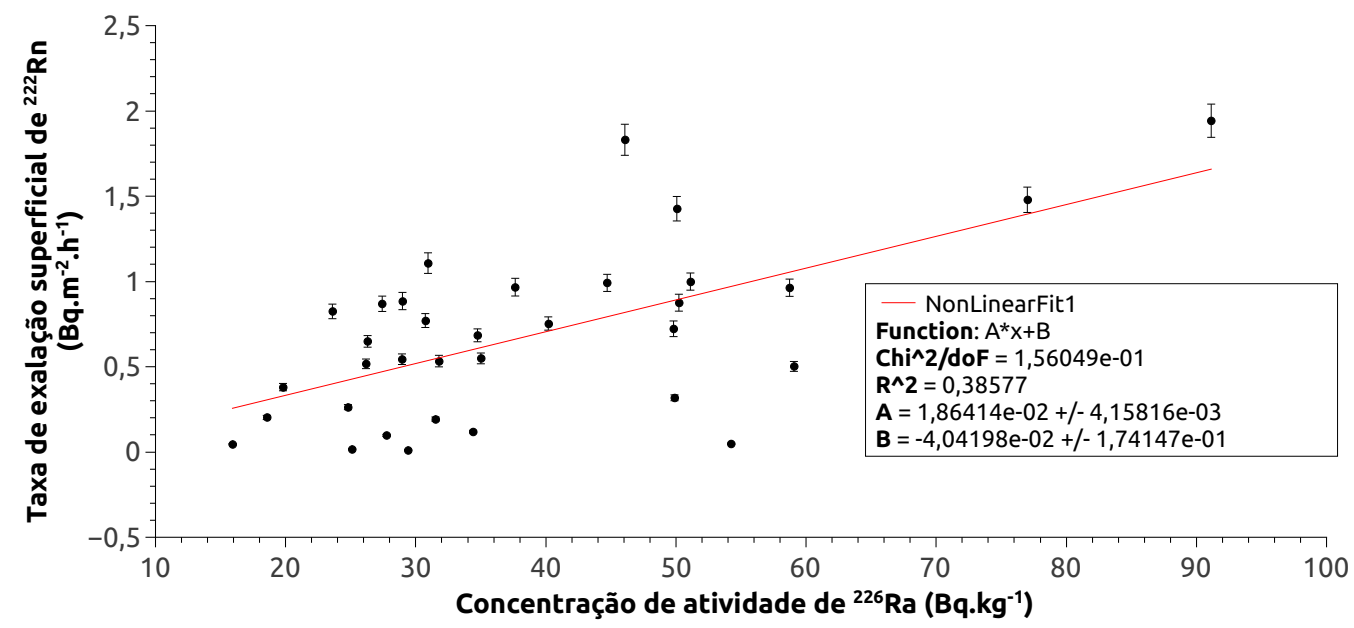

Figura 5.32: Taxa de exalação superficial de ${ }^{222} \mathrm{Rn}$ em função da concentração de atividade do ${ }^{226}$ Ra nas amostras de rochas estudadas.

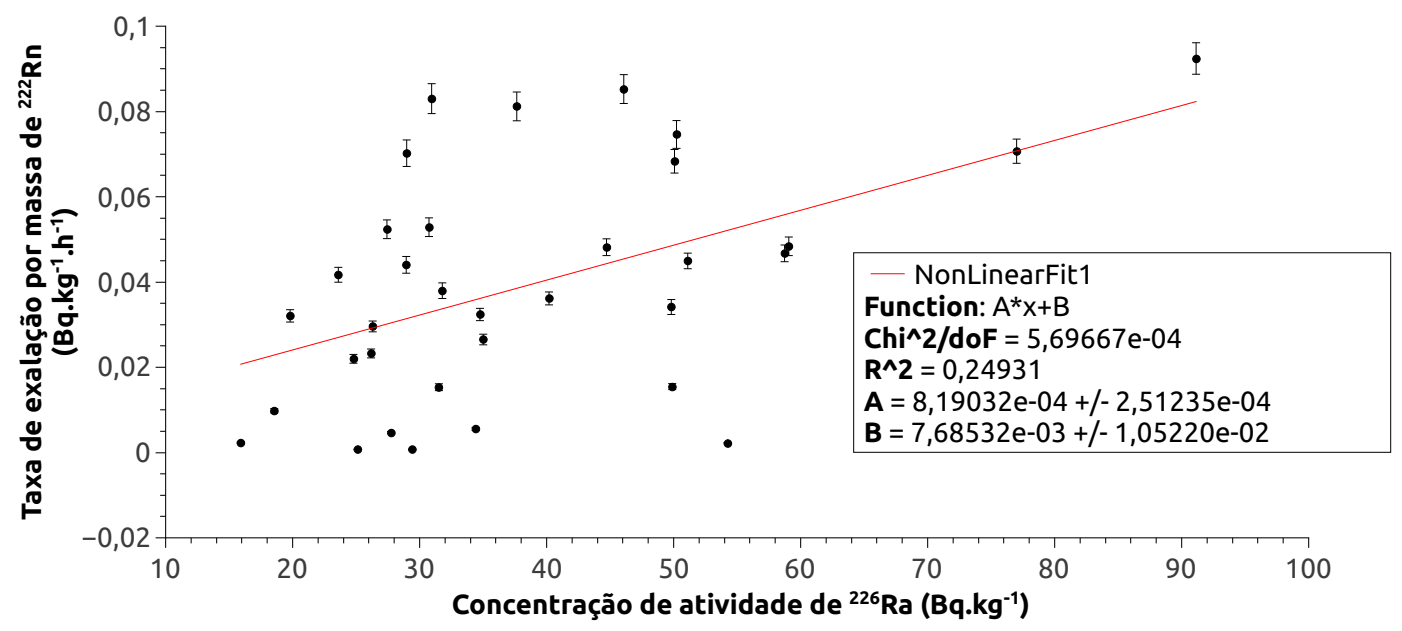

Figura 5.33: Taxa de exalação por massa de ${ }^{222} \mathrm{Rn}$ em função da concentração de atividade do ${ }^{226} \mathrm{Ra}$ nas amostras de rochas estudadas.

Estes resultados mostram que as correlações (Concentração de ${ }^{222} \mathrm{Rn}$ vs. concentração de atividade de ${ }^{226} \mathrm{Ra}, \mathrm{R}^{2}=0,40$ ), FIG. 5.31 e a (Taxa de Exalação superficial de ${ }^{222} \mathrm{Rn}$ vs. concentração de atividade de ${ }^{226} \mathrm{Ra}, \mathrm{R}^{2}=0,39$ ), FIG. 5.32, têm valores muito próximos, um resultado razoável, uma vez que a taxa de exalação superficial é basicamente derivada da concentração normalizada pela área da amostra. A correlação (Taxa de Exalação por massa de ${ }^{222} \mathrm{Rn}$ vs. concentração de atividade de $\left.{ }^{226} \mathrm{Ra}, \mathrm{R}^{2}=0,25\right)$, FIG. 5.33 tem um valor menor mostrando que a influência da área é mais importante que da massa da amostra na taxa de exalação do radônio.

Esta baixa correlação entre concentração de atividade de ${ }^{226} \mathrm{Ra}$ e taxa de exalação superficial de ${ }^{222} \mathrm{Rn}$, é consequência dos baixos valores percentuais medidos 
para fração de emanação destas amostras, cujos resultados foram apresentados no item 5.2.1. Em termos gerais, estes resultados mostram que há outros fatores que influenciam a emanação de radônio e consequentemente a taxa de exalação.

As FIG. 5.34 e 5.35 apresentam a taxa de exalação de radônio em função das concentrações de atividade de ${ }^{232} \mathrm{Th}$ e ${ }^{40} \mathrm{~K}$.

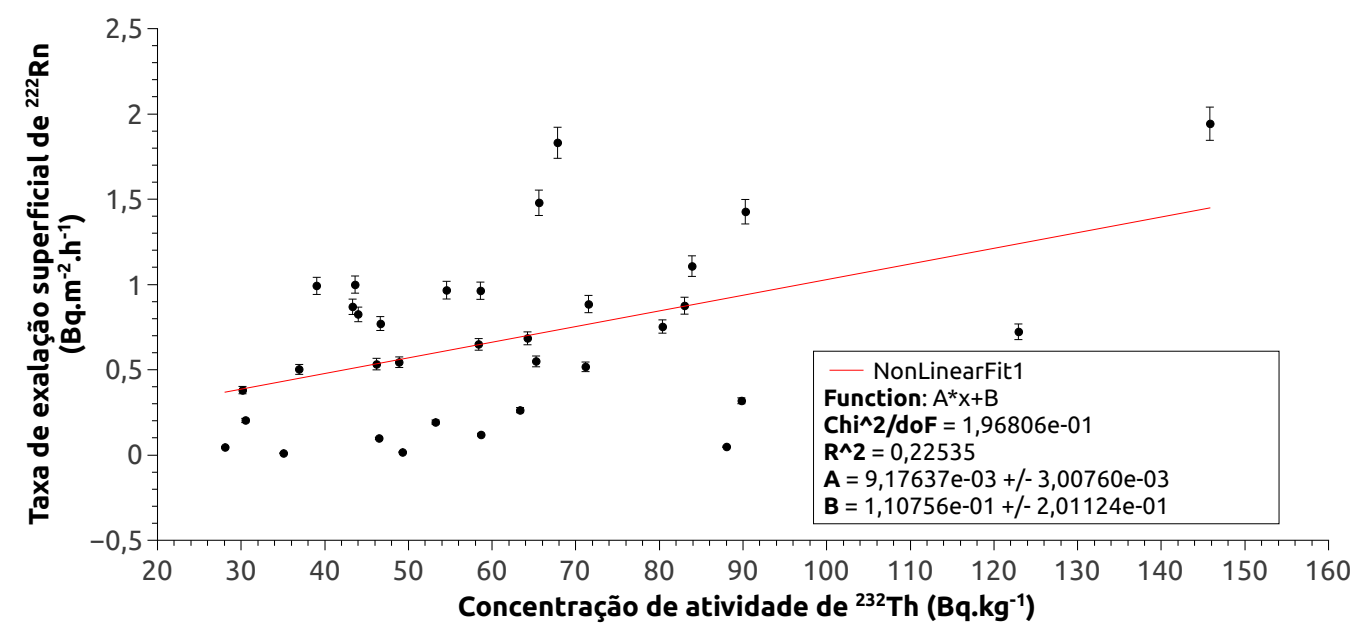

Figura 5.34: Taxa de exalação superficial de ${ }^{222} \mathrm{Rn}$ em função da concentração de atividade de ${ }^{232} \mathrm{Th}$ nas amostras de rochas estudadas.

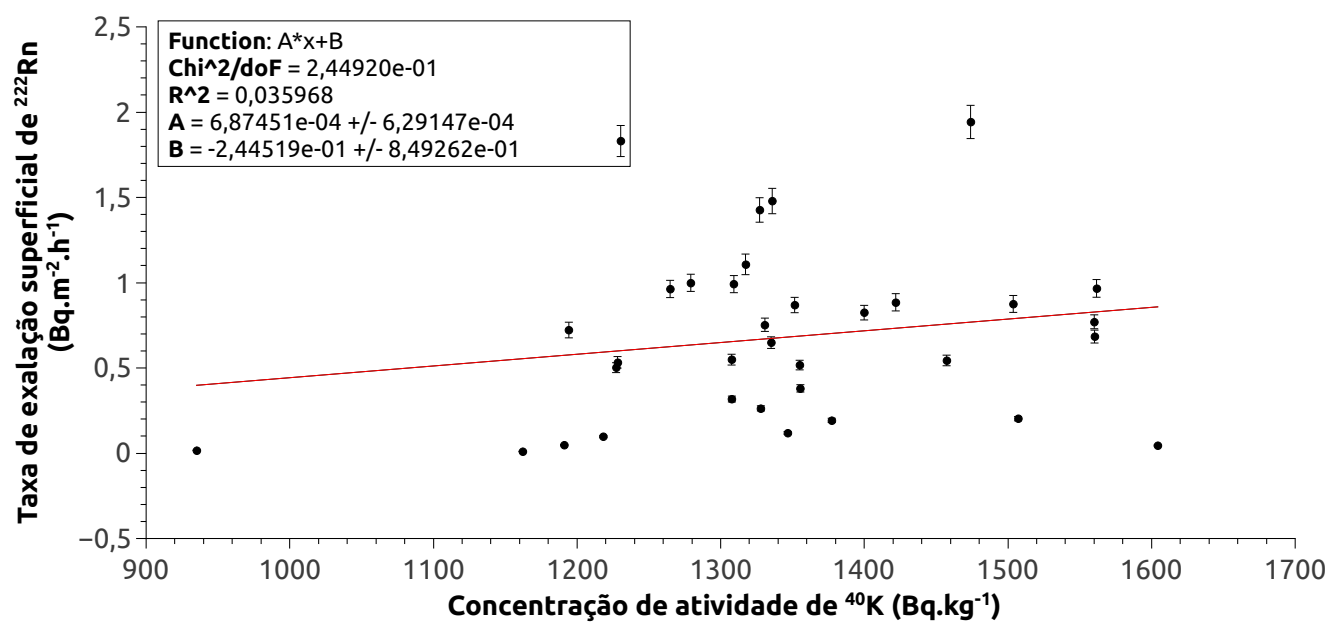

Figura 5.35: Taxa de exalação superficial de ${ }^{222} \mathrm{Rn}$ em função da concentração de atividade de ${ }^{40} \mathrm{~K}$ nas amostras de rochas estudadas. 
A correlação com o potássio, FIG. $5.35\left(\mathrm{R}^{2}=0,04\right)$, é muito baixa, resultado esperado uma vez que potássio não gera isótopos de radônio e não esta associado a nenhum mineral que o contenha ou que influencie a sua taxa de exalação nas amostras. Já a correlação do radônio com o tório é mais significativa FIG. 5.34, $\left(\mathrm{R}^{2}=0,22\right)$, pois, este tem um boa correlação com o rádio nas amostras analisadas, como mostra a FIG. 5.36,

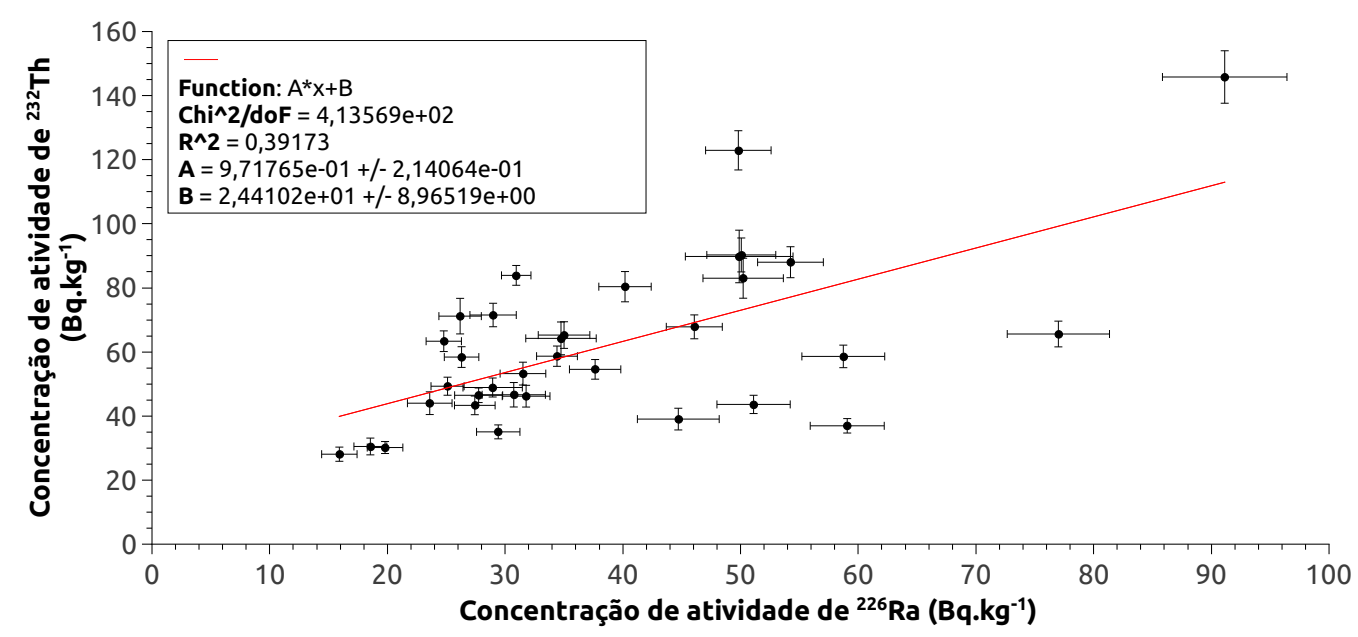

Figura 5.36: Concentração de atividade de ${ }^{232} \mathrm{Th}$ em função da concentração de atividade do ${ }^{226} \mathrm{Ra}$ nas amostras de rochas estudadas.

\subsubsection{Correlações entre Rádio e Radônio normalizadas pelas propriedades físicas}

Para verificar a influência das propriedades físicas (densidade aparente e porosidade aparente) nas correlações entre concentração de atividade de rádio e taxa de exalação de radônio, foram realizadas as correlações apresentadas nas figuras a seguir. 


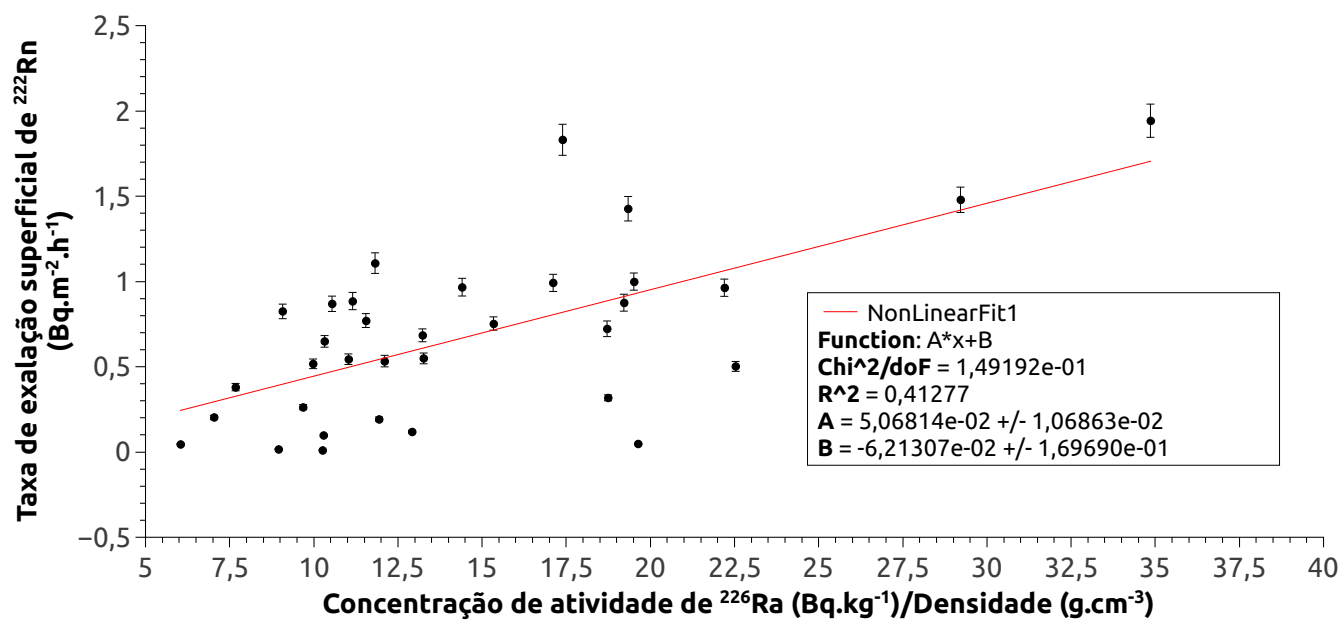

Figura 5.37: Taxa de exalação superficial de ${ }^{222} \mathrm{Rn}$ em função da razão (concentração de atividade de ${ }^{226} \mathrm{Ra} /$ densidade).

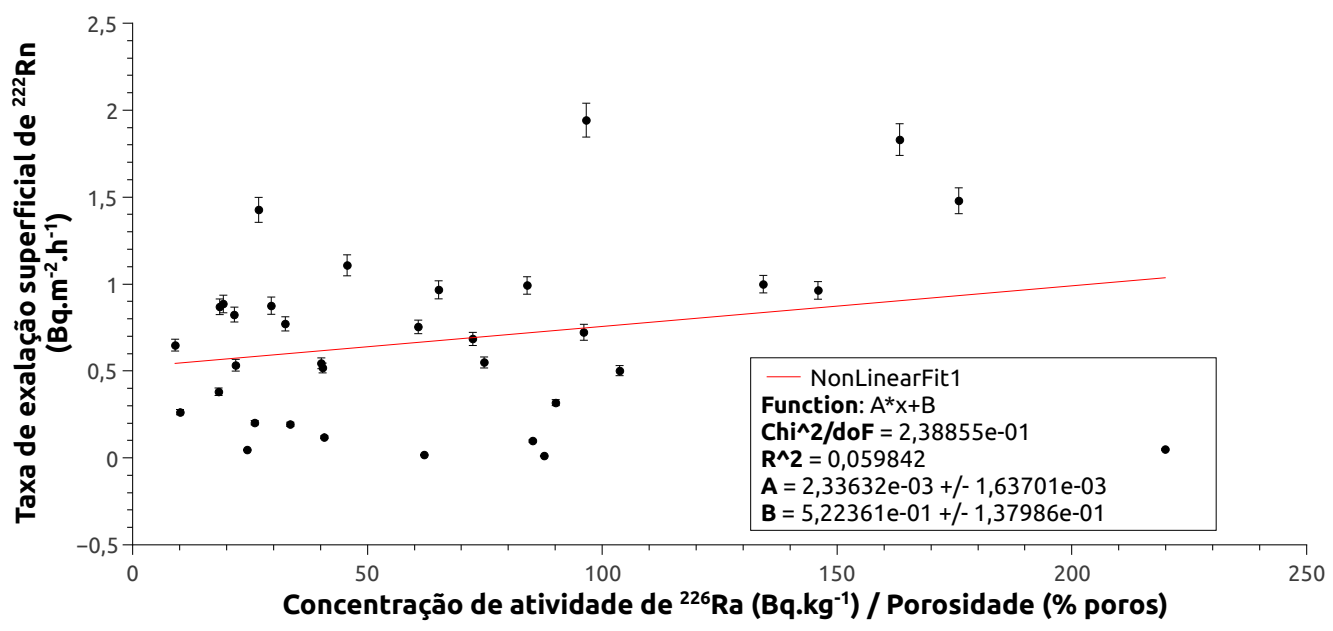

Figura 5.38: Taxa de exalação superficial de ${ }^{222} \mathrm{Rn}$ em função da razão (concentração de atividade de ${ }^{226} \mathrm{Ra} /$ porosidade). 
5.5 - Correlações entre ${ }^{226} R a,{ }^{222} R n$, principais óxidos componentes e propriedades físicas 102

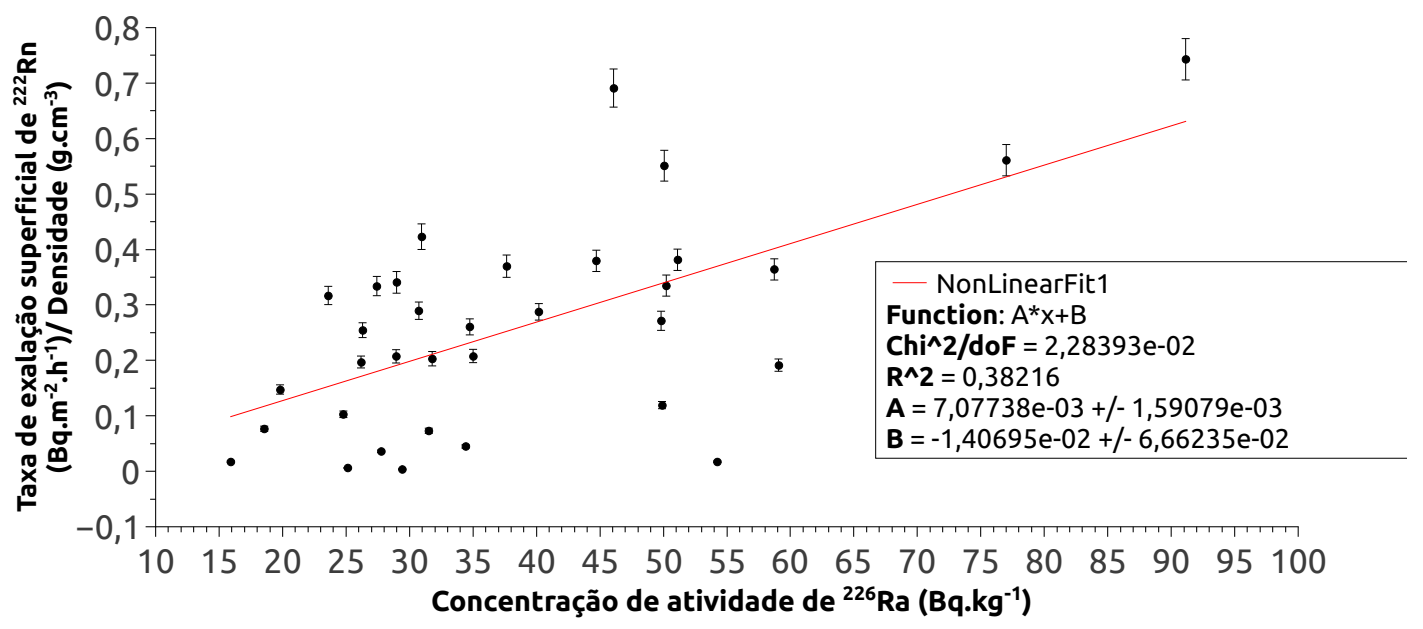

Figura 5.39: Razão (Taxa de exalação superficial de ${ }^{222} \mathrm{Rn} /$ Densidade) em função da concentração de atividade de ${ }^{226} \mathrm{Ra}$.

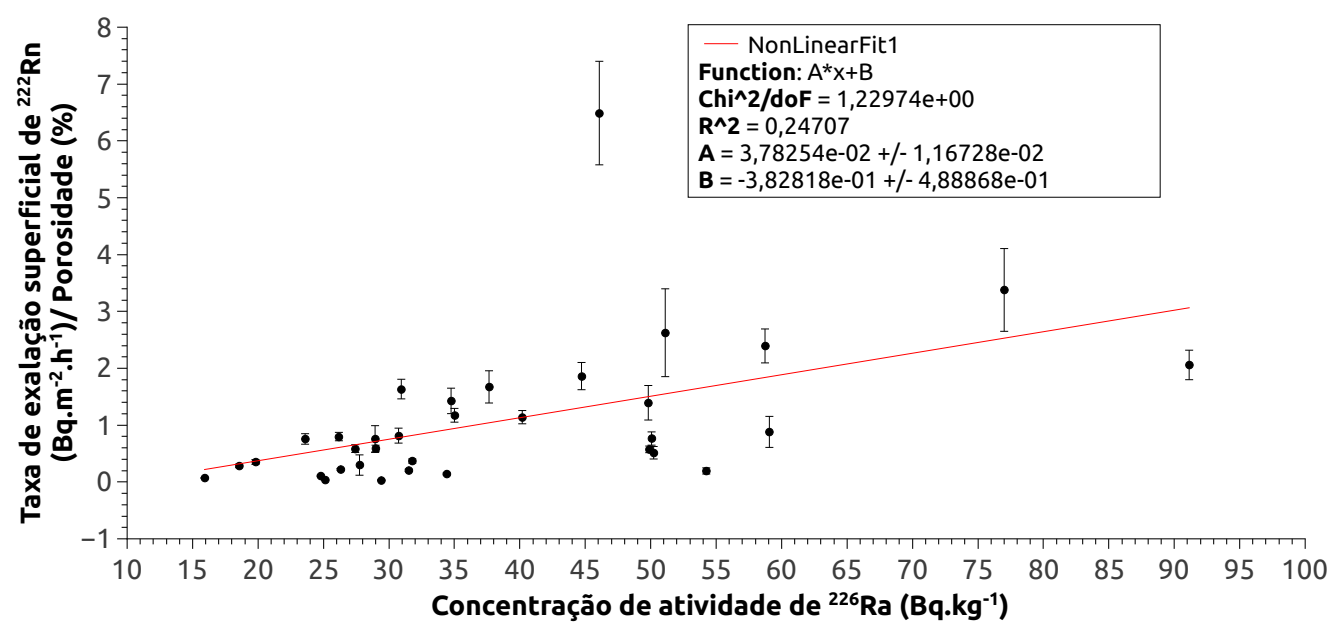

Figura 5.40: Razão (Taxa de exalação superficial de ${ }^{222} \mathrm{Rn} /$ Porosidade) em função da concentração de atividade de ${ }^{226}$ Ra.

As correlações, FIG. 5.37, 5.38, 5.39 e 5.40 mostram que a taxa de exalação normalizada pela densidade, FIG. 5.37, obtêm uma correlação com a concentração de atividade de ${ }^{226} \mathrm{Ra}$ de $\mathrm{R}^{2}=0,41$, que é maior que o valor $\mathrm{R}^{2}=0,06$ obtido com a normalização pela porosidade FIG. 5.38, indicando que, para estas amostras, o parâmetro densidade é mais importante em termos de influência na taxa de exalação do que a porosidade. Chega-se a uma conclusão semelhante, comparando-se os valores obtidos nas FIG. $5.39 \mathrm{R}^{2}=0,38$ e $5.40 \mathrm{R}^{2}=0,25$ com o resultado mostrado na FIG. $5.32 \mathrm{R}^{2}=0,38$. 


\section{CAPÍTUlo}

\section{CONCLUSÕES}

Os valores medidos para as atividades do ${ }^{226} \mathrm{Ra},{ }^{232} \mathrm{Th}$ e ${ }^{40} \mathrm{~K}$ determinadas para as amostras estão na mesma faixa de variação de resultados determinados para amostras geológicas semelhantes, estudadas em outras regiões no Brasil e também no exterior.

Os valores determinados para os três índices físicos $\mathrm{Ra}_{e q}, \mathrm{H}_{E X}$ e $\mathrm{I}_{\gamma}$ estão abaixo dos limites estabelecidos, de acordo com a aplicação, com algumas exceções (para determinado tipo de aplicação) que não inviabilizam a utilização das respectivas, apenas, tornam necessário fazer uma avaliação mais específica da forma e quantidade da aplicação destes materiais na construção.

Esta avaliação foi realizada por meio do cálculo para o incremento da dose efetiva anual externa e interna (decorrente da aplicação das amostras estudadas como revestimento interno em todas as paredes de uma sala modelo com dimensões $4 \mathrm{~m}$ x $5 \mathrm{~m}$ x 2, $8 \mathrm{~m}$ considerando tempo de exposição anual de $7000 \mathrm{~h}$ ), cujos resultados mesmo somados atingiram no máximo $20 \%$ de limite aceito de dose ao público, que é de $1 \mathrm{mSv} \cdot \mathrm{a}^{-1}$, para todas as amostras estudadas.

Conclui-se, portanto, que todas as rochas estudadas não apresentam riscos radiológicos ao público, considerando os cenários que foram descritos neste trabalho. Contudo como que estes cenários foram definidos supondo condições (revestimento interno em todas as paredes e tempo anual) que podem não refletir uma aplicação real, estes modelos de forma geral, em comparação com situações práticas, podem gerar valores superestimados indo em direção a segurança radiológica.

Comparando-se os valores obtidos para o incremento a dose efetiva anual decorrente da aplicação da rochas estudadas como revestimento superficial interno da sala modelo, verificou-se que a contribuição devido a radiação gama externa é, para a maioria das amostras, maior que a contribuição devido a inalação do radônio. Como a dose efetiva anual (interna) foi calculdada a partir da medida da taxa de exalação de radônio este resultado indica que propriedades petrofísicas das amostras influenciam a taxa de exalação do radônio e consequentemente a concentração deste no interior da sala.

Das propriedades físicas determinadas, a densidade tem influência mais importante na taxa de exalação de radônio nas amostras estudadas, pois, a porosidade apresentou valores baixos. A influência da densidade deve estar relacionada ao alcance 
do átomo de recúo de radônio, que, uma vez atingindo os poros ou fissuras (com valores baixos e variação pequena nas amostras estudadas) está livre para se difundir.

Os resultados obtidos para a concentração de radônio na câmara selada e, consequentemente, as grandezas derivadas desta determinação, taxa de exalação superficial, taxa de exalação por massa e fração de emanação obtiveram boa correlação comparadas com valores teóricos e faixa de variação semelhante àquela obtida para rochas similares na literatura, mostrando que a técnica utilizada para estas medidas é robusta.

\subsection{Sugestões para trabalhos futuros}

A partir das conclusões deste trabalho, ficam aqui algumas sugestões para trabalhos futuros em termos da correlação entre concentração de atividade de ${ }^{226} \mathrm{Ra}$ e taxa de exalação de ${ }^{222} \mathrm{Rn}$ :

Para verificar a influência da porosidade na taxa de exalação de radônio, realização um estudo com materiais geológicos de ampla faixa de variação de porosidade, e/ou microporosidade e conectividade entre poros, por microtomografia;

Caracterização mineralógica de uma ou algumas amostras geológicas para posterior estudo da influência na fração de emanação de radônio destas amostras decorrente da concencentração destes minerais;

Comparação entre contribuições a dose externa e interna decorrente de todos os materiais de uma construção. 


\section{REFERÊNCIAS BIBLIOGRÁFICAS}

ABNT. ABNT NBR 15845:2010 Rochas para Revestimento-Métodos de ensaio, (2010).

ADAMS, J. A. S. Nuclear Geology: Cap. 2.2: Uranium and Thorium: Uranium and Thorium contents of Vulcanic Rocks, pages 89 - 98. John Wiley \& Sons, Inc. (1957).

ALBERIGI, S. Avaliação da exposição ao Rn-222 nas cavernas do Parque Estadual Turístico do Alto Ribeira (Petar). Disssertação (Mestrado), Instituto de Pesquisas Energéticas e Nucleares Autarquia associada à Universidade de São Paulo, (2006).

ALBERIGI, S. Sobre a influência de fatores ambientais nos níveis de radônio em cavernas dos parques estaduais do vale do Ribeira, SP e avaliação do equilíbrio radioativo e fator de equílibrio entre radônio e seus descendentes. Tese (Doutorado), Instituto de Pesquisas Energéticas e Nucleares Autarquia associada à Universidade de São Paulo, (2011).

AMARAL, P., GALEMBECK, T., BONOTTO, D., ARTUR, A. Uranium distribution and radon exhalation from brazilian dimension stones. Applied Radiation and Isotopes, 70(4):808 - 817, (2012).

Anjos, R., VEIGA, R., SOARES, T., SANTOS, A., AGUIAR, J., FRASCÁC, M., BRAGE, J., UZÊDA, D., MANGIA, L., FACURE, A., MOSQUERA, B., CARVAlHO, C., GOMES, P. Natural radionuclide distribution in brazilian commercial granites. Radiation Measurements, 39(3):245 - 253, (2005).

Anjos, R., AYUB, J. J., CID, A., CARDOSO, R., LACERDA, T. External gamma-ray dose rate and radon concentration in indoor environments covered with brazilian granites. Journal of Environmental Radioactivity, 102(11):1055 1061, (2011).

BARROS NETO, B., SCARMINIO, I. S., BRUNS, R. E. Como fazer experimentos: Pesquisa e desenvolvimento na ciência e na indústria. Editora da Unicamp, Campinas, (2001).

BARTON, T. P. e ZIEMER, P. L. The effects of particle size and moisture content on the emanation of rn from coal ash. Health Physics, 50:581-588, (1986).

BASTOS, R. O. Radioatividade de rochas provenientes das formações geológicas pertencentes à bacia hidrográfica do rio Tibagi. Tese (Doutorado) Departamento de Física, Universidade Estadual de Londrina, Londrina, (2008). 
BASTOS, R. O. e APPOLONI, C. R. Radioactivity of rocks from the geological formations belonging to the Tibagi river hydrographic basin. In International Nuclear Atlantic Conference - INAC 2009 Rio de Janeiro, RJ, Brazil, September 27 to October 2, ISBN: 978-85-99141-03-8, (2009).

BAYKARA, O., DOGRU, M., INCEOZ, M., AKSOY, E. Measurements of radon emanation from soil samples in triple-junction of north and east anatolian active faults systems in Turkey. Radiation Measurements, 39(2):209 - 212, (2005).

BERETKA, J. e MATHEW, P. J. Natural radioactivity of australian building materials, industrial wastes and by-products. Health Physics, 48(1):87-95, (1985).

BURKE, A. K. M. J. Estudo da emanação de Rn-222 em amostras de concreto com composições diferentes. Dissertação (Mestrado) Faculdade de engenharia civil, UNICAMP, Campinas, (2002).

CAMPOS, M. P. e PECEQUILO, B. R. S. Exposure assessment due to building materials in ordinary houses at São Paulo, Brazil. Research and Development Brazilian Journal, 5(2):60-65, (2003).

COSTA, L. J. P. Estudo da exalação de radônio em placas e tijolos de fosfogesso de diferentes procedências. Dissertação (Mestrado), Instituto de Pesquisas Energéticas e Nucleares Autarquia associada à Universidade de São Paulo. (2011).

CUTSHAll, N. H., LARSEN, I. L., OLSEN, C. R. Direct analysis of Pb-210 in sediment samples, self-absorption corrections. Nuclear Instruments and Methods in Physics Research, 206:309 - 312, (1983).

DNPM/MINEROPAR Plano diretor de mineração para região metropolitana de Curitiba 2004, Disponível em: $<$ http://www.mineropar.pr.gov.br/modules/conteudo $>$ Acesso em: Julho de 2010 .

EC Radiological protection principles concerning the natural radioactivity of building materials, radiation protection report RP-112. Technical report, European Commission. Radiation Protection Unit, Luxembourg, (1999).

EISENBUD, M. Environmental Radioactivity. Academic Press, Orlando, 2nd edition, (1987).

EL-ARABI, A. Ra-226, Th-232 and K-40 concentrations in igneous rocks from eastern desert, Egypt and its radiological implications. Radiation Measurements, 42(1):94 - 100, (2007).

EL-DINE, N. W. Study of natural radioactivity and the state of radioactive disequilibrium in U-series for rock samples, north eastern desert, Egypt. Applied Radiation and Isotopes, 66(1):80 - 85, (2008). 
EVANS, R. D. The Atomic Nucleus. New Delhi: TATA MCGRAW HILL, (1979).

FAHEEM, M., MATIULLAH, MUJAHID, S. A. Assessment of radiological hazard due to the natural radioactivity in soil and building material samples collected from six districts on the Punjab province-Pakistan. Radiation Measurements, 43(8):1443-1447. (2008).

FERREIRA, A. O., BASTOS, R. O., APPOLONI, C. R. Some geological characteristics in a regolith-limey shale rock profile through natural radionuclides distribution. Applied Radiation and Isotopes, 68(9):1774-1779, (2010).

FERREIRA, A. O. e PECEQUILO, B. R. S. A study of self-attenuation correction for geological measures of Paraná state granites with high resolution gamma-ray spectrometry. In International Nuclear Atlantic Conference (INAC 2011), Belo Horizonte, MG, (2011).

FIOR, L. Ánalise da concentração de radônio proveniente dos materiais de construção. Dissertação (Mestrado), Universidade Tecnologica Federal do Paraná, Curitiba, (2008).

FLEISCHER, R., PRICE, P., WALKER, R. Nuclear Tracks in Solids: Principles and Applications. Univ. of California Press, Berkeley, (1975).

FLEISCHER, R. L. Moisture and Rn-222 emanation. Health Physics, 52(6):797-799, (1987).

GREEN, J. R. e MARGERISON, D. Statistical treatment of experimental data Elsevier. Elsevier, (1978).

IAEA Set of 8 calibrated gamma-emitting sources (ems). Viena, jan de 1982, (1982).

IAEA-TECDOC-1363 Guidelines for radioelement mapping using gamma ray spectrometry data. Technical report, International Atomic Energy Agency (IAEA), (2003).

INTERWINNER6.0 Mca emulation, data acquisition and analysis software for gamma and alpha spectroscopy. ORTEC, Oak Ridge, TN, USA, (2004).

JOSHUA, E., ADEMOlA, J., AKPANOWO, M., OYEBANJO, O., OLORODE, D. Natural radionuclides and hazards of rock samples collected from southeastern Nigéria. Radiation Measurements, 44(4):401 - 404, (2009).

KATHREN, R. L. Norm sources and their origins. Applied Radiation and Isotopes, 49:149-168, (1998).

KHAN, A., PRASAD, R., TYAGI, R. Measurement of radon exhalation rate from some building materials. International Journal of Radiation Applications and Instrumentation. Part D. Nuclear Tracks and Radiation Measurements, 20(4):609 - 610, (1992). 
KNOLL, G. F. Radiation Detection and Measurement. John Wiley \& Sons, Inc., New York, 3rd edition, (1999).

KRSTI'C, D., NIKEZI'C, D., STEVANOVI'C, N., VUCI'C, D. Radioactivity of some domestic and imported building materials from south eastern europe. Radiation Measurements, 42(10):1731 - 1736, (2007).

LARSEN, E. S. J. e GEORGE, P. (1957). Nuclear Geology: Cap 2.1 Uranium and Thorium: The distribution of uranium and thorium in igneous rocks, chapter 2.1, pages 75 - 89. John Wiley \& Sons, Inc.

LNHB Laboratoire national Henri Becquerel, Disponível em $<$ http://www.nucleide.org/> Acesso em: Janeiro de 2013.

LU, X. e ZHANG, X. Radionuclide content and associated radiation hazards of building materials and by-products in Baoji, west China. Radiation Protection Dosimetry, 128(4):471-476, (2008).

MAHUR, A. K., KUMAR, R., SONKAWADE, R. G., SENGUPTA, D., PRASAD, R. Measurement of natural radioactivity and radon exhalation rate from rock samples of Jaduguda uranium mines and its radiological implications. Nuclear Instruments and Methods in Physics Research Section B: Beam Interactions with Materials and Atoms, 266(8):1591 - 1597, (2008).

MARKKANEN, M. Radiation Dose Assesments for Materials with Elevated Natural Radioactivity. Report STUK-B-STO 32,. Technical Report, Radiation and Nuclear Safety Authority, STUK, (1995).

MAROCCHI, M., RIGHI, S., BARGOSSI, G. M., GASPAROTTO, G. Natural radionuclides content and radiological hazard of commercial ornamental stones, an integrated radiometric and mineralogical-petrographic study. Radiation Measurements, 46:538-545, (2011).

MINEROPAR Disponível em <http://www.mineropar.pr.gov.br $>$ Acesso em: Maio de 2010.

MORAWSKA, L. e PHILLIPS, C, R. Dependence of the radon emanation coefficient on radium distribution and internal structure of the material. Geochimica et Cosmochimica Acta, 57(8):1783 - 1797, (1993).

MOURA, C. L. Radioatividade natural e emanação de Rn-222 em rochas ornamentais provenientes de diferentes séries magmáticas. Geologia regional, Tese (Doutorado) UNESP, Rio Claro, (2005).

MOURA, C. L., ARTUR, A., BOnOtTO, D. M., GUEDES, S., MARTINELliC, D. M. Natural radioactivity and radon exhalation rate in brazilian igneous rocks. Applied Radiation and Isotopes, (2011). 
MÁDUAR, M. F. Determinação de fatores de conversão de dose para radiação gama externa em residências. Dissertação (Mestrado), Instituto de Pesquisas Energéticas e Nucleares Autarquia associada à Universidade de São Paulo, São Paulo, (2000).

MÁDUAR, M. F. e HIROMOTO, G. Evaluation of indoor gamma radiation dose in dwellings. Radiation Protection Dosimetry, 111(2):221-228, (2004).

NCRP Measurement of radon and radon daughter in air. Technical report, National Council on Radiation Protection and Measurements, (1998).

NEMAN, E. S. Medida da contaminação radioativa do ar ambiental por radônio-222 e filhos em residências de Campinas. Dissertação (Mestrado) IFWG, UNICAMP, CAMPINAS, (2000).

NEMAN, E. S. Medida Separada de Radônio-222 e de seus filhos no ar, Monitoração na Cidade de Poços de Caldas MG e comparação de atividades envolvendo 2 outras técnicas de medida de Rn-222 no ar. Tese (Doutorado) IFWG, UNICAMP, Campinas, (2004).

NGACHIN, M., GARAVAGLIA, M., GIOVANI, C., NJOCK, M. K., NOURREDDINE, A. Assessment of natural radioactivity and associated radiation hazards in some cameroonian building materials. Radiation Measurements, 42(1):61 - 67, (2007).

ORLANDO, C., ORLANDO, P., PATRIZII, L., TOMMASINO, L., TONNARINI, S., TREVISI, R., VIOLA, P. A passive radon dosimeter suitable for workplaces. Radiation Protection Dosimetry, 102(2):163-168, (2002).

PAKOU, A., ASSIMAKOPOULOS, P., PRAPIDIS, M. Natural radioactivity and radon emanation factors in building material used in Epirus (north-western Greece). Science of The Total Environment, 144(1-3):255 - 260, (1994).

PASCHUK, A, S., FIOR, L., CORRÊA, J. N., POTTKER, F., SILVA, R. D. F., SCHELIN, H. R., DENYAK, V., MELO, V. P., HORMAZA, J. M. (2007). Rn-222 measurement at Federal University of Technology UTFPR Curitiba Pr, In Book of Abstracts of VIII NRE, Búzios RJ, (2007).

PAULO, S. R. Dosimetria ambiental de Rn-222 e filhos: Medida da eficiência absoluta do CR-39 levando-se em conta os efeitos do plate-out e fatores ambientais. Tese (Doutorado), UNICAMP, Campinas, (1991).

PYLON, E. I. Pylon flow-through source model Rn-1025, Instruction manual, Pylon Eletronics INC.(2001).

QtiPlot0.9.8.8 (2011). Qtiplot 0.9.8.8 svn 2255 copyright (c) 2004-2011 Ion Vasilief. http://soft.proindependent.com/qtiplot.html. 
RIGHI, S. e BRUZZI, L. Natural radioactivity and radon exhalation in building materials used in italian dwellings. Journal of Environmental Radioactivity, $88(2): 158-170,(2006)$.

SAKODA, A., HANAMOTO, K., ISHIMORI, Y., NAGAMATSU, T., YAMAOKA, K. Radioactivity and radon emanation fraction of the granites sampled at Misasa and Badgastein. Applied Radiation and Isotopes, 66:648-655, (2008).

SAKODA, A., HANAMOTO, K., ISHIMORI, Y., KATAOKA, T., KAWABE, A., YAMAOKA, K. First model of the effect of grain size on radon emanation. Applied Radiation and Isotopes, 68(6):1169 - 1172, (2010).

SANTOS, R. N. Implantação da metodologia de espectrometria alfa para determinação de isótopos de $\mathrm{U}$ e Th em rochas ígneas: Aplicação ao estudo do desequilíbrio radioativo na ilha da Trindade. Tese (Doutorado), Departamento de Geofísica, Instituto Astrônomico e Geofísico, Universidade de São Paulo. (2001).

SCAPIN, M. A. (2003). Aplicação da difração e fluorescência de raios-X (WDXRF): Ensaios em argilominerais. Dissertação (Mestrado), Instituto de Pesquisas Energéticas e Nucleares Autarquia associada à Universidade de São Paulo.

SEMKOW, T. M. Recoil-emanation theory applied to radon release from mineral grains. Geochimica et Cosmochimica Acta, 54(2):425 - 440, (1990).

SHWEIKANI, R. e RAJA, G. Radon exhalation from some finishing materials frequently used in Syria. Radiation Measurements, 44:1019 - 1023, (2009).

SILVA, A. A. R. Radônio e filhos em residências da cidade de São Paulo. Tese (Doutorado) IF, Universidade de São Paulo, São Paulo, (2005).

SONKAWADE, R., KANT, K., MURALITHAR, S., KUMAR, R., RAMOLA, R. Natural radioactivity in common building construction and radiation shielding materials. Atmospheric Environment, 42(9):2254 - 2259, (2008).

SRS33 Radiation protection against radon in workplaces other than mines, Safety Report Séries 33. Technical report, (2003).

STATISTICA9 (2009). Statsoft inc.

STRANDEN, E. Some aspects on radioactivity of building materials. Physica Norvegica, 8:167-173, (1976).

STRANDEN, E. e BERTEIG, L. Radon in dwellings and influencing factors. Health Physics, 39, (1980).

STRANDEN, E., KOLSTAD, A., LIND, B. The influence of moisture and temperature on radon exhalation. Radiation Protection Dosimetry, 7:55-58, (1984). 
TECDOC-619 Evaluated data (XG Standard), (2012).

TUFAIL, M., MIRZA, S. M., MAHMOOD, A., A.QURESHI, A., ARFAT, Y., KHAN, H. Application of a closed-can-technique for measuring radon exhalation from mine samples of Punjab, Pakistan. Journal of Environmental Radioactivity, 50(3):267 - 275, (2000).

TURHAN, S. Assessment of the natural radioactivity and radiological hazards in turkish cement and its raw materials. Journal of Environmental Radioactivity, 99(2):404-414, (2008).

UNSCEAR The 2000 Report to the general assembly with scientific annexes. Technical Report, United Scientific Committee on the Effects of Atomic Radiation, New York, (2000).

VEIGA, R., SANCHES, N., ANJOS, R., MACARIO, K., BASTOS, J., IGUATEMY, M., AGUiAR, J., SANTOS, A., MOSQUERA, B., CARVAlhO, C., FILHO, M. B., UMISEDO, N. Measurement of natural radioactivity in brazilian beach sands. Radiation Measurements, 41(2):189 - 196, (2006).

VILALOBOS, A. P. O. Medida do coeficiente de difusão do Rn-222 através de tintas usadas na construção civil. Tese (Doutorado) IFWG, UNICAMP, Campinas, (1991).

VILLAVERDE, F. L. Avaliação da exposição externa em residência construída com fosfogesso. Dissertação (Mestrado), Instituto de Pesquisas Energéticas e Nucleares Autarquia associada à Universidade de São Paulo, São Paulo, (2008).

WHO International radon project, Report of the 3rd meeting. Technical Report, World Health Organization, Munich, (2007).

WILliamS, H., TURNER, F. J., GILBERT, C. M. Petrografia, Uma Introdução ao Estudo das Rochas em Seções Delgadas. Polígono Editora da Universidade de São Paulo, São Paulo, (1970).

ZEISS Ks 100 imaging system release 3.0, (1997). 
CAPÍTUlo

APÊNDICES 


\subsection{Apêndice A}

\section{Concentrações de atividades de ${ }^{40} \mathrm{~K},{ }^{232} \mathrm{Th}$ e ${ }^{226} \mathrm{Ra}$ nas amostras de rochas estudadas.}

\begin{tabular}{|c|c|c|c|c|c|c|c|}
\hline \multirow{2}{*}{$\begin{array}{c}\text { Amostra } \\
\text { (ID) }\end{array}$} & \multicolumn{3}{|c|}{ Concentrações de atividade $\left(\mathrm{Bq} \cdot \mathrm{kg}^{-1}\right)$} & \multirow{2}{*}{$\begin{array}{c}\text { Amostra } \\
\text { (ID) }\end{array}$} & \multicolumn{3}{|c|}{ Concentrações de atividade $\left(\mathrm{Bq} \cdot \mathrm{kg}^{-1}\right)$} \\
\hline & ${ }^{40} \mathrm{~K}$ & ${ }^{232} \mathrm{Th}$ & ${ }^{226} \mathrm{Ra}$ & & ${ }^{40} \mathrm{~K}$ & ${ }^{232} \mathrm{Th}$ & ${ }^{226} \mathrm{Ra}$ \\
\hline 1 & $1335 \pm 58$ & $58 \pm 3$ & $26 \pm 1$ & 26 & $1351 \pm 63$ & $43 \pm 3$ & $27 \pm 2$ \\
\hline 2 & $1227 \pm 63$ & $37 \pm 2$ & $59 \pm 3$ & 27 & $1336 \pm 77$ & $66 \pm 4$ & $77 \pm 4$ \\
\hline 3 & $1422 \pm 83$ & $72 \pm 4$ & $29 \pm 2$ & 28 & $1279 \pm 75$ & $44 \pm 3$ & $51 \pm 3$ \\
\hline 4 & $1317 \pm 53$ & $84 \pm 3$ & $31 \pm 1$ & 29 & $1309 \pm 93$ & $39 \pm 3$ & $45 \pm 3$ \\
\hline 5 & $1194 \pm 51$ & $123 \pm 6$ & $50 \pm 3$ & 30 & $1308 \pm 64$ & $65 \pm 4$ & $35 \pm 2$ \\
\hline 6 & $1356 \pm 72$ & $30 \pm 2$ & $20 \pm 2$ & 31 & $1162 \pm 66$ & $35 \pm 2$ & $29 \pm 2$ \\
\hline 7 & $1560 \pm 109$ & $47 \pm 4$ & $31 \pm 3$ & 32 & $1355 \pm 61$ & $71 \pm 6$ & $26 \pm 2$ \\
\hline 8 & $1562 \pm 78$ & $55 \pm 3$ & $38 \pm 2$ & 33 & $1604 \pm 94$ & $28 \pm 2$ & $16 \pm 2$ \\
\hline 9 & $1265 \pm 79$ & $59 \pm 4$ & $59 \pm 4$ & 34 & $1474 \pm 87$ & $146 \pm 8$ & $91 \pm 5$ \\
\hline 10 & $1328 \pm 71$ & $63 \pm 3$ & $25 \pm 2$ & 35 & $0246 \pm 16$ & $09 \pm 1$ & $05 \pm 1$ \\
\hline 11 & $1228 \pm 68$ & $46 \pm 3$ & $32 \pm 2$ & 36 & $1097 \pm 58$ & $90 \pm 4$ & $84 \pm 3$ \\
\hline 12 & $1560 \pm 117$ & $64 \pm 5$ & $35 \pm 3$ & 37 & $1070 \pm 54$ & $91 \pm 4$ & $43 \pm 2$ \\
\hline 13 & $1331 \pm 62$ & $80 \pm 5$ & $40 \pm 2$ & 38 & $1070 \pm 54$ & $41 \pm 2$ & $39 \pm 2$ \\
\hline 14 & $1504 \pm 104$ & $83 \pm 6$ & $50 \pm 3$ & 39 & $1171 \pm 54$ & $53 \pm 2$ & $38 \pm 2$ \\
\hline 15 & $1507 \pm 87$ & $30 \pm 3$ & $19 \pm 1$ & 40 & $1283 \pm 63$ & $49 \pm 2$ & $23 \pm 1$ \\
\hline 16 & $1377 \pm 67$ & $53 \pm 4$ & $32 \pm 2$ & 41 & $1332 \pm 67$ & $164 \pm 7$ & $68 \pm 3$ \\
\hline 17 & $1308 \pm 133$ & $90 \pm 8$ & $50 \pm 5$ & 42 & $0836 \pm 67$ & $59 \pm 2$ & $34 \pm 1$ \\
\hline 18 & $1457 \pm 78$ & $49 \pm 3$ & $29 \pm 3$ & 43 & $1296 \pm 64$ & $76 \pm 3$ & $89 \pm 4$ \\
\hline 19 & $1218 \pm 62$ & $46 \pm 2$ & $28 \pm 2$ & 44 & $1398 \pm 72$ & $94 \pm 4$ & $31 \pm 2$ \\
\hline 20 & $1347 \pm 55$ & $59 \pm 3$ & $34 \pm 2$ & 45 & $1153 \pm 58$ & $141 \pm 6$ & $61 \pm 5$ \\
\hline 21 & $1230 \pm 67$ & $68 \pm 4$ & $46 \pm 2$ & 46 & $1390 \pm 51$ & $55 \pm 3$ & $31 \pm 2$ \\
\hline 22 & $1327 \pm 79$ & $90 \pm 5$ & $50 \pm 3$ & 47 & $1135 \pm 49$ & $84 \pm 3$ & $41 \pm 2$ \\
\hline 23 & $1191 \pm 67$ & $88 \pm 5$ & $54 \pm 3$ & 48 & $1480 \pm 74$ & $49 \pm 3$ & $30 \pm 2$ \\
\hline 24 & $0935 \pm 46$ & $49 \pm 3$ & $25 \pm 1$ & 49 & $1554 \pm 77$ & $50 \pm 3$ & $26 \pm 1$ \\
\hline 25 & $1400 \pm 78$ & $44 \pm 4$ & $24 \pm 2$ & 50 & $1267 \pm 67$ & $63 \pm 3$ & $34 \pm 2$ \\
\hline
\end{tabular}




\subsection{Apêndice $B$}

\section{Taxa de exalação superficial e taxa de exalação por massa das amostras de rochas estudadas.}

\begin{tabular}{|c|c|c|c|c|c|}
\hline Amostra (ID) & $\begin{array}{c}\text { Taxa de exalação } \\
\text { superficial } \\
\left(\text { Bq.m }{ }^{-2} \cdot \mathrm{h}^{-1}\right)\end{array}$ & $\begin{array}{c}\text { Taxa de exalação } \\
\text { por massa } \\
\left(\mathrm{Bq} \cdot \mathrm{kg}^{-1} \cdot \mathrm{h}^{-1}\right)\end{array}$ & Amostra (ID) & $\begin{array}{c}\text { Taxa de exalação } \\
\text { superficial } \\
\left(\text { Bq. } \mathrm{m}^{-2} \cdot \mathrm{h}^{-1}\right)\end{array}$ & $\begin{array}{c}\text { Taxa de exalação } \\
\text { por massa } \\
\left(\mathrm{Bq} \cdot \mathrm{kg}^{-1} \cdot \mathrm{h}^{-1}\right)\end{array}$ \\
\hline 1 & $0,65 \pm 0,03$ & $0,030 \pm 0,001$ & 18 & $0,54 \pm 0,03$ & $0,044 \pm 0,002$ \\
\hline 2 & $0,50 \pm 0,03$ & $0,048 \pm 0,002$ & 19 & $0,10 \pm 0,01$ & $0,005 \pm 0,001$ \\
\hline 3 & $0,89 \pm 0,05$ & $0,070 \pm 0,003$ & 20 & $0,12 \pm 0,01$ & $0,006 \pm 0,001$ \\
\hline 4 & $1,11 \pm 0,04$ & $0,083 \pm 0,004$ & 21 & $1,83 \pm 0,09$ & $0,085 \pm 0,003$ \\
\hline 5 & $0,72 \pm 0,05$ & $0,034 \pm 0,002$ & 22 & $1,43 \pm 0,07$ & $0,068 \pm 0,003$ \\
\hline 6 & $0,38 \pm 0,02$ & $0,032 \pm 0,001$ & 23 & $0,05 \pm 0,01$ & $0,002 \pm 0,001$ \\
\hline 7 & $0,77 \pm 0,04$ & $0,053 \pm 0,002$ & 24 & $0,02 \pm 0,01$ & $0,001 \pm 0,001$ \\
\hline 8 & $0,97 \pm 0,05$ & $0,081 \pm 0,003$ & 25 & $0,82 \pm 0,04$ & $0,042 \pm 0,002$ \\
\hline 9 & $0,96 \pm 0,05$ & $0,047 \pm 0,002$ & 26 & $0,87 \pm 0,04$ & $0,052 \pm 0,002$ \\
\hline 10 & $0,26 \pm 0,02$ & $0,022 \pm 0,001$ & 27 & $1,48 \pm 0,07$ & $0,071 \pm 0,003$ \\
\hline 11 & $0,53 \pm 0,03$ & $0,038 \pm 0,002$ & 28 & $1,00 \pm 0,05$ & $0,045 \pm 0,002$ \\
\hline 12 & $0,68 \pm 0,04$ & $0,032 \pm 0,001$ & 29 & $0,99 \pm 0,05$ & $0,048 \pm 0,002$ \\
\hline 13 & $0,75 \pm 0,04$ & $0,036 \pm 0,002$ & 30 & $0,55 \pm 0,03$ & $0,27 \pm 0,001$ \\
\hline 14 & $0,88 \pm 0,05$ & $0,075 \pm 0,003$ & 31 & $0,01 \pm 0,01$ & $0,001 \pm 0,001$ \\
\hline 15 & $0,20 \pm 0,01$ & $0,010 \pm 0,001$ & 32 & $0,52 \pm 0,03$ & $0,023 \pm 0,001$ \\
\hline 16 & $0,19 \pm 0,01$ & $0,015 \pm 0,001$ & 33 & $0,05 \pm 0,01$ & $0,002 \pm 0,001$ \\
\hline 17 & $0,32 \pm 0,02$ & $0,015 \pm 0,001$ & 34 & $1,94 \pm 0,10$ & $0,092 \pm 0,004$ \\
\hline
\end{tabular}

